ROY ANDRES GOMEZ MORALES

MODELAGEM E ANÁLISE DE SISTEMAS FLEXÍVEIS DE MANUFATURA TOLERANTES À FALHAS BASEADO EM REDE BAYESIANA E REDE DE PETRI

Dissertação apresentada à Escola Politécnica da Universidade de São Paulo para obtenção do título de Mestre em Engenharia

São Paulo 
ROY ANDRES GOMEZ MORALES

\section{MODELAGEM E ANÁLISE DE SISTEMAS FLEXÍVEIS DE MANUFATURA TOLERANTES À FALHAS BASEADO EM REDE BAYESIANA E REDE DE PETRI}

Dissertação apresentada à Escola Politécnica da Universidade de São Paulo para obtenção do título de Mestre em Engenharia

Área de Concentração:

Engenharia de Controle e Automação Mecânica.

Orientador:

Prof. Dr. Paulo Eigi Miyagi

São Paulo 
Este exemplar foi revisado e alterado em relação à versão original sob responsabilidade única do autor e com a anuência de seu orientador.

São Paulo, 7 de Dezembro de 2009

Roy Morales (autor) Paulo Eigi Miyagi (orientador)

FICHA CATALOGRÁFICA - EDIÇÃO REVISADA

ROY ANDRES GOMEZ MORALES

MODELAGEM E ANÁLISE DE SISTEMAS FLEXÍVEIS DE MANUFATURA TOLERANTES À FALHAS BASEADO EM REDE BAYESIANA E REDE DE PETRI.

$135 p$.

Dissertação (Mestrado) - Escola Politécnica da Universidade de São Paulo. Departamento de Engenharia Mecatrônica e Sistemas Mecânicos.

1. Sistemas discretos ; 2. Redes de Petri; 3. Redes Neurais; 4. Sistemas flexíveis de manufatura,5. Falhas computacionais 
A meu pai Guido, responsável pela maioria das coisas boas que aconteceram na minha vida.

...vai por você... 
FICHA CATALOGRÁFICA ELABORADA PELA BIBLIOTECA DA ENGENHARIA MECÂNICA/NAVAL DA ESCOLA POLITÉCNICA $(E P M N)-U S P$.

ROY ANDRES GOMEZ MORALES

MODELAGEM E ANÁLISE DE SISTEMAS FLEXÍVEIS DE MANUFATURA TOLERANTES À FALHAS BASEADO EM REDE BAYESIANA E REDE DE PETRI.

$135 p$.

Dissertação (Mestrado) - Escola Politécnica da Universidade de São Paulo. Departamento de Engenharia Mecatrônica e Sistemas Mecânicos.

1. Sistemas discretos ; 2. Redes de Petri; 3. Redes Neurais; 4. Sistemas flexíveis de manufatura,5. Falhas computacionais 


\section{AGRADECIMENTO}

Poderiam ser páginas e páginas de listas das pessoas responsáveis pela concretização deste trabalho, entretanto me limito a lembrar daquelas que por ordem de prioridade permitiram concretizar este projeto e mais do que isso este sonho. A todas elas, eternamente agradecido.

Ao meu orientador Prof. Paulo Eigi Miyagi, por acreditar na proposta, aportar com um infinito conhecimento e incentivar constantemente o projeto. Obrigado por tanta paciência.

A toda minha família, meus pais, meus avos, tios e primos. Entretanto, especial agradecimento aos meus irmãos, que em tempos de dificuldade aceitaram a minha ausência, carregando o peso que eu devia ter carregado como irmão mais velho. Sergio e Samanta, para sempre: obrigado.

À infinita luz que ilumina meu caminho para todo lugar que eu vou. Deus proteja para sempre esse brilho.

Aos meus colegas e amigos da Poli, cuja presença permitiu esquecer a solidão e entender melhor a palavra amizade: José, Percy, Juan, Marcosiris, Marília, Luis, Fabrício, Carlos, Cleber, Caio e tantos outros que formaram parte desta pequena história.

A todas as outras pessoas que por um motivo ou outro apoiaram a minha estadia no Brasil, eu sei que todas elas se sentiram aludidas.

À Escola Politécnica da USP, ao Departamento de Engenharia Mecatrônica e de Sistemas Mecânicos e ao centro de apoio à pesquisa CNPq, que institucionalmente viabilizaram este trabalho. 


\section{SUMÁRIO}

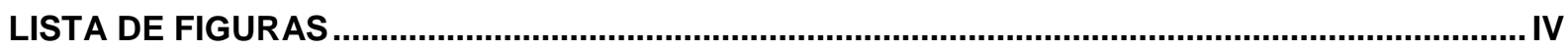

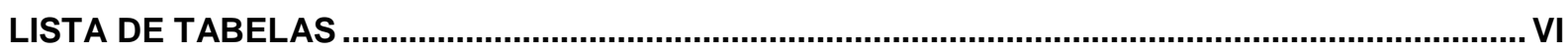

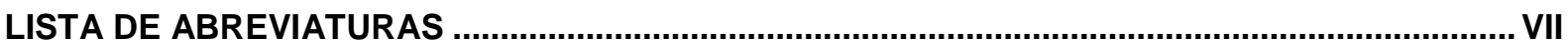

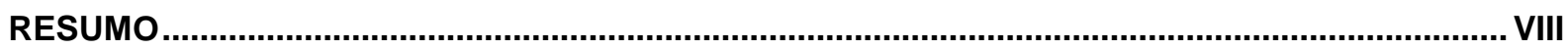

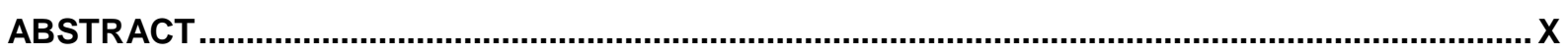

1. INTRODUÇÃO

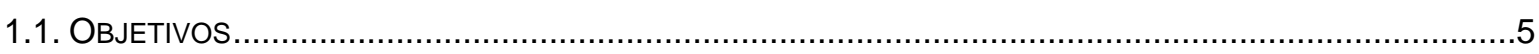

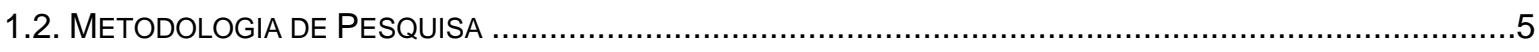

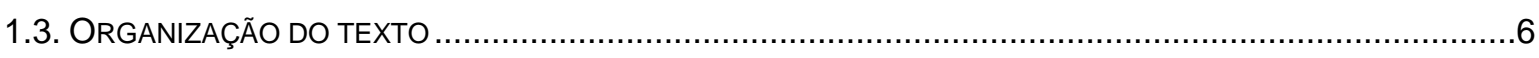

2. DIAGNÓSTICO E TRATAMENTO DE FALHAS EM SISTEMAS DE MANUFATURA......................9

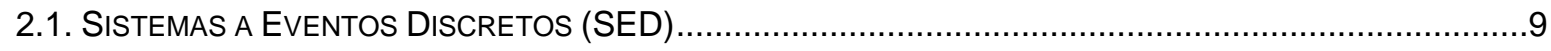

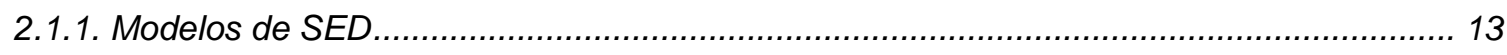

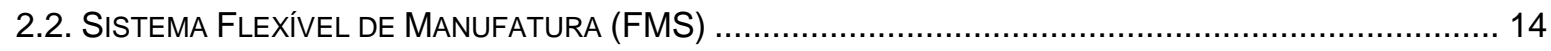

2.2.1. Modelagem de Sistemas Flexíveis de Manufatura ........................................................ 18

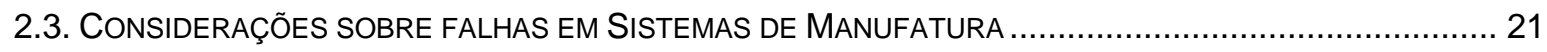

2.3.1. Falha

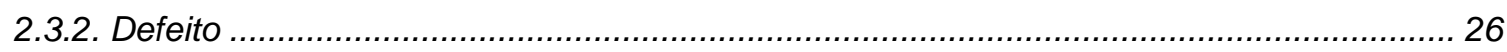

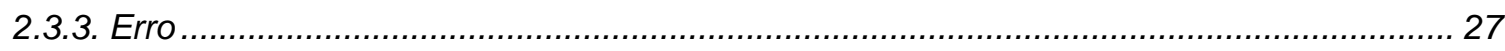

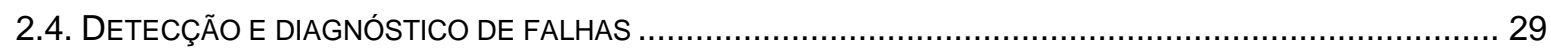

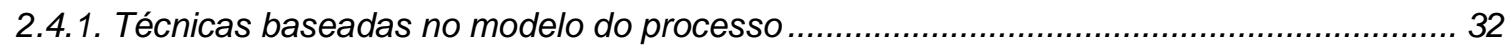

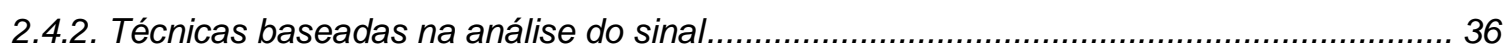

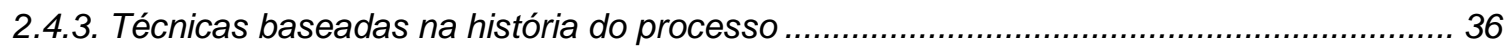

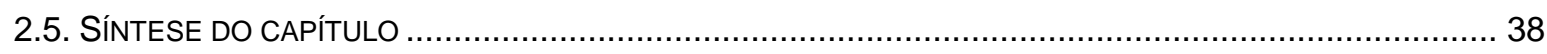

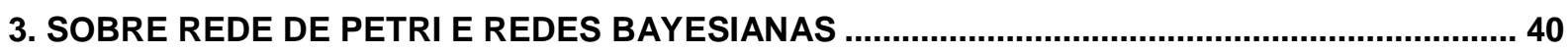

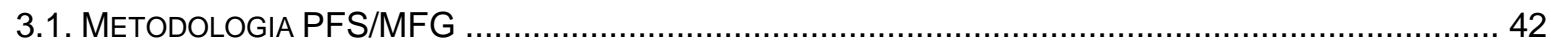

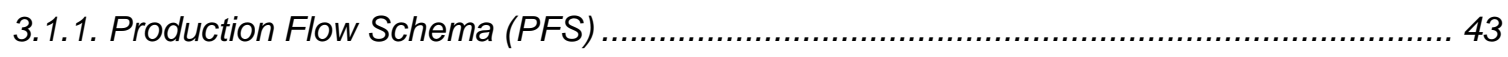

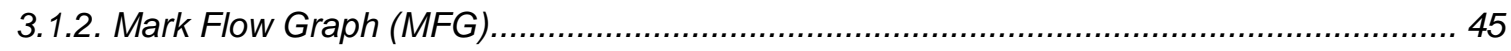




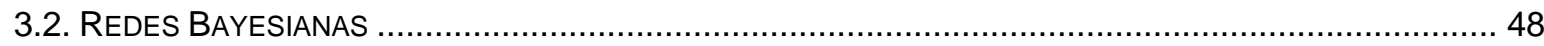

4. PROCEDIMENTO PARA O DIAGNÓSTICO E TRATAMENTO DE FALHAS EM FMS................. 52

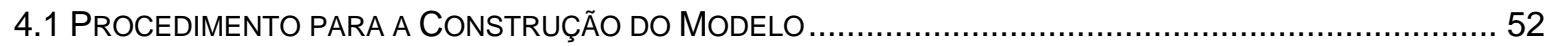

4.1.1. Construção do Modelo do Processo Produtivo ............................................................. 54

4.1.2. Classificação dos componentes do modelo do processo produtivo com base nas suas

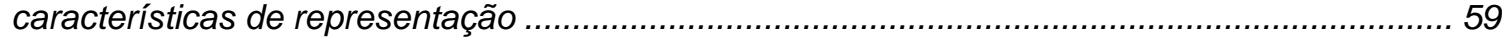

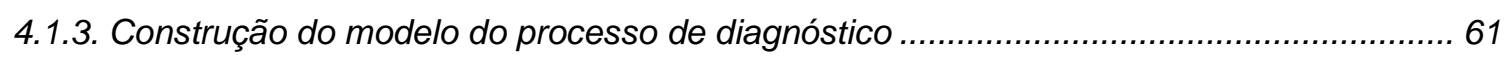

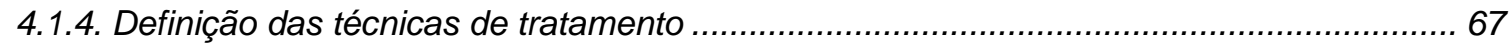

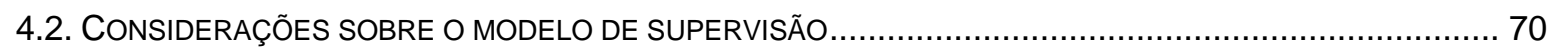

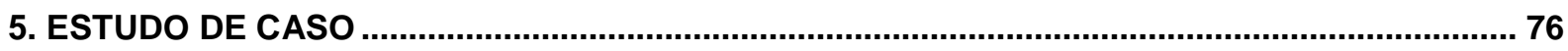

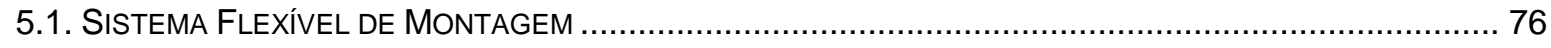

5.1.1. Construção do Modelo do Processo Produtivo ............................................................. 84

5.1.2. Classificação dos Componentes da rede de Controle Local ........................................ 105

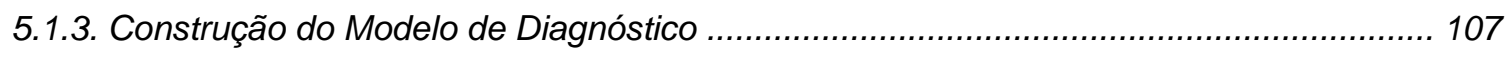

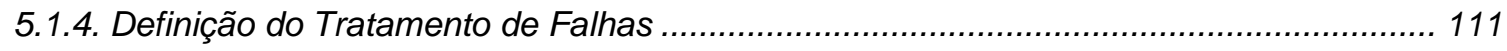

6. CONCLUSÕES E RESULTADOS

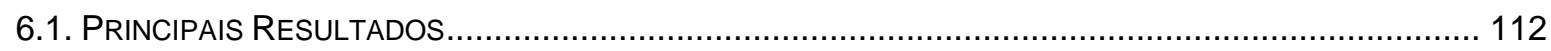

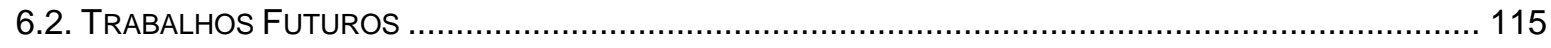

7. REFERÊNCIAS 


\section{LISTA DE FIGURAS}

FIGURA 1.1. EVOLUÇÃO DOS PROCESSOS DE PRODUÇÃO AO LONGO DO TEMPO......................................................

FIGURA 1.2 CICLO DE DESENVOLVIMENTO DA METODOLOGIA PROPOSTA. ...................................................... 6

FIGURA 2.1. PROCESSO DE MODELAGEM DE SISTEMAS INSTANTÂNEOS E DINÂMICOS. ............................................. 10

FIGURA 2.2. CLASSIFICAÇÃO DOS SISTEMAS CONFORME CASSANDRAS (1993) .................................................... 12

FIGURA 2.3. COMPORTAMENTO DO SVC COMPARADO COM O COMPORTAMENTO DO SED.................................... 13

FigURA 2.4. NíVEIS DE CONTROLE SEGUNDO (A) AS FUNCIONALIDADES DOS EQUIPAMENTOS, E (B) AS

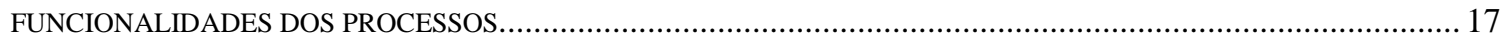

FIGURA 2.5. RELAÇão ENTRE USUÁRIO/PROVEDOR EM NÍVEIS DE CONTROLE............................................................. 22

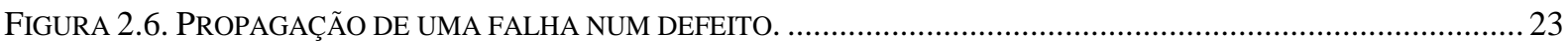

FIGURA 2.7. CLASSIFICAÇÃO DE FALHAS ADAPTADO DE AVIZIENIS ET AL. (2004)................................................ 25

FigURA 2.8. CLASSIFICAÇÃO DE DEFEITO SEGUNDO AVIZIENIS ET AL., (2004). .................................................... 27

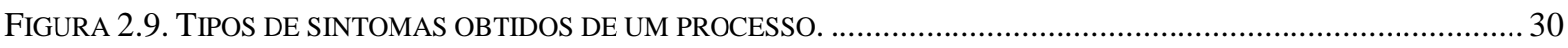

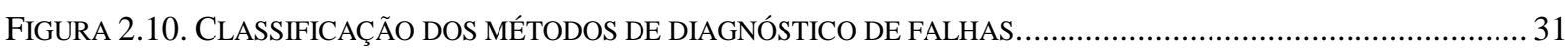

FIGURA 2.11. ESQUEMA GERAL DE DIAGNÓSTICO BASEADO NO MODELO DO PROCESSO. ......................................... 33

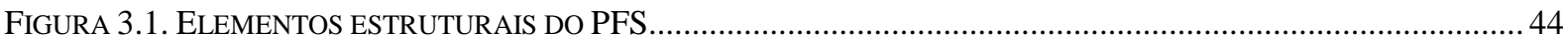

FIGURA 3.2. INICIO / FINALIZAÇÃO DE UMA ATIVIDADE POR MAIS DE UM EVENTO...................................................... 45

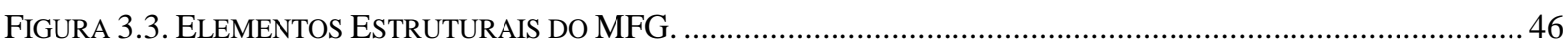

FIGURA 3.4. EXEMPLO DE UMA REDE BAYESIANA, ADAPTADO DE MORALES ET AL., (2007C)............................ 50

FigURA 4.1. PROCEDIMENTO GERAL PARA A CONSTRUÇÃO DE MODELOS. .........................................................53

Figura 4.2. Ciclo de PRototipagem PARA o PRocedimento (ADAPTADO DE MIYAGI, 1996). ........................53

FigURA 4.3. SEQÜÊNCIA DE CONSTRUÇÃO DE MODELOS DE PROCESSOS PRODUTIVOS BASEADO EM REDES DE PETRI

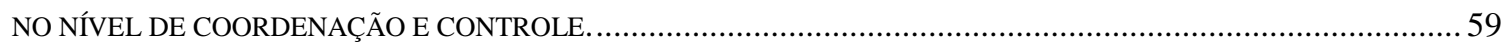

Figura 4.4. Lugares TiPo A E LugaRes TiPo B (ADAPTADO DE MORALES ET AL., 2007B).............................. 60

FIGURA 4.5. PROCEDIMENTO PARA A CONSTRUÇÃO DE MODELOS DE DIAGNÓSTICO BASEADO EM REDES

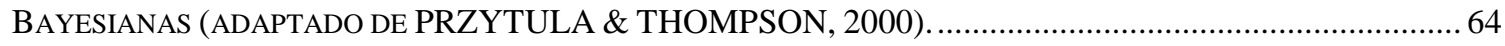

FIGURA 4.6. PROCEDIMENTO PROPOSTO PARA A CONSTRUÇÃO DE MODELOS DE DIAGNÓSTICO. ............................... 66

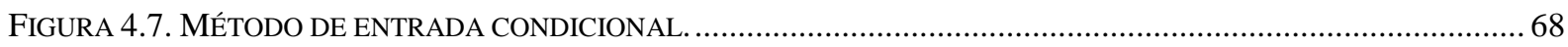

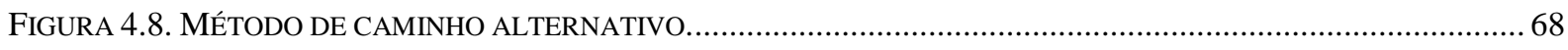

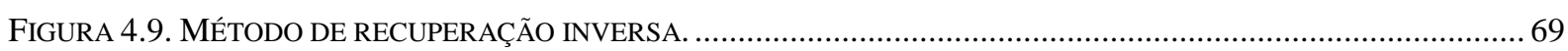

FIGURA 4.10. MÉTODO DE RECUPERAÇÃO COMPLEMENTAR......................................................................... 70

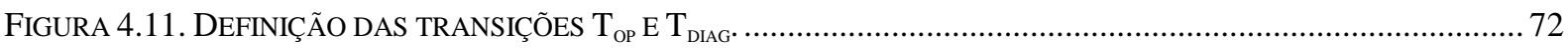

FIGURA 4.12. DEFINIÇÃO DE REGRAS DE DISPARO DAS TRANSIÇÕES DE TRATAMENTO. ……..................................... 73

FIGURA 4.13. TRANSIÇÕES DE INSPEÇÃO NA REDE DE PETRI NO NÍVEL DE COORDENAÇÃO. ..................................... 74

FIGURA 4.14. REPRESENTAÇÃO DA SEQÜÊNCIA DE CONSTRUÇÃO DE MODELOS. ...................................................... 75

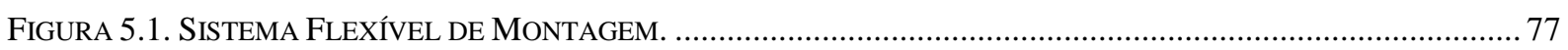




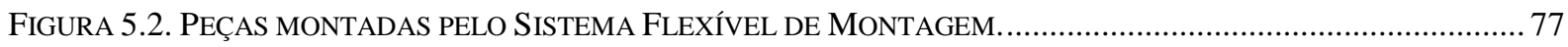

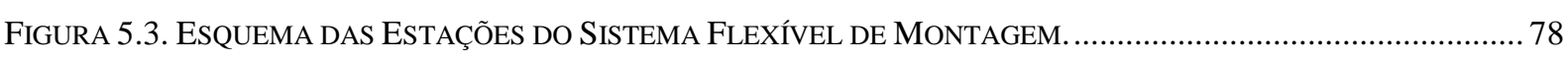

FIGURA 5.4. REDE DE COORDENAÇÃO EM PFS DO SISTEMA FLEXÍVEL DE MONTAGEM. ...................................... 85

FIGURA 5.5. REDE DE COORDENAÇÃO EM PFS DA CÉLULA DE ENTRADA DE MATERIAL (I)..................................86

FIGURA 5.6. REDE DE COORDENAÇÃO EM PFS DA ESTAÇÃO DE ALIMENTAÇÃO (SU)...........................................86

FIGURA 5.7. REDE DE COORDENAÇÃO EM PFS DA ESTAÇÃO DE ALIMENTAÇÃO (SU)...........................................86

FIGURA 5.8. REDE DE COORDENAÇÃO EM PFS DA ESTAÇÃO DE ALIMENTAÇÃO (SU).........................................8 87

FIGURA 5.9. REDE DE COORDENAÇÃO EM PFS DA ESTAÇÃO DE TESTE (TE) ..................................................... 87

FIGURA 5.10. REDE DE COORDENAÇÃO EM PFS DA ESTAÇÃO DE TESTE (TE) ……......................................... 88

FIGURA 5.11. REDE DE COORDENAÇÃO EM PFS DA ESTAÇÃO DO ROBÔ (Ro).................................................... 89

FIGURA 5.12. REDE DE COORDENAÇÃO EM PFS DA ESTAÇÃO DE MONTAGEM (AS). .........................................90

FIGURA 5.13. REDE DE COORDENAÇÃO EM PFS DA ESTAÇÃO DE MONTAGEM (AS). ........................................ 91

FIGURA 5.14. REDE DE COORDENAÇÃO EM PFS DA ESTAÇÃO DE MONTAGEM (AS).......................................... 91

FIGURA 5.15. REDE DE COORDENAÇÃO EM PFS DA ESTAÇÃO DE MONTAGEM (AS). ..........................................91

FIGURA 5.16. REDE DE COORDENAÇÃO EM PFS DA ESTAÇÃO DE TRANSPORTE(T) ............................................92

FIGURA 5.17. REDE DE COORDENAÇÃO EM PFS DA ESTAÇÃO DE TRANSPORTE(T),..........................................9. 92

FIGURA 5.18. REDE DE COORDENAÇÃO EM PFS DA ESTAÇÃO DE TRANSPORTE(T) ..........................................92

Figura 5.19. REDE DE CONTROLE LOCAL DA ESTAÇÃO DE ALIMENTAÇÃO (SU) ...............................................93

FIGURA 5.20. REDE DE CONTROLE LOCAL DA ESTAÇÃO DE TESTE (TE) ......................................................94

Figura 5.21. REDE DE CONTROLE LOCAL DA ESTAÇÃO DE RoBÔ NA ATIVIDADE “PEGAR PALLET” (Ro)..............95

FIGURA 5.22. REDE DE CONTROLE LOCAL DA ESTAÇÃO DE ROBÔ NA ATIVIDADE “TRANSPORTAR PALLET” (Ro). 95 Figura 5.23. REDE DE CONTROLE LOCAL DA ESTAÇÃo DE ROBÔ NA ATIVIDADE “PEGAR PEÇA CORPO” (Ro)...... 96 FIGURA 5.24. REDE DE CONTROLE LOCAL DA ESTAÇÃO DE ROBÔ NA ATIVIDADE “TRANSPORTE PEÇA CORPO” (RO).

FIGURA 5.25. REDE DE CONTROLE LOCAL DA ESTAÇÃO DE RoBÔ NA ATIVIDADE “PEGA EMBOLO” (Ro). .............97

FIGURA 5.26. REDE DE CONTROLE LOCAL DA ESTAÇÃO DE RoBÔ NA ATIVIDADE “MONTAGEM DE EMBOLO” (Ro). 98

Figura 5.27. REDE DE CONTROLE LOCAL DA ESTAÇÃO DE RobÔ NA ATIVIDADE “PEGAR MOLA” (Ro). ...............99

FIGURA 5.28. REDE DE CONTROLE LOCAL DA ESTAÇÃO DE ROBÔ NA ATIVIDADE “MONTAR MOLA” (Ro)............. 99

Figura 5.29. REDE DE CONTROLE LOCAL DA ESTAÇÃO DE RobÔ NA ATIVIDADE “PEGAR TAMPA” (Ro). ............ 100

FIGURA 5.30. REDE DE CONTROLE LOCAL DA ESTAÇÃO DE RoBÔ NA ATIVIDADE “FIXAR TAMPA” (Ro). ............. 101

FIGURA 5.31. REDE DE CONTROLE LOCAL DA ESTAÇÃO DE ROBÔ NA ATIVIDADE “MOVIMENTAR PEÇA MONTADA”

(Ro) 102

FIGURA 5.32. REDE DE CONTROLE LOCAL DA ESTAÇÃo DE RoBÔ NA ATIVIDADE “PEGAR PALLET” (Ro)............ 103

FIGURA 5.33. REDE DE CONTROLE LOCAL DA ESTAÇÃo DE RoBÔ NA ATIVIDADE “DEPOSITA PALLET" (Ro)....... 104

FIGURA 5.34. REDE DE CONTROLE LOCAL DA ESTAÇÃO DE TRANSPORTE (T) ............................................... 105

FIGURA 5.35. REDE DE DiAgNÓSTICO DA ESTAÇÃO DE ALIMENTAÇÃO (SU) ................................................... 108

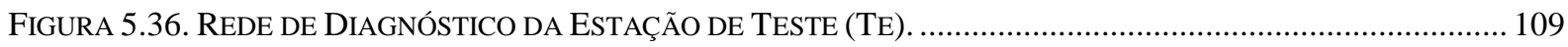

FIGURA 5.37. REDE DE DIAGNÓSTICO DA ESTAÇÃo DE RoBÔ (Ro). ............................................................... 110 


\section{LISTA DE TABELAS}

TABEla 2.1. ClassificAÇÃo DE Modelos DE SED, (HO,1992). 14

TABELA 5.1. LISTA DOS DISPOSITIVOS DE ATUAÇÃO DA ESTAÇÃO DE ALIMENTAÇÃO........................................... 79

TABELA 5.2. LISTA DOS DISPOSITIVOS DE CONTROLE DA ESTAÇÃO DE ALIMENTAÇÃO..........................................79

TABELA 5.3. LISTA DOS DISPOSITIVOS DE DETECÇÃO DA ESTAÇÃO DE ALIMENTAÇÃO......................................... 79

TABELA 5.4. LISTA DOS DISPOSITIVOS DE ATUAÇÃO DA ESTAÇÃO DE TESTE...................................................... 79

TABELA 5.5. LISTA DOS DISPOSITIVOS DE CONTROLE DA ESTAÇÃO DE TESTE..................................................... 79

TABELA 5.6. LISTA DOS DISPOSITIVOS DE DETECÇÃO DA ESTAÇÃO DE TESTE.................................................... 80

TABELA 5.7. LISTA DOS DISPOSITIVOS DE ATUAÇÃO DA ESTAÇÃO DE MONTAGEM............................................... 80

TABELA 5.8. LISTA DOS DISPOSITIVOS DE CONTROLE DA ESTAÇÃO DE MONTAGEM. ........................................... 80

TABELA 5.9. LISTA DOS DISPOSITIVOS DE DETECÇÃO DA ESTAÇÃO DE MONTAGEM. ............................................ 80

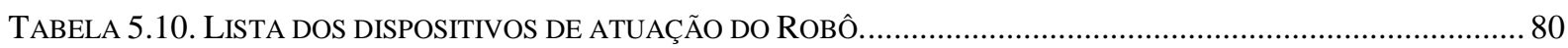

TABELA 5.11. LISTA DOS DISPOSITIVOS DE CONTROLE DO ROBÔ. ............................................................... 81

TABELA 5.12. LISTA DOS DISPOSITIVOS DE DETECÇÃO DO ROBÔ. .................................................................... 82

TABELA 5.13. LISTA DOS DISPOSITIVOS DE ATUAÇÃO DA ESTAÇÃO DE TRANSPORTE. ..........................................83

TABELA 5.14. LISTA DOS DISPOSITIVOS DE CONTROLE DA ESTAÇÃO DE TRANSPORTE........................................83

TABELA 5.15. LISTA DOS DISPOSITIVOS DE DETECÇÃO DA ESTAÇÃO DE TRANSPORTE..........................................8 84

TABELA 5.16. LISTA DOS LOCAIS TIPO B NA REDE DE CONTROLE DA ESTAÇÃO DE ALIMENTAÇÃO....................... 106

TABELA 5.17. LISTA DOS LOCAIS TIPO B NA REDE DE CONTROLE DA ESTAÇÃO DE TESTE................................... 106

TABELA 5.18. LISTA DOS LOCAIS TIPO B NA REDE DE CONTROLE DE ATUAÇÃO DO ROBÔ................................... 106

TABELA 5.19. LISTA DOS LOCAIS TIPO B NA REDE DE CONTROLE DE ESTAÇÃO DE TRANSPORTE......................... 107

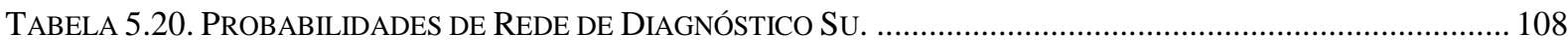

TABELA 5.21. ProbabiLIDAdES DE REdE DE Diagnóstico TE...................................................................... 109

TABEla 5.22. Probabilidades de Rede DE Diagnóstico Ro. ¡ERror! MARCADOR NO DEFINIDO. 


\section{LISTA DE ABREVIATURAS}

$\begin{array}{ll}\text { ANN } & \text { - Artificial Neural Network } \\ \text { AMS } & \text { - Agile Manufacturing System } \\ \text { ARMA } & \text { - Auto-Regressive Moving Average } \\ \text { CIM } & \text { - Computer Integrated Manufacturing } \\ \text { C}^{3} \text { N } & - \text { Sistemas de Comando, Comunicação e Controle } \\ & \text { Inteligente } \\ \text { DAG } & - \text { Directed Acyclic Graph } \\ \text { FMS } & - \text { Flexible Manufacturing System } \\ \text { GSPN } & - \text { General Stochastic Petri Net } \\ \text { MFG } & - \text { Mark Flow Graph } \\ \text { PFS } & - \text { Production Flow Schema } \\ \text { SDG } & - \text { Signed Directed Graph } \\ \text { SED } & - \text { Sistemas a Eventos Discretos } \\ \text { SVC } & - \text { Sistemas de Variáveis Contínuas } \\ \text { QTA } & - \text { Qualitative Tree Analysis }\end{array}$




\section{RESUMO}

O objeto de estudo deste trabalho é a construção de modelos que permitam a estruturação do projeto do controle de sistemas flexíveis de manufatura que considerem não somente estados de operação normal, mas também estados anormais, isto é, em situações de falhas. Entende-se como falha o desvio de pelo menos uma propriedade do sistema que leva o mesmo a um estado de defeito, que por sua vez se define como um comportamento incomum, não projetado, do sistema sob estudo, que finalmente é manifestado como um defeito. Sistemas flexíveis de manufatura são sistemas que executam múltiplos processos visando à produção de diversos bens. O processo é um conjunto de ações de transformação que por sua parte requerem um conjunto de recursos que são compartilhados por outros processos simultaneamente. Sistemas flexíveis de manufatura envolvem um número relativamente grande de componentes, máquinas, equipamentos e operadores humanos, que interagem de maneira diversificada manipulando um grande conjunto de informação e diferentes materiais em ambientes que podem até ser agressivos. Independentemente de qualquer programa de manutenção, falhas são eventos que são possíveis de acontecer em qualquer sistema de tal natureza. Num ambiente ideal, o funcionamento de todos os componentes poderia ser monitorado com o objetivo de detectar as falhas prematuras, mas devido ao custo envolvido, isso se torna inviável. Neste sentido surge o desafio de detectar as falhas a partir da observação do contexto do funcionamento do processo, mediante a monitoração de alguns parâmetros, em geral de fácil acesso, e tomando em consideração manifestações (sintomas) das falhas de um ponto de vista qualitativo.

O presente trabalho propõe a utilização de redes Bayesianas para o diagnóstico de falhas em sistemas flexíveis de manufatura. As redes Bayesianas constituem uma ferramenta útil para a representação das relações que existem entre as causas (componentes em estado de falha) e os sintomas (observações anormais do processo). A partir deste modelo, inferências podem ser feitas para o diagnóstico do sistema. 
Por outro lado, nos últimos anos a rede de Petri tem sido utilizada exitosamente na representação dos aspectos de controle de sistemas produtivos e particularmente de sistemas de manufatura e, desta forma, considera-se aqui tal ferramenta para a modelagem do sistema não só em condições normais de funcionamento como também para a representação do tratamento de falhas, no contexto de um sistema tolerante a anomalias do processo. Especial ênfase é dada à estruturação de uma metodologia que permita a concepção de um procedimento eficaz para a construção de modelos de controle. 


\section{ABSTRACT}

The objective of the present work is the construction of models proper for the easy implementation of flexible manufacturing control systems able to handle not only with normal behavioral conditions, but with abnormal (or faulty) behavior as well. A fault is defined as a deviation of at least one system property that drives the system into an error state. An error is defined as an uncommon behavior, not expected from the system functionalities. Flexible manufacturing systems are systems that execute multiple processes for the production of several items in several ways. A process is a sequence of certain transformation tasks that require a set of resources shared simultaneously by multiple processes. In this sense, flexible manufacturing systems are constituted of a relatively great number of devices, machines, equipments and human operators that work together manipulating great quantities of information and materials. This work is usually performed in aggressive environments. So, independent of any maintenance program, faults are events that cannot be totally avoided. In an ideal environment, the monitoring of all components is the way to avoid faults. Nevertheless, due to the cost involved, this is an impossible task. In this context, there is a challenge to properly detect faults from the observation of the systems context, through the monitoring and observation of some parameters in general easy to access, including also qualitative information from operators.

In the present work, it is proposed the use of Bayesian networks for the fault diagnosis in flexible manufacturing systems. Bayesian networks constitute a useful tool for the modeling of the causal relation between the causes (faulty components) and the symptoms (manifestations). Based on this model, inference can be done for the system diagnosis task.

Additionally, in the last years Petri net has been successfully used for the modeling of control systems of productive systems and particularly, manufacturing control systems. In this work, beyond the use of Petri net for the modeling of normal situations of the system, Petri net is used for the modeling of the fault treatment techniques. This drives the system tolerance to faults. 
Especial emphasis is laid into methodological issues that allows for the structuration of a systematic procedure proper for the modeling and construction of control systems. 


\section{INTRODUÇÃO}

Nos últimos anos, sistemas ${ }^{1}$ produtivos e em especial sistemas de manufatura vêm experimentando uma reestruturação principalmente em relação às estratégias de produção que incluem mudanças em como os bens ou serviços são projetados, desenvolvidos, produzidos e distribuídos. O comportamento variável e volátil dos usuários tem motivado as empresas a mudar os paradigmas de produção visando o aumento da competitividade. A abertura de novos mercados trouxe consigo novos desafios como a demanda de produtos de maior qualidade com custos menores. Assim, as empresas necessitam apresentar maior capacidade de inovação, maior eficiência na prestação de serviços, e habilidade para a coordenação de sistemas geograficamente distribuídos. Isto indica que o sucesso das empresas não depende só de políticas de proteção por parte dos governos para garantir mercados internos, mas sim, da capacidade de desenvolver novas estratégias de produção.

BOLWIJN \& KUMPE (1990) apresentam no seu trabalho a evolução que os sistemas industrializados tiveram que sofrer para garantir a sua sobrevivência. Segundo estes autores, até aproximadamente 1960 o preço dos produtos não era um fator relevante para o aumento das vendas e, portanto, esforços eram concentrados simplesmente no aumento do volume da produção. A partir de então se começa a perceber que as indústrias podiam alcançar mercados afastados geograficamente. Esse movimento por sua vez fez com que os consumidores tivessem acesso a produtos de vários países e regiões o que aumentou a possibilidade de escolha. Neste ponto o preço final do produto começa a ser um fator relevante.

No final dos anos 60 , um outro fator começa a ganhar importância na escolha dos produtos: a qualidade. As empresas, portanto, incluem nos seus processos certas técnicas para obter um equilíbrio entre o preço e a qualidade e assim garantir um espaço no mercado.

\footnotetext{
1 Neste texto entende-se por sistemas como um conjunto de componentes com características particulares que trabalham de forma conjunta para atender um objetivo em comum.
} 
A partir do final dos anos 70 , devido ao relativo decremento do investimento necessário para a implementação de novas indústrias, surgem produtos de todo tipo com preços diversificados, causando que a produção comece a exceder a demanda. Os consumidores passam assim a ter mais influência nas decisões sobre o que produzir e como produzir.

Dos anos 90 e até hoje um novo fator torna-se relevante para o sucesso de uma empresa: a capacidade de inovação. A Figura 1.1 ilustra de maneira resumida a evolução que as empresas produtivas tiveram ao longo dos últimos anos.

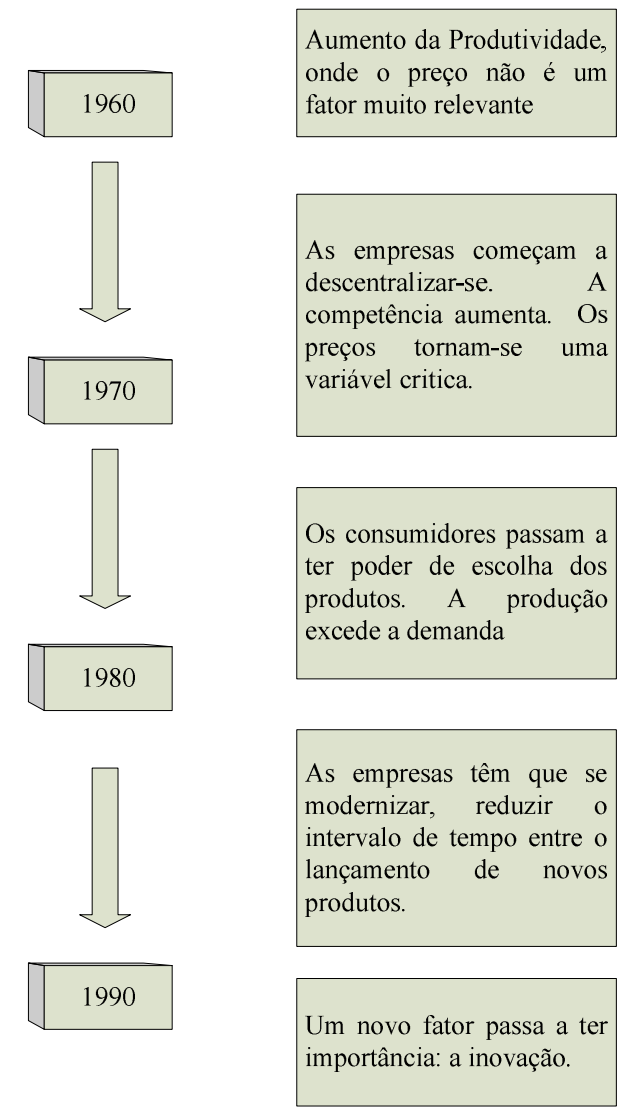

Figura 1.1. Evolução dos processos de produção ao longo do tempo.

Observa-se que, no passado a demanda do mercado era relativamente mais estável, os tempos de desenvolvimento e produção de novos produtos eram maiores e o ciclo de vida dos produtos permitia produções em grandes lotes de um único tipo de produto, a chamada produção 'Fordista' (BEACH et al., 2000). Nos últimos 
tempos, a capacidade de introduzir novos produtos no mercado de maneira eficaz e com a mesma estrutura de produção é um fator importante a ser considerado para manter as empresas competitivas. Esta mudança no cenário do mercado trouxe consigo a necessidade de novas estratégias de manufatura, tomando em consideração aspectos como os custos, a qualidade, os prazos de entrega, e flexibilidade. MUSCAT \& FLEURY (1993) incluem nesta lista a capacidade de inovação. Assim podem ser identificados os seguintes focos das estratégias de manufatura:

- custos - é a capacidade de produzir bens ou serviços mantendo preços baixos. A regra geral é que produtos padronizados tendem a ter custos de produção menores;

- qualidade - é a capacidade de manter os clientes satisfeitos com o produto produzido;

- tempo - que comporta duas possibilidades básicas: (a) assegurar qualidade aos clientes no menor prazo possível; e (b) atender aos clientes dentro de uma faixa de tempo, com a menor variação possível;

- flexibilidade - é a capacidade de responder a mudanças do mercado de forma rápida e eficaz;

- inovação - que visa atender os clientes sempre com produtos diferenciados e com características sem precedentes.

$A$ adoção de tais focos tem sido de modo seqüencial e em geral, acumulativo (MUSCAT \& FLEURY, 1993). Assim, se a empresa adota a estratégia de qualidade, esta adotando ao mesmo tempo, a estratégia de custos.

Entretanto, na prática, nenhuma destas estratégias pode ser efetivamente implementada se não são considerados possíveis falhas e erros do sistema. Por exemplo, tanto o custo como a qualidade do produto serão diretamente afetados devido à ocorrência de uma falha no processo. O tempo para a produção também será afetado devido a falhas no sistema em geral, que precisam de um tempo de 
correção e a devida manutenção/calibração dos respectivos equipamentos. A flexibilidade não poderá ser devidamente implementada se a detecção e o diagnostico de falhas não são realizados de maneira sistemática. A capacidade de inovação só poderá ser incluída no sistema quando existe confiabilidade aceitável dos processos.

Tais exigências têm levado os sistemas de manufatura a aumentarem a sua complexidade, e isso tem exigido o uso de modelos que permitam a avaliação e a análise de certas propriedades desejáveis e indesejáveis dos sistemas. Neste sentido, sistemas de manufatura podem ser modelados considerando uma seqüência de passos derivado da evolução de um conjunto de estados decorrente da ocorrência de eventos considerados instantâneos, isto é, como um sistema a eventos discretos. Assim, podem ser utilizadas ferramentas como a rede de Petri para a modelagem deste tipo de sistemas (CASSANDRAS, 1993), bem como as suas extensões (como o $\mathrm{PFS}^{2}$ e o $\mathrm{MFG}^{3}$ ) que permitem uma modelagem hierárquica e sistemática dos sistemas.

Por outro lado, o crescimento do porte estrutural dos sistemas produtivos tem criado um novo desafio enquanto à detecção de falhas. O número de componentes que compõem o sistema produtivo junto com a alta interdependência entre estes, torna inviável o monitoramento continuo de todas as variáveis envolvidas. Além disso, existem falhas que não podem ser detectadas diretamente a partir de dados monitorados e requerem um processo de diagnóstico. Assim, o desafio consiste em identificar falhas e erros a partir do contexto do sistema e de certas manifestações inerentes à falha. Técnicas de raciocínio probabilístico, entre as quais destacam-se as redes Bayesianas, permitem a realização de inferências probabilísticas a partir de certos estados do sistema, o que permite que o diagnóstico possa ser feito de maneira sistemática, considerando alguns sintomas do processo em falha.

\footnotetext{
${ }^{2}$ PFS - Production Flow Schema (MIYAGI, 1996)

${ }^{3}$ MFG - Mark Flow Graph (MIYAGI, 1996)
} 
O presente trabalho focaliza-se na sistematização de uma metodologia ${ }^{4}$ para a construção de modelos a serem analisados visando a detecção e tratamento de falhas em sistemas flexíveis de manufatura baseado em conceitos de sistemas a eventos discretos (SED), rede de Petri e a teoria de rede Bayesiana.

\subsection{OBJETIVOS}

O objetivo do presente trabalho é propor um método para estruturar a construção de modelos que detalhem os processos envolvidos em um sistema flexível de manufatura para assim permitir a análise do seu sistema de controle considerando não só as condições normais, mas também as condiciones anormais (em estado de falha) de funcionamento. Este método aborda tanto a detecção de falhas quanto o tratamento das mesmas utilizando técnicas derivadas da rede de Petri, rede Bayesiana e teorias sobre SED.

\subsection{METODOLOGIA DE PESQUISA}

A metodologia de pesquisa adotada no presente estudo segue um ciclo de desenvolvimento do trabalho onde as técnicas, introduzidas para a concepção de soluções de casos de aplicações práticas, dão suporte direto à implementação de técnicas de modelagem através do uso e/ou desenvolvimento de ferramentas com base em métodos definidos a partir de teorias sobre SED, teoria de falhas, e probabilidade. A Figura 1.2 ilustra os principais aspectos da metodologia cuja interação visa encontrar soluções alternativas e dentre estas identificar a mais

\footnotetext{
${ }^{4}$ Neste texto entende-se metodologia como o estudo de um conjunto de métodos que permite a estruturação de processos.
} 
adequadada para tratar o problema do diagnóstico e tratamento de falhas em sistemas flexíveis de manufatura.

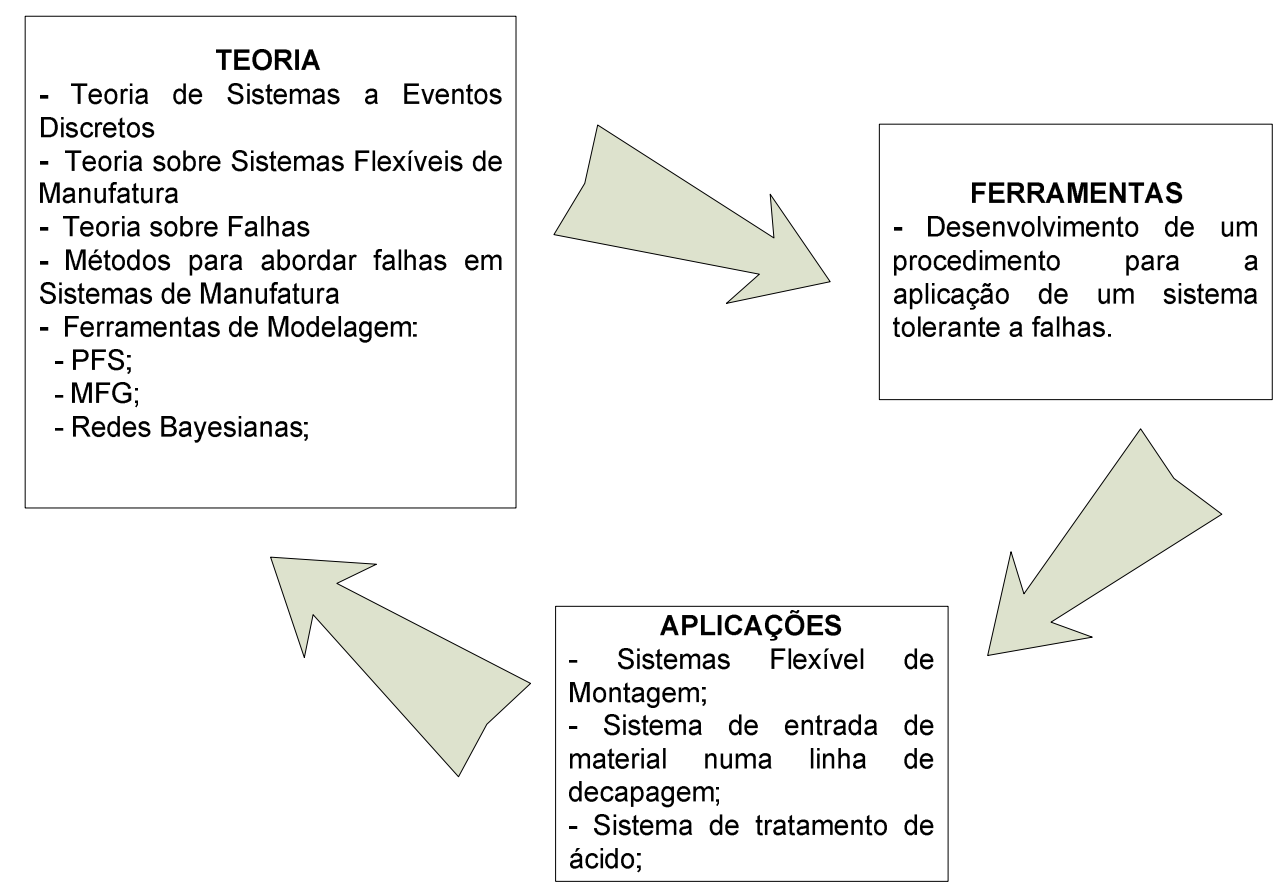

Figura 1.2 Ciclo de desenvolvimento da metodologia proposta.

\subsection{ORGANIZAÇÃO DO TEXTO}

No capitulo 2 é descrito o resultado do levantamento bibliográfico realizado para formar uma base de conhecimento para a definição do problema do diagnóstico de falhas em sistemas flexíveis de manufatura e para desenvolver uma proposta alternativa mais eficaz para este tipo de situações. Este levantamento também situa o trabalho dentro do contexto atual das pesquisas correntes na área sendo assim uma referência para avaliar as vantagens e desvantagens da proposta desenvolvida frente a outras possíveis soluções. Neste capitulo incluem-se a teoria de sistemas a eventos discretos (SED); teoria sobre falhas em sistemas produtivos; modelagem de SED; rede de Petri e suas extensões; e a rede Bayesiana. São estudadas as 
principais características dos sistemas automatizados de manufatura considerando as condições necessárias para a manifestação de eventuais falhas. São caracterizados em particular, os sistemas flexíveis de manufatura cujas propriedades requerem a construção de modelos para serem devidamente avaliadas e analisadas.

No capitulo 3 são formalmente introduzidos os conceitos de rede de Petri e suas extensões como ferramentas/metodologias empregadas para a modelagem de sistemas a eventos discretos. Especial ênfase é dada à metodologia PFS/MFG que define um procedimento hierárquico e sistemático, baseando-se em representações conceituais e dinâmicas do sistema. São também discutidas algumas propriedades e técnicas de análise que permitem a verificação do comportamento do sistema.

Também é descrita a rede Bayesiana como uma ferramenta que permite a representação do sistema sob um ponto de vista do seu comportamento em condições anormais de funcionamento (estado de falha). Baseado neste tipo de rede pode-se fazer inferências que permitem, a partir de um conjunto de manifestações do sistema, obter as causas com maior probabilidade de serem responsáveis por tais anomalias. São discutidas as principais técnicas de modelagem e aprendizado, bem como as principais técnicas de inferência utilizadas.

É apresentado no capitulo 4 a metodologia proposta para a modelagem do processo de diagnóstico e tratamento de falhas em sistemas de manufatura. Esta metodologia adota uma abordagem hierárquica utilizando métodos de representação e análise com base na teoria de SED, rede de Petri e rede Bayesiana. A metodologia propõe a rede de Petri como uma ferramenta para a descrição do comportamento do sistema em situações normais de funcionamento, bem como a descrição das técnicas de tratamento em condições anormais. Propõe-se o diagnóstico de falhas utilizando supervisores distribuídos no chão de fabrica que permitem observar manifestações que, através das redes Bayesianas, serão considerados como sintomas para a identificação das causas da falha. Assim, uma abordagem modular é adotada considerando os seguintes pontos:

- representação do sistema em condições normais de funcionamento; 
- execução do diagnóstico de falhas, e

- representação do tratamento de falhas ou de situações anormais de funcionamento.

No capitulo 5 são apresentados um conjunto de exemplos de aplicação que ilustram a funcionalidade da proposta.

Por fim, no capitulo 6 são apresentadas as observações, conclusões e principais resultados do projeto. Futuros trabalhos são sugeridos para dar continuidade à proposta apresentada. 


\section{DIAGNÓSTICO E TRATAMENTO DE FALHAS EM SISTEMAS DE MANUFATURA}

Neste capítulo procura-se apresentar o levantamento bibliográfico realizado para desenvolver uma abordagem que considera o problema do diagnóstico e tratamento de falhas em sistemas de manufatura automatizados com características de autonomia e flexibilidade. Assim, é apresentada uma descrição de sistemas flexíveis de manufatura considerando níveis de representação hierárquicos baseados nas funcionalidades do sistema, com especial ênfase na integração e complementaridade dos aspectos tecnológicos. É apresentada uma taxonomia sobre as principais definições que permitem caracterizar o conceito de falha. São discutidas também as principais técnicas de detecção e diagnóstico de falhas bem como as suas diferenças e limitações. Finalmente, o presente trabalho é identificado como uma alternativa para o diagnóstico e tratamento de falhas.

\subsection{SISTEMAS A EVENTOS DISCRETOS (SED)}

Ao longo da evolução tecnológica iniciada no final do século 19, muitas soluções para os problemas de produção foram implementadas explorando a capacidade humana de abstrair situações e fazer com que sistemas se comportem de forma automática segundo uma lógica predefinida. Foram criados assim os sistemas concebidos e feitos pelo homem e para o homem (ITO, 1991) (man made systems) tentando abordar sistemas como linhas de produção e montagem, redes computacionais e de comunicação, sistemas de edifícios inteligentes, sistemas de transito, sistemas de comando, comunicação e controle inteligente $\left(\mathrm{C}^{3} \mathrm{l}\right)$, etc. $(\mathrm{HO}$, 1987). Neste sentido, CASSANDRAS (1993) apresenta uma classificação de sistemas, que considera os diferentes aspectos que os caracterizam. Esta classificação é adotada para realizar uma definição mais formal de SED: 
- Sistemas Instantâneos e Dinâmicos: os sistemas instantâneos têm a característica de que suas variáveis de saída $\boldsymbol{y}(k)$ são independentes do valor das suas variáveis anteriores, isto é, só dependem das variáveis atuais de entrada $\boldsymbol{x}(k)$; entretanto, nos sistemas dinâmicos as variáveis de saída $\boldsymbol{y}(k)$, além de dependerem dos valores atuais das variáveis de entrada $\boldsymbol{x}(k)$, dependem dos valores anteriores $\boldsymbol{u}(k)$ (Figura 2.1).
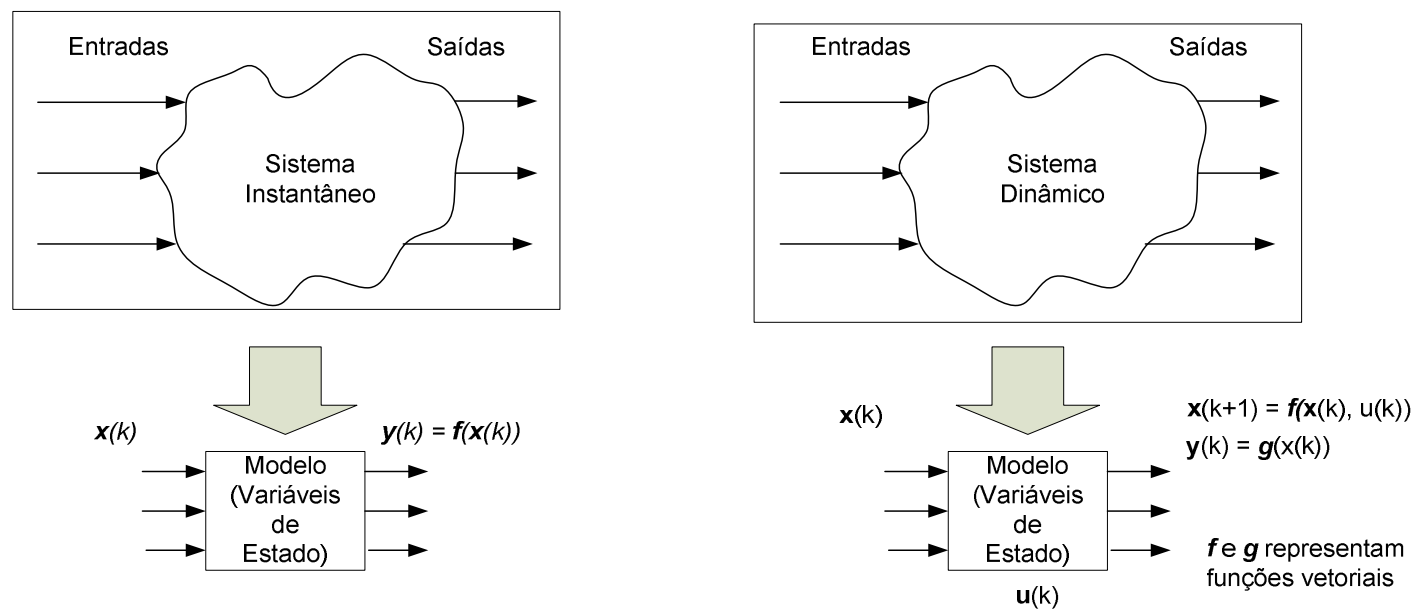

Figura 2.1. Processo de modelagem de sistemas instantâneos e dinâmicos.

- Sistemas Variantes no Tempo e Invariantes no Tempo: nos sistemas invariantes no tempo o comportamento do sistema não muda ao longo do tempo, isto é, para um conjunto de entradas, a saída correspondente é sempre a mesma. Se não houver esta relação o sistema é chamado de variante no tempo.

- Sistemas Lineares e Não-Lineares: Um sistema linear satisfaz o principio da superposição $g\left(a_{1} u_{1}+a_{2} u_{2}\right)=a_{1} g\left(u_{1}\right)+a_{2} g\left(u_{2}\right)$, onde $u_{1}$ e $u_{2}$ são dois vetores de entrada, $a_{1}$ e $a_{2}$ são números reais e $g($.) é uma função. Caso esta condição não seja satisfeita o sistema será não-linear.

- Sistemas de Estado Contínuo e Estado Discreto: nos sistemas de estado contínuo, as variáveis podem assumir valores contínuos e reais. Se as variáveis pertencem ao domínio de valores discretos (inteiros positivos, variáveis lógicas, etc.), o sistema é chamado de discreto. 
- Sistemas Dirigidos pelo Tempo e Dirigidos por Eventos: em sistemas dirigidos pelo tempo, as variáveis de estado do sistema mudam continuamente de acordo com a evolução do tempo. Em sistemas dirigidos por eventos, as variáveis de estado do sistema evoluem segundo a ocorrência de eventos discretos em geral imprevisíveis. O estado do sistema entre dois eventos consecutivos permanece constante e inalterado.

- Sistemas Estocásticos e Sistemas Determinísticos: se uma ou mais variáveis de um sistema podem assumir valores aleatórios, o sistema pertence ao grupo de sistemas estocásticos. Se não houver nenhuma variável aleatória, o sistema é chamado de determinístico.

- Sistemas de Tempo Discreto e Tempo Contínuo: no caso em que exista uma amostragem de variáveis no tempo, isto é, que os valores das variáveis de entrada, estado ou saída só sejam reconhecidas em certos instantes no tempo (valores discretizados), o sistema é chamado de tempo discreto. Se as variáveis são definidas para todos os possíveis valores do tempo, o sistema é chamado de contínuo no tempo.

A Figura 2.2 apresenta uma esquematização da classificação dos sistemas conforme CASSANDRAS (1993). Segundo esta classificação, um SED é um sistema dinâmico, invariante no tempo, não linear, de estado discreto e dirigido por eventos.

A ocorrência de eventos no SED é em geral em intervalos de tempo irregulares e desconhecidos (RAMADGE \& WONHAM, 1989) o que caracteriza no sistema um primeiro nível de indeterminismo com relação ao tempo (SANTOS FILHO, 2000). Estes eventos (como a chegada de material, 'inicio' ou 'término' de uma tarefa ou processo, etc.) determinam a mudança de um estado para outro, que por sua vez é mantido constante até a ocorrência de um novo evento (CURY, 2001). Em contraposição, existem os sistemas de variáveis contínuas (SVC), cuja mudança de estado ocorre de forma continua ao longo do tempo, e cuja dinâmica é descrita por variáveis contínuas. 


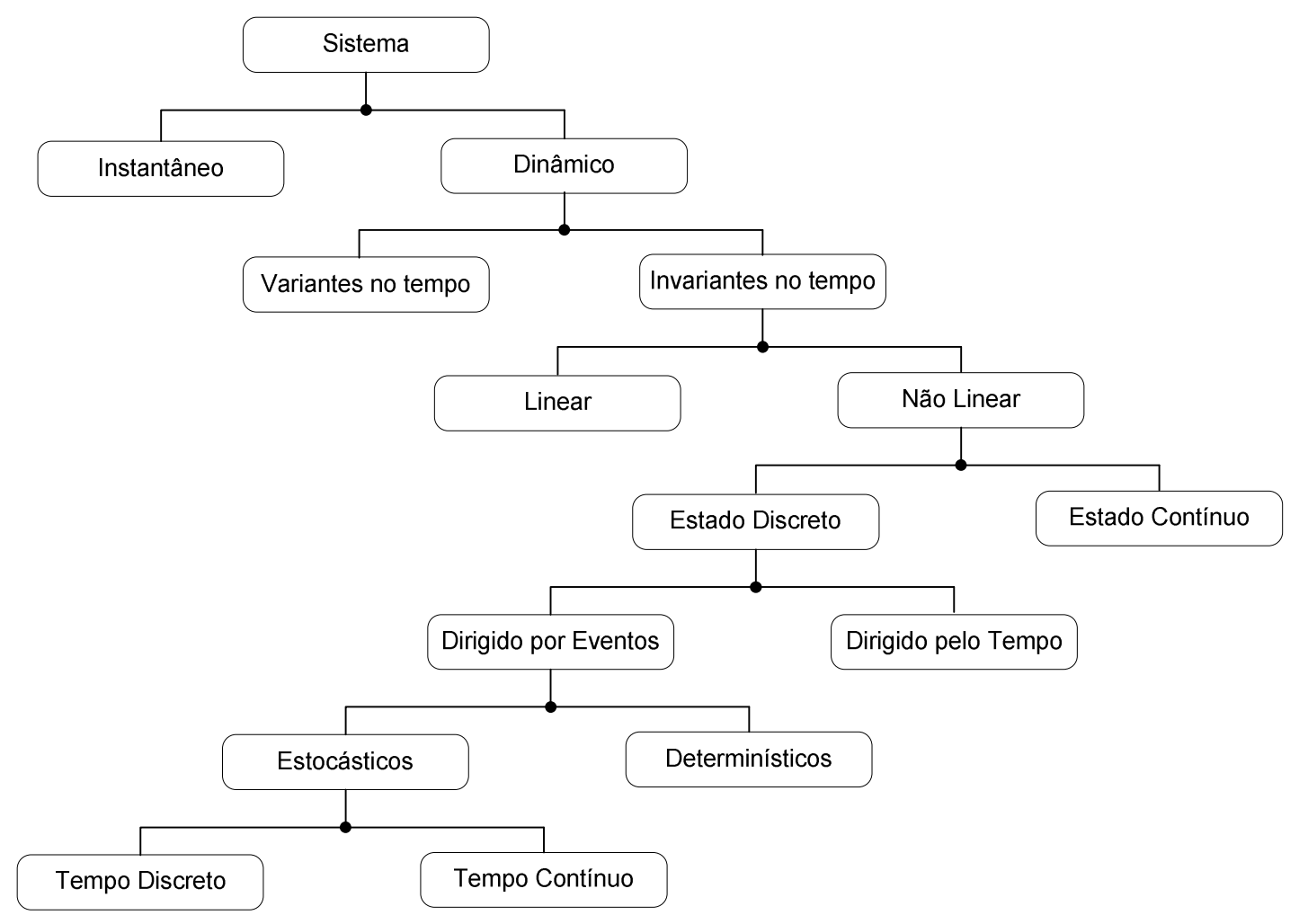

Figura 2.2. Classificação dos sistemas traduzido de Cassandras (1993).

Embora a história do controle de SED seja tão antiga quanto ao do controle de SVC (MIYAGI, 1996), o estudo de SED é relativamente recente em relação ao conhecimento alcançado nos SVC. Nota-se que a modelagem matemática dos SED ainda está longe de sua consolidação (HO, 1992), (CASSANDRAS \& LaFORTUNE, 1999). A Figura 2.3 apresenta o comportamento de SED comparado com o comportamento de SVC. Esta comparação evidencia as diferenças que existem entre tais sistemas, sendo que nos SVC as variáveis pertencem a um conjunto infinito de valores, enquanto que nos SED as variáveis podem tomar valores de um conjunto discreto e finito, e cuja mudança só é realizada na ocorrência de um evento considerado instantâneo.

O problema de controle em SED consiste em estabelecer um conjunto de regras e restrições que permitam ao sistema se comportar segundo uma lógica préestabelecida, atuando conforme uma seqüência de procedimentos que atendam o objetivo da produção, no caso de sistemas produtivos ou de manufatura. 


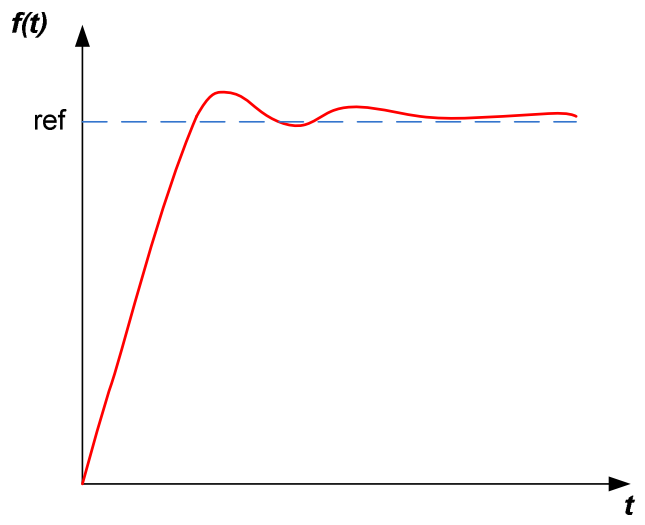

(a) $\mathrm{SVC}$

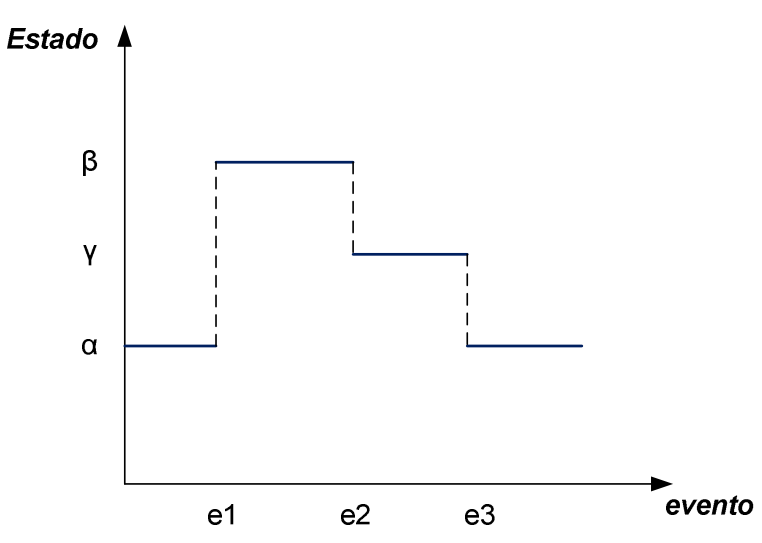

(b) SED

Figura 2.3. Comportamento do SVC comparado com o comportamento do SED.

\subsubsection{Modelos de SED}

Com base na bibliografia consultada, nota-se que não existe uma técnica universal generalizada que possa ser adotada para tratar qualquer tipo de SED em aplicações práticas. No entanto, algumas técnicas têm sido bem sucedidas para tratar problemas de modelagem em aplicações particulares. Entre elas estão (HO, 1989), (CAO, 1989), (ZHOU \& DiCESARE, 1993):

- Teoria de filas;

- Álgebra min - 13ax;

- Processos semi-markovianos generalizados, incluídos aqui as linguagens de simulação discreta;

- Cadeias de Markov;

- Máquina de estados finitos;

- Rede de Petri e suas extensões. 
Uma classificação destas técnicas é possível considerando-se: os tipos de variáveis utilizadas pelo modelo (lógicos, algébricos ou de análise de desempenho); a dependência ou não do tempo para a ocorrência de eventos (temporizados ou não temporizados); e a forma como acontecem os eventos (determinísticos ou estocásticos). A seguir, na Tabela 2.1, é apresentada esta classificação (HO, 1992):

Tabela 2.1. Classificação de Modelos de SED, adaptado de (HO,1992).

\begin{tabular}{|c|c|c|}
\hline & Temporizados & Não-temporizados \\
\hline Lógicos & Rede de Petri Temporal & $\begin{array}{l}\text { Rede de Petri lugar/transição } \\
\text { Maquinas de estado finito }\end{array}$ \\
\hline Algébricos & Álgebra min-max & $\begin{array}{l}\text { Processos recursivamente finitos } \\
\text { Processos seqüenciais de } \\
\text { comunicação }\end{array}$ \\
\hline Desempenho & $\begin{array}{l}\text { Cadeias de Markov } \\
\text { Rede de Filas, GSPN } \\
\text { GSPN/simulação }\end{array}$ & \\
\hline & Estocásticos $\rightarrow$ & $\leftarrow$ Determinísticos \\
\hline
\end{tabular}

O sistema flexível de manufatura (flexible manufacturing systems, FMS) apresenta funcionalmente características como reinicialização, assincronismo, paralelismo, concorrência entre eventos, etc., motivo pelo qual tais tipos de sistemas podem ser modelados como SED. Portanto, realiza-se a seguir uma contextualização de FMS.

\subsection{SISTEMA FLEXÍVEL DE MANUFATURA (FMS)}

A manufatura tem passado por várias mudanças ao longo da história. Começando com a produção manual intensiva e as linhas de produção em massa, as primeiras tentativas de automação industrial começam com a implementação de linhas automatizadas de produção adotadas pela indústria automobilística no século XIX. Posteriormente são introduzidos os flow shops, com o intuito de aumentar a produtividade baseada numa produção de peças praticamente idênticas através de 
tarefas repetitivas e cíclicas; os job shops e a manufatura celular com o objetivo de produzir de forma eficiente, vários tipos de produtos com algum grau de similaridade de maneira mais eficaz. Com a introdução de recursos computacionais são desenvolvidas ferramentas que permitem incluir maior flexibilidade, o que viabiliza alterações no que é produzido e como é produzido. Assim, foi concebida a idéia de sistema flexível de manufatura (FMS) que por sua vez subsidia os conceitos de manufatura integrada por computador (CIM) e sistemas ágeis de manufatura (MAS).

Nos trabalhos que têm sido publicados flexibilidade em sistemas de manufatura tem sido utilizada de maneira reativa. A flexibilidade provê a capacidade de um sistema se modificar baseado em incertezas do ambiente tanto externo como interno (BEACH et al., 2000). Entretanto, o custo envolvido com a implementação da flexibilidade impõe uma restrição baseada nas especificações do sistema produtivo. Há uma afirmação que sintetiza como deve ser o procedimento básico para selecionar a tecnologia de automação mais adequado a cada caso:

"Deve-se projetar um sistema produtivo tão rígido quanto seja possível e tão flexível quanto seja necessário".

Considerando as características estruturais de um FMS, RANKY (1990) define este como um sistema que envolve o processamento de dados distribuídos e o fluxo automatizado de material mediante o uso de máquinas controladas por computador, células de montagem, robôs industriais, máquinas de inspeção, etc. formando um conjunto que inclui ainda um sistema de movimentação de material integrada por computador e sistemas de armazenamento de materiais.

Os componentes principais do FMS são, em geral (DAVIS et al., 1997) (REMBOLD \& TANCHOCO, 1994):

- máquinas ferramentas com comando numérico computadorizado; 
- sistema de movimentação de materiais automatizado;

- sistema de intercâmbio de informação, através de redes de comunicação;

- sistema de controle global que coordena as funções das máquinas ferramenta e o sistema de movimentação.

O custo envolvido com a implementação de um FMS exige também que seja feita uma distinção/classificação da flexibilidade considerada. Assim, com base nas características do sistema, podem ser reconhecidos os seguintes tipos de flexibilidade:

- flexibilidade de produto, que é a capacidade do sistema de manufatura modificar-se para produzir um novo conjunto de itens, de forma rápida e econômica;

- flexibilidade de processo, que é a capacidade de produzir um item de várias maneiras;

- flexibilidade de operação, que é a capacidade de reordenar as operações do sistema de manufatura num processo produtivo de um item.

A flexibilidade pode ainda ser considerada como um elemento importante na regulagem e mudanças no ambiente operacional, permitindo desse modo respostas adaptativas a situações imprevisíveis. Contudo, a flexibilidade pode ir além do aspecto adaptativo. A flexibilidade possui também uma função pró-ativa que pode ser útil para lidar com incertezas de mercado, preferências dos consumidores, ou ainda, incertezas no ambiente entre as quais outras empresas concorrentes não seriam capazes de enfrentar.

O FMS pode ser concebido como um conjunto de subsistemas distribuídos cujo controle em geral, pode ser descrito segundo uma hierarquia que depende da quantidade de equipamentos, layout de fábrica, filosofia de gerenciamento, disponibilidade de software e equipamentos computadorizados, grau de automação, 
etc. Neste sentido, alguns autores descrevem tal sistema segundo as funcionalidades dos equipamentos e/ou conjunto de equipamentos envolvidos, enquanto que outros utilizam características dos processos. A Figura 2.4 apresenta os níveis de controle segundo estas duas abordagens (CHINTAMANENI et al., 1988), (HASEGAWA, 1996), (COMBACAU \& COURVOISIER, 1990):

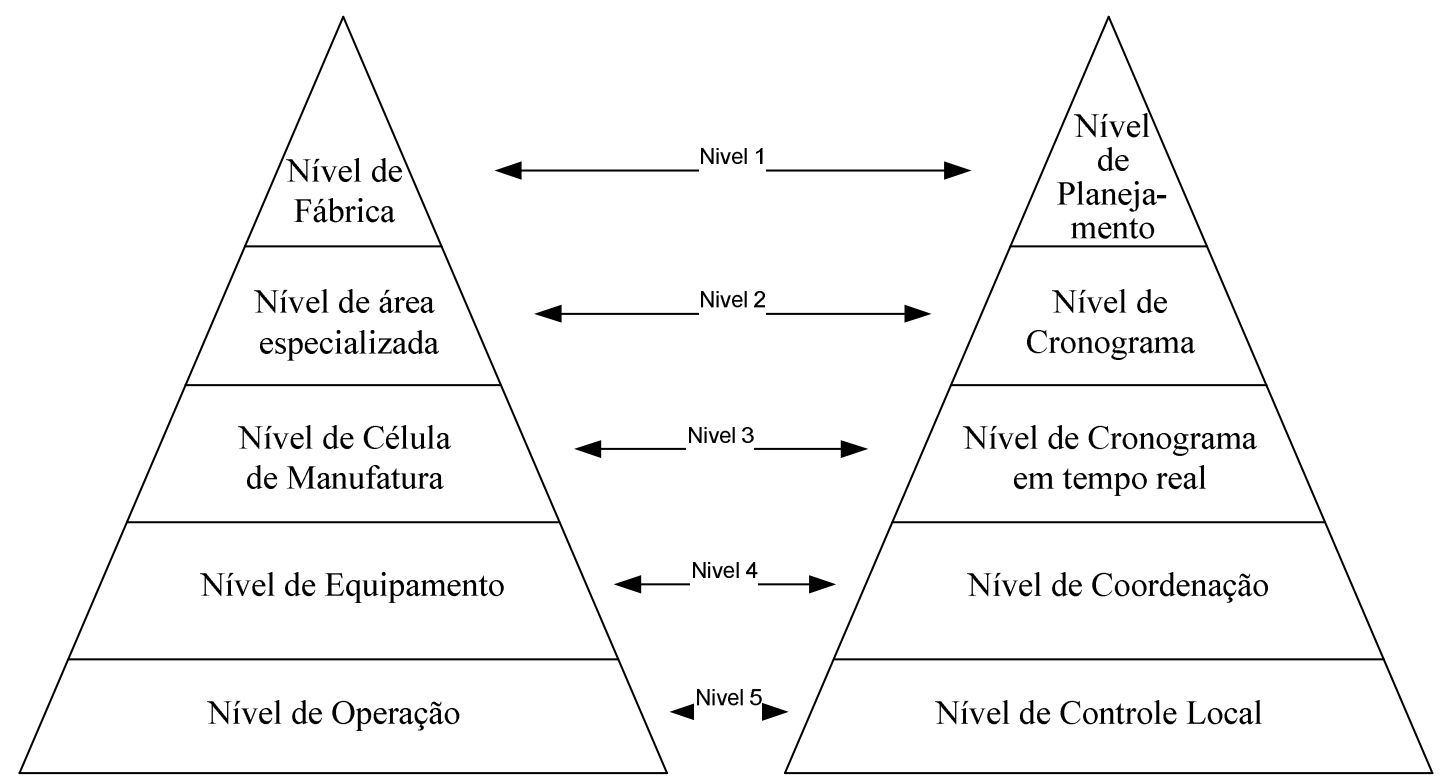

(a)

(b)

Figura 2.4. Níveis de controle segundo (a) as funcionalidades dos equipamentos, e (b) as características dos processos.

Observa-se que existe uma relação entre as duas abordagens: no primeiro nível (o nível mais elevado) são abordados os conceitos da engenharia da manufatura, o gerenciamento das informações e o gerenciamento da produção; no segundo nível tem-se o gerenciamento dos trabalhos e recursos numa área dedicada a processos específicos; no terceiro nível é abordado o problema do seqüenciamento de lotes de produção de partes; no quarto nível é feita a coordenação das operações dos equipamentos e, finalmente, no quinto nível são controlados individualmente os dispositivos de cada máquina. Naturalmente, as técnicas de especificação e ferramentas de desenvolvimento e implementação utilizadas por cada um destes níveis diferirão de uma abordagem a outra desde que a funcionalidade dos equipamentos assegure a realização dos processos envolvidos. 
Nota-se que cada um dos níveis apresenta exigências distintas quanto a capacidade e velocidade de processamento dos recursos computacionais envolvidos. Enquanto os níveis inferiores envolvem transferência de dados relativamente simples (normalmente sinais e códigos tratados como variáveis Booleanas) com características de sincronização e exigências em tempo real críticas; os níveis superiores envolvem uma grande quantidade e variedade de informações, em geral de natureza qualitativa, cujas exigências em tempo real são menos críticos.

O alcance da presente proposta inclui a construção de modelos para obter a partir destes, estratégias de controle para os níveis 3, 4 e 5.

\subsubsection{Modelagem de Sistemas Flexíveis de Manufatura}

O funcionamento do FMS apresenta uma natureza assíncrona, envolvendo em geral, processos concorrentes e paralelos que incluem vários componentes e subsistemas que compartilham recursos limitados e que interagem entre si de maneira relativamente complexa e em tempo real. Neste sentido, dois problemas são usualmente destacados em tais sistemas: possibilidade de deadlock, e possibilidade de conflito (SANTOS FILHO, 2000). O deadlock se define como um estado a partir do qual o sistema não pode evoluir mais, e no qual permanece por tempo indefinido. O conflito por sua vez é definido como um estado no qual dois ou mais processos requerem simultaneamente um mesmo recurso do sistema. Neste sentido, a modelagem de FMS deve assegurar a devida representação destas situações e do seqüenciamento dos processos, sendo uma forma de ajudar na especificação da solução de situações de conflito e de estados de deadlock. Portanto, o problema da modelagem de FMS não é trivial. Uma primeira dificuldade envolve a modelagem da incerteza que existe em relação ao instante da ocorrência de eventos. Uma outra dificuldade envolve a modelagem do compartilhamento de recursos limitados. Estas dificuldades são características próprias do FMS que, em geral, resulta numa explosão de estados no modelo. Isto faz com que o determinismo em relação à seqüência de eventos seja perdido e, portanto, 
aparecem incertezas quanto ao seqüenciamento de processos. Estas dificuldades podem ser entendidas como a complexidade envolvida na modelagem do FMS.

O processo de abstração de FMS envolve o processo de síntese onde se tem a concepção do sistema a partir do conhecimento do funcionamento das partes individualmente. Entretanto, o processo de análise parte da compreensão geral do sistema como um todo, sem visar necessariamente as partes individualmente. Portanto, a complexidade surge quando os conhecimentos individuais das partes que compõem o sistema não necessariamente refletem o comportamento do conjunto, e assim, a descrição ou predição da evolução do sistema torna-se complexo.

Um outro tipo de complexidade no FMS é caracterizado quando elementos do sistema são capazes de tomar decisões, como no caso de operadores humanos. Não obstante, esse caso esta fora do escopo do presente estudo.

Assim, com o objetivo de tratar estas dificuldades, é necessário diferenciar duas etapas na concepção de FMS:

- Estruturação: onde são determinadas as estruturas lógica e física da planta. Nesta estruturação, a organização dos equipamentos é definida com base na implementação prevista dos processos produtivos.

- Operação: que considera problemas como o planejamento, supervisão, controle, compartilhamento e alocação de recursos, etc.

Enquanto que para a primeira etapa são encontradas técnicas de organização física de plantas (Transfer lines, Production lines, Flow Shop, Job Shop, etc.), a segunda etapa requer normalmente o uso de um modelo que abstraia o comportamento do sistema real.

Com base nas dificuldades de operação presentes nos FMS, e considerando a teoria desenvolvida na área de pesquisa abordando tais desafios, os sistemas flexíveis de manufatura (FMS) no presente trabalho serão modelados mediante a 
teoria de SED (RAMADGE \& WOHAM, 1989), (HO, 1992); (CASSANDRAS, 1993); (MIYAGI, 1996).

$\mathrm{Na}$ modelagem de FMS deve-se considerar também os seguintes aspectos (DESROCHERS, 1995):

- incerteza do conhecimento da demanda de produção (em qualquer nível da estruturação hierárquica);

- capacidade finita de recursos; e

- incerteza enquanto a ocorrência de falhas dos equipamentos e duração dos tempos de manutenção.

Existem ainda as incertezas em relação aos tempos de fornecimento da matéria prima, mas isto não faz parte do escopo da presente proposta.

A incerteza do conhecimento da demanda impede o dimensionamento ótimo da capacidade da manufatura, do número de máquinas, do número de equipamentos, do número de operadores, etc. necessários para satisfazer tal demanda. A capacidade finita de recursos de manufatura restringe a quantidade de processos que podem ser levados a cabo simultaneamente.

Falhas e quebras de equipamentos também impedem uma programação otimizada das tarefas envolvidas com as operações do sistema produtivo. Dificultam também o planejamento da produção e a determinação dos prazos de entrega. Falhas exigem que seja feita uma revisão do processo de manufatura, tomando em conta os procedimentos de manutenção necessários para o correto funcionamento da planta.

Portanto, as incertezas no conhecimento da demanda de produção e capacidades finitas de recursos de manufatura devem ser devidamente incorporadas no modelo do FMS de modo a permitir uma análise efetiva em distintos níveis do sistema de controle. Alem disso, faz-se necessário um procedimento sistemático para incluir o problema das falhas nos sistemas produtivos. 
Com o objetivo de analisar os métodos que permitem abordar falhas em sistemas de manufatura, é necessária a compreensão do conceito de falha e das condições que permitem sua manifestação e possibilidade de detecção.

\subsection{CONSIDERAÇÕES SOBRE FALHAS EM SISTEMAS DE MANUFATURA}

Com relação ao diagnóstico, detecção e tratamento de falhas em sistemas de manufatura, percebe-se que não existe uma terminologia consolidada nos trabalhos encontrados na área. Isto dificulta a compreensão e a comparação dos diversos trabalhos sobre o tema. Neste sentido, as definições adotadas na presente proposta se baseiam no trabalho de ISERMANN \& BALLÉ (1997), que apresentam um compêndio dos principais conceitos adotados pela International Federation of Automatic Control IFAC SAFEPROCESS technical committee, encarregada do estudo da detecção de falhas, supervisão e segurança de processos técnicos. Adicionalmente, são considerados os trabalhos de AVIZIENIS et al. (2004) e CHANG et al. (1991). A seguir as principais definições:

(i) Falha (fault em inglês) é um desvio de pelo menos uma propriedade característica ou um parâmetro do sistema de uma condição aceitável, usual, ou padrão. Uma falha pode acontecer mesmo que o sistema não apresente erros nas entradas nem nas especificações inicias do comportamento do sistema.

(ii) Erro (error em inglês) é um estado indesejável do sistema ou subsistema que se alcança quando o comportamento atual se desvia do comportamento esperado para o qual o sistema foi projetado. Em geral é considerado como um desvio entre o valor medido ou computado de uma variável de saída e o valor teórico ou esperado.

(iii) Defeito (failure em inglês) é uma interrupção da capacidade de um sistema realizar certa função requerida sob condições específicas de operação. 
Com respeito ao FMS, pode-se considerar cada nível de funcionalidade (Figura 2.4) como um prestador de serviços que pode ser composto por uma ou mais entidades chamadas de provedores (Figura 2.5). O provedor é encarregado de realizar um serviço específico tanto para outros provedores do mesmo nível quanto para os provedores no nível imediato superior. Chama-se de usuário àquela entidade do mesmo nível de um provedor que recebe do provedor do mesmo nível ou de um nível superior um tipo de serviço específico necessário para a correta evolução do seu funcionamento. Nota-se que um provedor pode ser simultaneamente um usuário dependendo do processo. Assim, um defeito acontece quando um usuário percebe que o provedor não realiza o serviço que esperava receber. Considera-se então, que o provedor contém erro o que significa que atinge um ou vários estados indesejáveis não especificados.

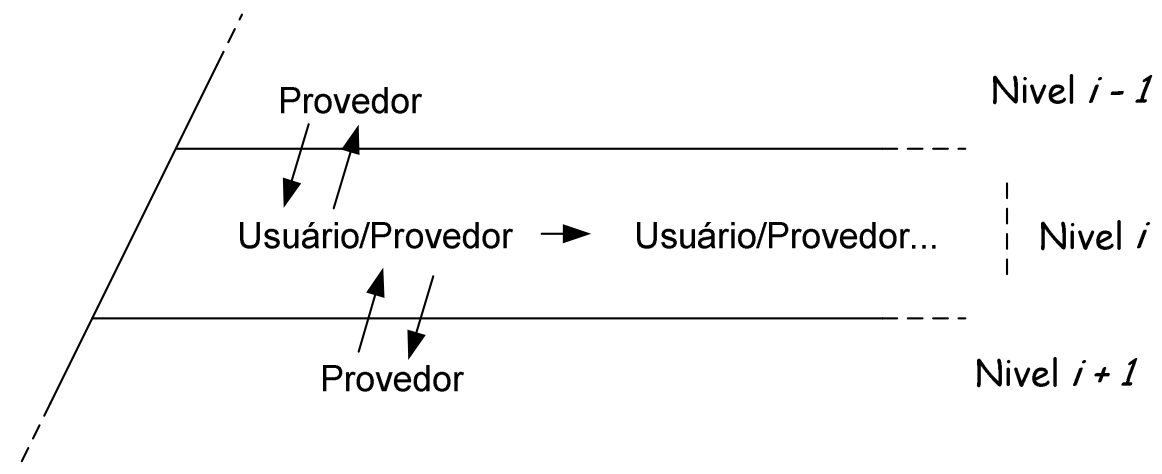

Figura 2.5. Relação entre usuário/provedor em níveis de controle.

Uma falha é entendida como a causa do erro ou da seqüência de erros que aconteceram no provedor. Observa-se então, que uma falha causa um erro, e que um erro se manifesta no serviço ao usuário como um defeito. Existem também, situações nas quais um erro não necessariamente se manifesta como um defeito. Tal situação é chamada de erro latente.

Neste contexto, a detecção e diagnóstico de falhas em sistemas de manufatura começa com a observação de um defeito num certo processo ou equipamento. São então observados os estados que se encontram os subsistemas para verificar a ocorrência de algum erro ou conjunto de erros. Assim, com base nestes erros são 
identificadas a(s) falha(s) que ocasionaram tais anomalias. A Figura 2.6 apresenta a evolução de uma falha num sistema de manufatura. São consideradas falhas internas e falhas externas. Um erro torna-se defeito quando se manifesta como um serviço indevido para outro subsistema.

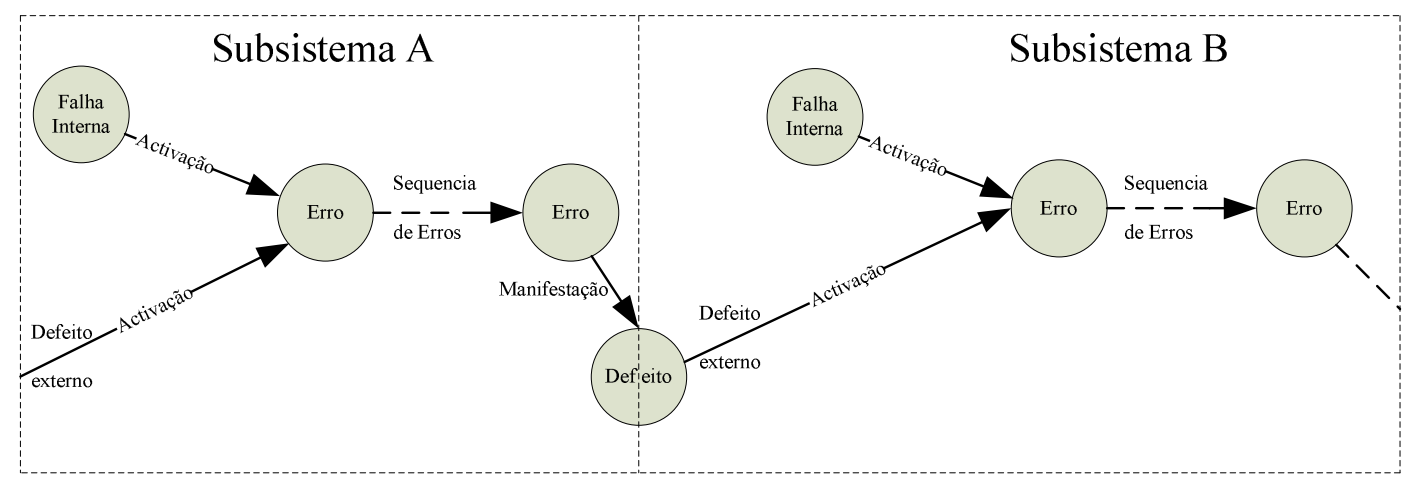

Figura 2.6. Propagação de uma falha num defeito.

Complementando os predicados envolvidos na caracterização do diagnóstico de falhas em sistemas de manufatura tem-se o sintoma que é aqui definido como um desvio de uma variável observável do seu valor nominal.

\subsubsection{Falha}

Com respeito à caracterização de falhas, AVIZIENIS et al. (2004) apresenta no seu trabalho uma classificação de acordo com diferentes modos de encarar esta situação. No presente trabalho, a caracterização de falhas é baseada em cinco questões cujas respostas caracterizam as ocorrências plausíveis de acontecer particularmente em sistemas de manufatura. Tais perguntas são: quando aconteceu a falha?; aonde aconteceu a falha?; porque aconteceu a falha?; quem é afetado pela falha?, e; como a falha se manifesta?

- Quando: questão relacionada à ocorrência da falha: 
- desenvolvimento: falha que ocorre durante a fase de desenvolvimento do sistema ou durante a fase de manutenção;

○ operação: falha que acontece durante a operação do sistema.

- Aonde: questão relacionada à fronteira do sistema:

- externas: falha que se origina fora dos limites do sistema;

○ internas: falha que se origina dentro dos limites do sistema.

- Por que: questão relacionada à causa fenomenológica da falha:

- causas naturais: falha causada por fenômenos naturais sem intervenção humana;

- causas artificiais: falha causada por intervenção humana.

- A quem: questão relacionada ao domínio:

- hardware: falha que se origina ou afeta a componentes físicos;

- software: falha que afeta ao software do sistema.

- Como: questão relacionada à persistência da falha:

○ permanente: falha que é continua no tempo;

- transitórias: falha que é limitada no tempo e que pode até ser de tipo intermitente.

A Figura 2.7 apresenta os tipos de falhas e as suas combinações possíveis representadas em um diagrama de árvore adaptado de AVIZIENIS et al. (2004).

Desconsiderando as falhas prematuras dos dispositivos e equipamentos, uma das principais causas de falha de um sistema de manufatura acontece devido a uma especificação inadequada e/ou incompleta das funcionalidades do sistema. Particularmente, as falhas que acontecem no software dos controladores têm, em 
geral, origem numa definição incorreta da seqüência dos processos envolvidos na produção ou, devido a uma distribuição indevida dos recursos envolvidos no processo. Neste sentido, no presente trabalho abordam-se tais tipos de falha mediante a verificação do comportamento e das propriedades do sistema através de um modelo que permita a descrição e a análise de tais propriedades.

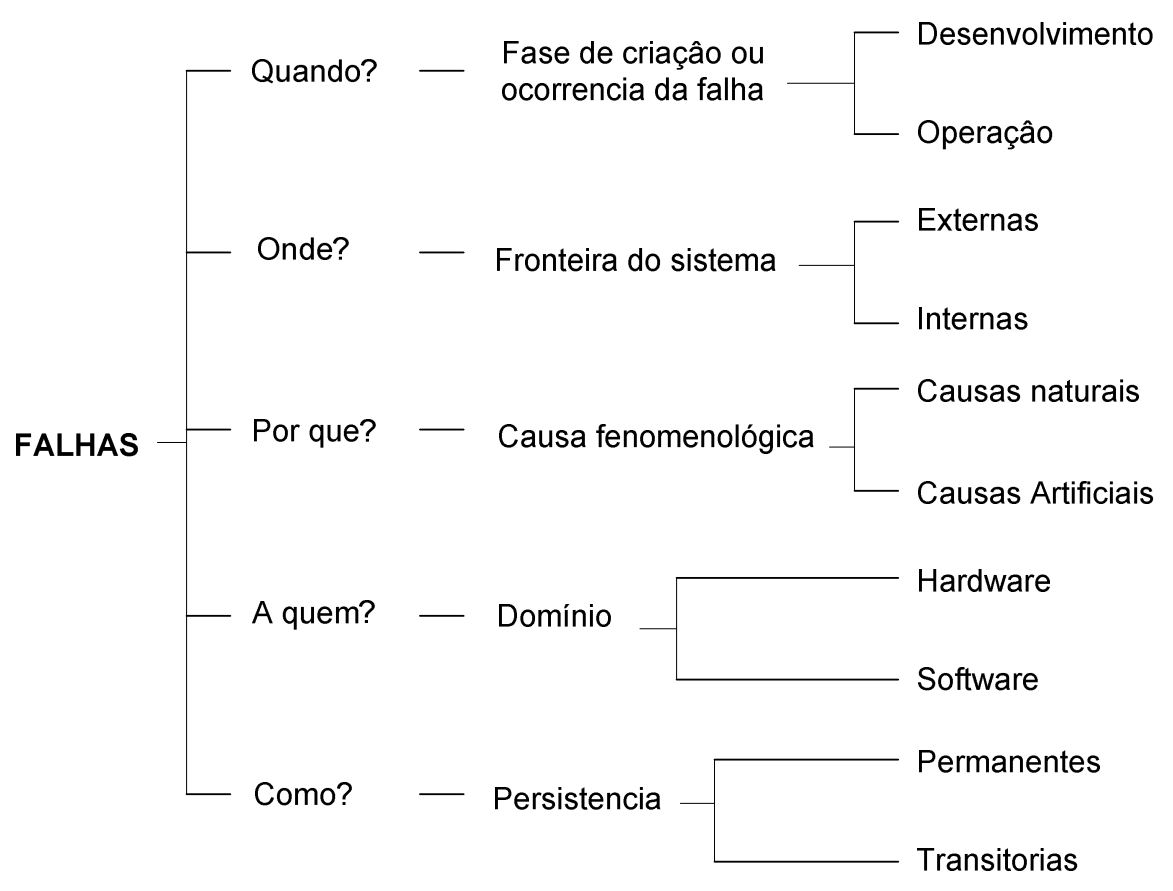

Figura 2.7. Classificação de falhas adaptado de Avizienis et al. (2004).

Por outro lado, falhas ocorridas também podem ser caracterizadas em função dos recursos de monitoração e do grau de automação do sistema. Esta propriedade é chamada de capacidade de sensoriamento (sensing capability) (FRANK, 1992), (CHANG et al., 1991). De acordo com esta característica, podem-se diferenciar falhas de dois tipos:

- falhas que podem ser detectadas diretamente mediante a monitoração de sinais, variáveis ou parâmetros específicos do equipamento através de sensores específicos. Por exemplo, o desgaste de uma ferramenta pode ser detectado através de um sensor que monitore este parâmetro. 
- falhas que não podem ser detectadas a partir do sensoriamento dos dispositivos, isto é, precisam de alguma técnica de identificação e detecção.

O presente trabalho focaliza-se no segundo tipo de falha.

Os métodos de identificação e deteç̧ão de falhas incluem desde a manutenção preventiva até técnicas de "raciocínio" e tomada de decisão, (MEHRANBOD et al., 2003), (RIASCOS, 2002).

\subsubsection{Defeito}

Quanto à caracterização dos defeitos em sistemas de manufatura, pode-se identificar defeitos considerando tanto a fase de desenvolvimento quanto a fase de operação. $\mathrm{Na}$ fase de desenvolvimento os defeitos mais comuns estão relacionados com um cronograma (entrega fora do prazo) ou falta de recursos para a concretização do projeto. $\mathrm{Na}$ fase operacional podem ser identificadas as seguintes classes de defeito (AVIZIENIS et al., 2004):

- Defeitos segundo o domínio:

- defeitos no produto ou serviço prestado de um subsistema a outro. Isto inclui peças intermédias defeituosas, informações errôneas, processos inconclusos, etc.

- defeitos no tempo de entrega. Por exemplo, chegada de material antes ou depois do previsto.

- Defeitos segundo a capacidade de ser detectável:

- defeitos detectáveis são aqueles que podem ser percebidos mediante sensores específicos e também sinalizados por alarmes sonoros, LEDs, IHMs, etc. 
- defeitos não detectáveis, que precisam de algum tipo de interpretação humana para serem reconhecidos.

- Defeitos segundo a consistência:

- defeitos consistentes, que se manifestam para todos os usuários, ou

- defeitos inconsistentes, que podem se manifestar somente para alguns usuários.

- Defeitos segundo a sua conseqüência, que dependendo das especificações do sistema, a freqüência e severidade de tais defeitos, podem ser classificadas desde defeitos menores até defeitos severos ou catastróficos.

A Figura 2.8 ilustra a classificação dos defeitos em sistemas de manufatura.

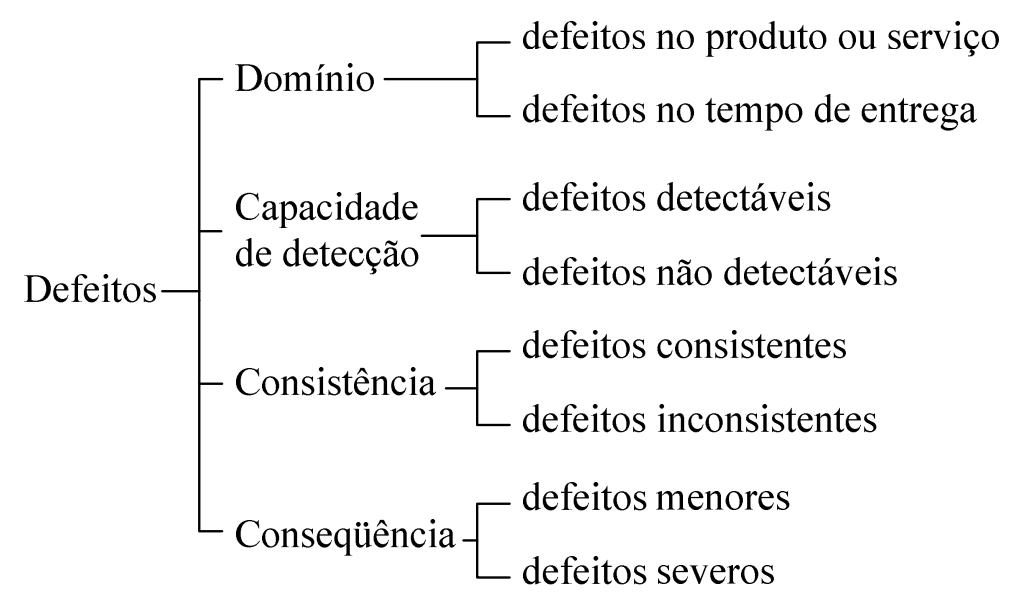

Figura 2.8. Classificação de defeito segundo Avizienis et al., (2004).

\subsubsection{Erro}

Nos sistemas de manufatura podem ocorrer erros que impedem que as tarefas sejam concluídas. Um sistema de manufatura envolve uma diversidade de 
componentes incluindo máquinas, robôs, ferramentas, dispositivos e partes, etc. Todos estes componentes interagem de diferentes formas para garantir o objetivo da produção. Assim, erros podem ser classificados com respeito à funcionalidade e com respeito à estrutura do sistema.

Com respeito à funcionalidade os erros podem ser definidos como:

- erros nas pré-condições de um procedimento específico: antes de ser realizada qualquer operação o sistema requer que certas condições sejam satisfeitas. Entretanto, muitas aplicações exigem um alto custo computacional para detectar tais condições. Portanto, pré-condições não verificadas podem levar a erros futuros.

- erros nas restrições de um processo: restrições evitam que estados indevidos sejam atingidos pelo sistema. Portanto, uma especificação indevida ou incompleta das restrições pode levar a erros.

- erros operacionais: estados indesejados que o sistema alcança devido a perturbações no seu sistema de controle.

Com respeito à estrutura do sistema são reconhecidos erros específicos de cada componente ou equipamento como por exemplo os erros de posicionamento e/ou orientação das ferramentas, erros de escolha de ferramenta, erros na ativação de dispositivos e erros de tolerância.

Muitos trabalhos têm sido realizados com o objetivo de desenvolver sistemas tolerantes a falhas cuja abordagem se baseia em recuperação de erros (error recovery) (ZHOU \& DiCESARE, 1989), (COMBACAU \& COURVOUSIER, 1990). Não obstante, existem muitos casos nos quais o custo para a detecção do erro é computacionalmente inviável e assim outras soluções ainda estão sendo investigadas. 


\subsection{DETECÇÃO E DIAGNÓSTICO DE FALHAS}

A pesar dos sistemas serem projetados com a finalidade de apresentar a menor quantidade de falhas possível, e incluir programas de manutenção preventiva para reduzir a probabilidade de anomalias, falhas são eventos que não podem ser eliminados na sua totalidade. Além disso, devido a sua natureza, a manifestação de uma falha, erro e posteriormente defeito de um processo é, em geral, de tipo abrupta e inesperada. Portanto, para atender a crescente demanda por maior desempenho e confiabilidade em sistemas produtivos e particularmente em sistemas de manufatura, é necessário contar com métodos para a detecção e o diagnóstico de falhas cada vez mais precisa e de rápida resposta (SAMPATH et al., 1995). Neste sentido, apresenta-se a seguir as principais técnicas para a detecção e o diagnóstico de falhas.

Entende-se como processo de detecção de falhas a determinação das falhas presentes num sistema (ISERMANN \& BALLÉ, 1997). O diagnóstico de falhas inclui por sua vez a determinação do tipo, da localização e do tempo de detecção das anomalias presentes no sistema. Portanto, o processo de diagnóstico é um tipo de refinamento do processo de deteç̧ão, e em geral, exige maior conhecimento sobre as relações de causa-efeito do sistema.

Em geral deseja-se que a detecção e o diagnóstico de falhas sejam realizados no menor tempo possível para que se tenha condições de realizar as ações necessárias com respeito a operações alternativas, serviços de manutenção e até recuperação parcial ou total do sistema. A detecção pode ser efetuada mediante a coleta de informações relevantes do sistema e a comparação com valores nominais do mesmo (ISERMANN, 1997). Neste sentido, as técnicas para detecção de falhas podem ser classificadas segundo o tipo de informação que é possível de ser obtida. Tais informações podem ser utilizadas para avaliar sintomas que permitem, através de uma análise, determinar a(s) falha(s). Assim, dois tipos de informação podem ser obtidos do sistema (ISERMANN, 1997): 
- Informações analíticas, que permitem obter através de informações quantificáveis, um conhecimento analítico do processo. Isto requer a realização de um processamento de dados baseado em variáveis mensuráveis. Algumas técnicas são:

- verificação de valor limite de referência, que indica se as variáveis ultrapassaram valores toleráveis.

- análise de sinal das variáveis mensuráveis mediante o uso de modelos de sinal como funções de correlação, espectro de freqüência, media móvel auto-reversível (ARMA), etc.

- análise do processo mediante o uso de modelos matemáticos.

- Informações heurísticas, que permitem a caracterização de sintomas através de heurísticas baseadas em informações qualitativas, em geral obtidas de operadores humanos. Isto inclui informações de ruídos, cores, vibrações anormais, etc. como também, históricos de manutenção, histórico de falhas, dados estatísticos, etc.

Neste sentido, a Figura 2.9 ilustra os tipos de informações que podem ser identificados de um processo.

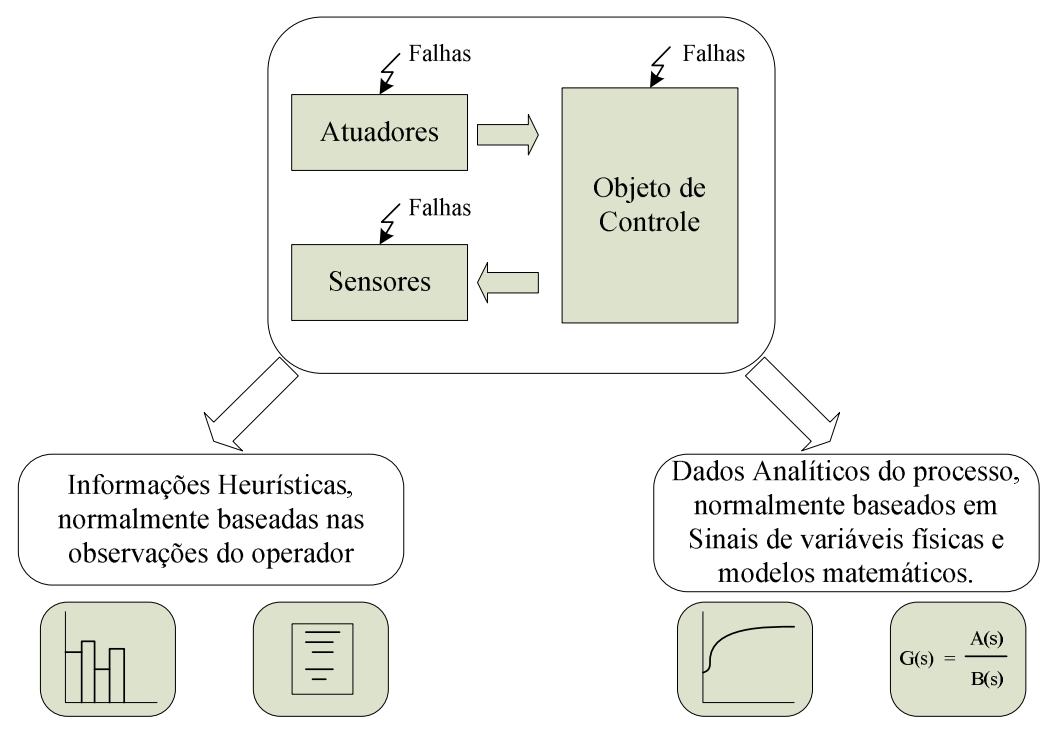

Figura 2.9. Tipos de informações obtidos de um processo. 
DASH \& VENKATASUBRAMANIAN, (1999) propõem no seu trabalho uma classificação das técnicas de detecção de falhas, tomando em consideração somente informações baseadas na análise do processo e no histórico de dados. Entretanto, considera-se que é necessário também incluir nesta caracterização técnicas de diagnóstico de falhas baseadas na análise do sinal da saída do sistema. Nesse sentido, a Figura 2.10 apresenta uma classificação das técnicas de diagnóstico e detecção de falhas. Nota-se na figura que não existe uma caracterização das técnicas probabilísticas. Não obstante, considera-se que técnicas probabilísticas podem ser classificadas como métodos baseados no modelo do processo tipo qualitativos que podem processar dados a partir do conhecimento humano ou dados a partir de levantamentos estatísticos do funcionamento do sistema.

Nota-se também que as técnicas apresentadas na Figura 2.10, não tomam em consideração o tipo de sistema sob estudo, isto é, se o sistema é de tipo SED ou SVC. Neste sentido, na descrição de cada uma das técnicas será apresentado o campo de aplicação respectivo.

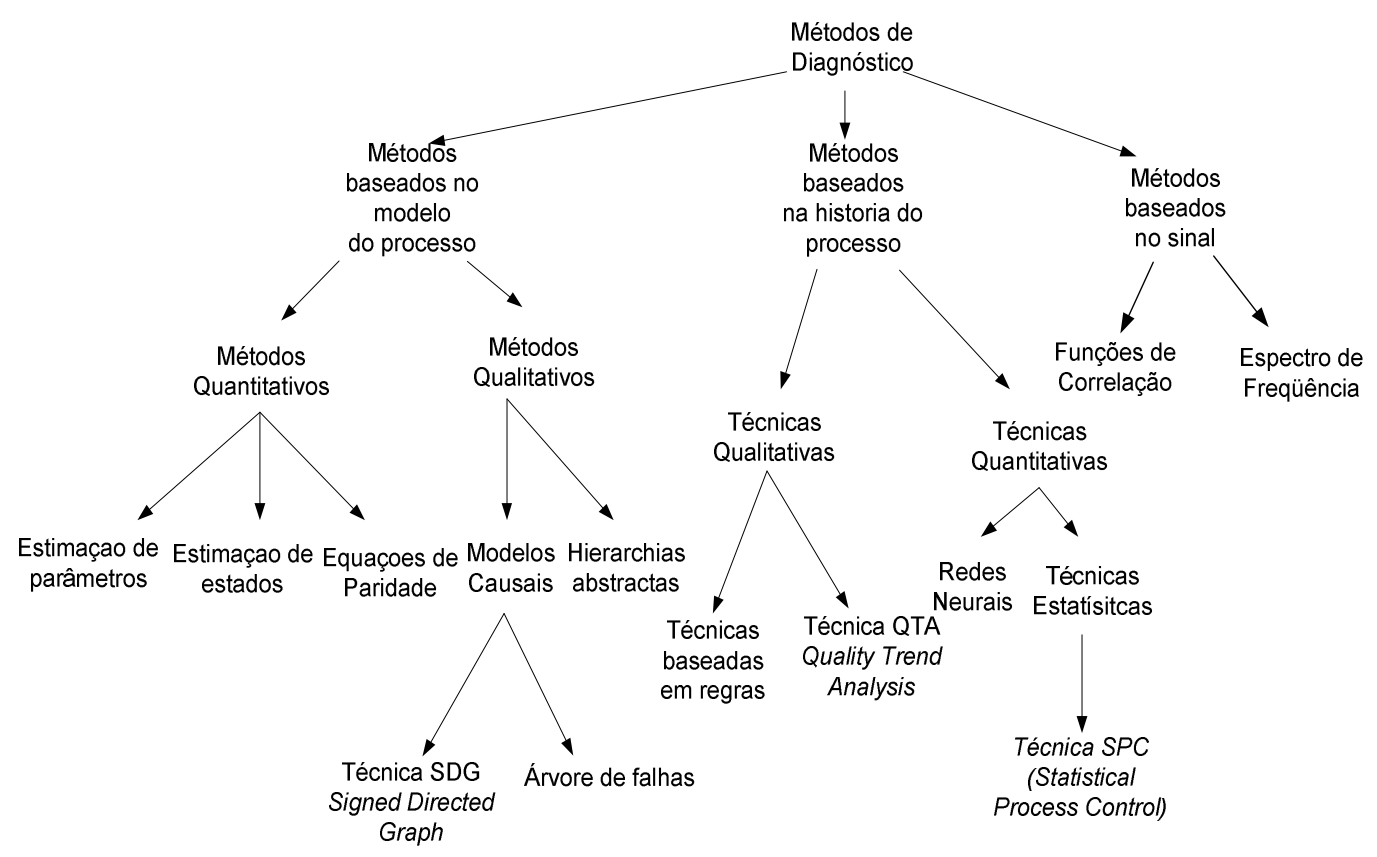

Figura 2.10. Classificação dos métodos de diagnóstico de falhas. 


\subsubsection{Técnicas baseadas no modelo do processo}

As técnicas baseadas no modelo do processo utilizam uma representação do sistema segundo um conhecimento da dinâmica e da estrutura do sistema. As técnicas baseadas no modelo do processo podem ser divididas em quantitativas ou qualitativas:

Técnicas quantitativas: nestas técnicas, o procedimento de detecção e diagnóstico de falhas tem dois passos básicos. No primeiro passo medem-se as discrepâncias entre os valores reais medidos no sistema e os valores esperados. Tais discrepâncias são chamadas de resíduos e podem ser obtidas mediante dispositivos redundantes ou através de descrições analíticas do processo (analytical redundancy), (FRANK, 1992), (VENKATASUBRAMANIAN et al., $2002^{\mathrm{a}}$ ). No segundo passo é realizada a análise de tais resíduos para decidir se o sistema encontra-se em estado de falha ou não. Nestas técnicas o calculo dos valores dos resíduos envolve uma descrição matemática do sistema. O modelo descreve as relações entre as variáveis e inclui relações fundamentais como transferência de calor e massa, relações cinéticas, resistência de materiais, etc. assim como os dados medidos de entrada-saída das variáveis (Figura 2.11). 


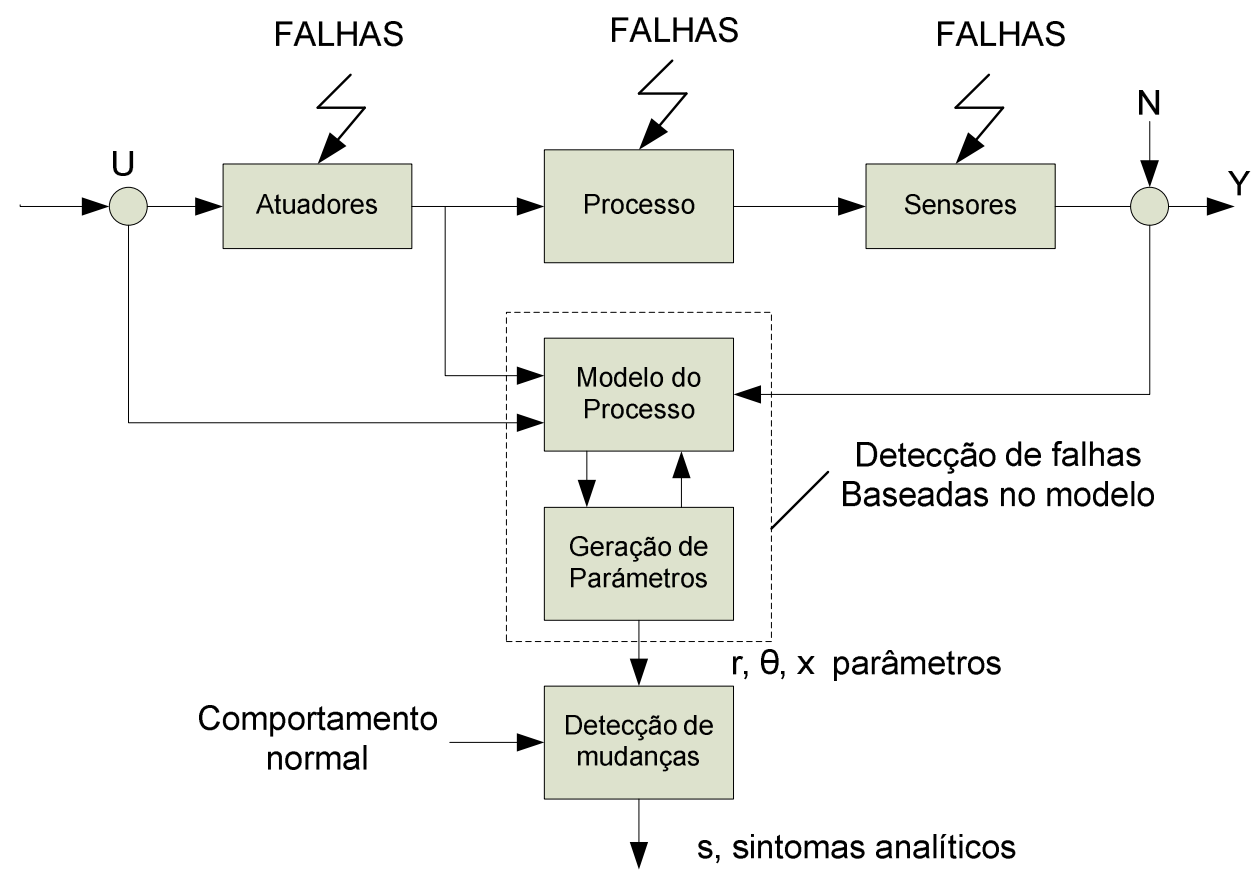

Figura 2.11. Esquema geral de diagnóstico baseado no modelo do processo.

O problema da detecção de falhas pode ser resumido como o processo de identificar o estado do sistema baseado no comportamento do processo. O comportamento do processo pode ser monitorado mediante a observação das variáveis de saída obtido através de sensores do sistema e das variáveis de entrada que são as entradas de comando. Quando uma falha acontece, as relações entre estas variáveis são modificadas, de modo que os resíduos se tornam diferentes de zero. A relação básica para a descrição de um modelo de um processo industrial pode ser representada pela equação (VENKATASUBRAMANIAN, 2002ª ):

$$
\mathbf{y}(t)=f(\mathbf{u}(t), w(t), \mathbf{x}(t), \theta(t))
$$

Onde $t$ é a variável independente relativa ao tempo, $\mathbf{y}(t)$ representa as variáveis mensuráveis do sistema, $\mathbf{u}(t)$ representa o vetor das variáveis de entrada, $\mathbf{x}(t)$ e $w(t)$ representam os estados observáveis e não observáveis (como perturbações) do sistema, e $\theta(t)$ representa os parâmetros do processo. Neste sentido, a medição de resíduos pode ser feita mediante a estimação dos parâmetros (parameter 
estimation), a estimação dos estados (state estimation), e mediante equações de paridade (parity equations) entre outros. Estas técnicas são particularmente utilizadas por sistemas de variáveis contínuas.

Técnicas Qualitativas: nestas técnicas as relações entre as variáveis do processo são descritas mediante modelos qualitativos baseados, em geral, em relações tipo causa-efeito das falhas e suas manifestações. Tais modelos podem ser concebidos como modelos causais (causal models) ou como decomposições do sistema em hierarquias abstratas (abstract hierarchies). Baseados nestes modelos, podem ser utilizadas técnicas de busca (search strategies) que permitam obter as causas da falha dado um conjunto de manifestações ou evidências do processo.

A idéia básica da técnica da hierarquia abstrata é decompor o sistema baseado na sua funcionalidade ou na sua estrutura, de uma maneira hierárquica e sistemática. Assim, quando uma falha ocorre num sistema, tal situação é estudada considerando o refinamento nos seus respectivos subsistemas chegando até os seus componentes, revelando a causa da anomalia (VENKATASUBRAMANIAN et al., 2002b). 
Dentro dos modelos causais podem ser destacadas duas técnicas:

- Técnica SDG (Signed Directed Graph): Nesta técnica as relações de causa-efeito das falhas são representadas mediante grafos direcionados. Cada arco orientado parte de um nó que representa uma causa até um nó que representa o respectivo efeito. Assim, o modelo descreve a transição do comportamento do sistema quando está em condições normais para as condições anormais e, mediante propagação de causalidade, obtém-se as causas das falhas do sistema. MURATA (1977) descreve como estas redes podem ser derivadas das redes de Petri. A grande desvantagem desta técnica é a possibilidade de se chegar a soluções ilegítimas que aparecem no modelo devido à natureza qualitativa e imprecisa das funções (OYELEYE \& KRAMER, 1988).

- Técnica de árvore de falhas. Esta técnica utiliza relações lógicas entre as variáveis que representam o sistema. Falhas são representadas como eventos primitivos, normalmente localizados na base (raiz) da árvore. Mediante propagação através dos conectores lógicos podem ser encontradas nas extremidades (folhas) da árvore, as respectivas causas dos desvios do sistema. Esta técnica é amplamente utilizada para análise de confiabilidade e análise de risco (MODARRES, 1992).

As técnicas qualitativas podem ser caracterizadas como técnicas que tentam representar o conhecimento cognitivo humano sendo armazenado numa base de dados, a partir do qual podem ser feitos raciocínios que permitam realizar inferências para obter explicações sobre alguns fenômenos que acontecem no sistema. Neste sentido, três propriedades são consideradas para definir o raciocínio (PEARL, 1988). A abdução (abductive reasoning) é a propriedade de realizar uma explanação dentre várias possibilidades com respeito a certas observações do sistema. A indução é a capacidade de um modelo classificar as evidências e observações; isto permite que, dado um conjunto de observações, possam ser tomadas em conta só as variáveis relevantes para realizar o raciocínio. Finalmente, a propriedade de não-monotonicidade (nonmonotonicity), 
permite que dado um raciocínio realizado com base a certas observações, as suas conclusões possam ser modificadas com base a novas evidencias do processo.

As técnicas anteriormente citadas não asseguram plenamente $\mathrm{e}$ simultaneamente tais propriedades, e assim técnicas alternativas têm sido desenvolvidas. Dentre estas se destaca o raciocínio probabilístico para o diagnóstico de falhas.

As técnicas qualitativas podem ser aplicadas tanto em sistemas de variáveis continuas quanto em sistemas de variáveis e eventos discretos. Não obstante, apresentam maior campo de aplicação em sistemas a eventos discretos.

\subsubsection{Técnicas baseadas na análise do sinal}

As técnicas baseadas na análise do sinal utilizam o processamento dos sinais observados do sistema, sem adotar nenhum tipo de modelo do processo (HARIHARA et al., 2003). Muitas saídas mensuráveis $y(t)$ apresentam oscilações que podem ser relacionadas com falhas no processo, nos atuadores ou nos sensores. Este tipo de técnica tem funcionado para a detecção de falhas como desbalanceamento de eixos, ruídos em motores, sobrecarga de geradores, etc. (ISERMANN, 2005). Os sinais podem ser coletados de fontes como sensores de posição, de velocidade, de aceleração, de corrente elétrica, de pressão, etc. e cujas oscilações podem caracterizar anomalias da dinâmica do processo.

\subsubsection{Técnicas baseadas na história do processo}

As técnicas baseadas na história do processo, ao contrario das técnicas baseadas no modelo do processo, utilizam uma grande quantidade de dados históricos 
(VENKATASUBRAMANIAN et al., 2002b), (POWER \& BAHRI, 2000). Portanto, estas técnicas permitem utilizar conhecimentos heurísticos do processo o que por outro lado, dificulta a representação de causalidade e a verificação em tempo real de falhas presentes no sistema. Estas técnicas também podem ser divididas em qualitativas e quantitativas.

Técnicas Qualitativas. Entre as técnicas qualitativas mais importantes, destacam-se duas: a técnica baseada em regras e a análise de tendência da qualidade (VENKATASUBRAMANIAN et al., 2002b).

- Técnica baseada em regras (rule-based systems): estas técnicas se baseiam em fatos, regras e um mecanismo de inferência (HAYESROTH, 1985). Uma regra é formada por um antecedente e uma conseqüência. Quando um fato determina 0 antecedente, a conseqüência é validada. Nesse sentido, o diagnóstico de falhas é feito mediante o mapeamento da série de eventos que levaram o sistema a uma falha conhecida. Assim, o histórico de dados do processo alimenta o sistema na forma de antecedentes e conseqüências, envolvendo o mapeamento de sintomas e das causas primárias (DASH e VENKATASUBRAMANIAN, 2000).

- Técnica QTA (qualitative trend analysis): estas técnicas aproveitam a diferença entre a tendência observada pela leitura dos valores nos sensores do processo em condições normais e a leitura em situações anormais. Isto é feito em dois passos (VENKATASUBRAMANIAN et al., 2002b): (i) identificação da tendência nas medidas e (ii) interpretação de tais tendências. Com o objetivo de evitar análises indevidas dos entre estados transitórios e das falhas, são utilizadas técnicas de filtragem para condicionamento dos sinais.

> Técnicas Quantitativas. Nestas técnicas o diagnóstico é abordado como um problema de reconhecimento de padrões (pattern recognition). Portanto, é feita uma classificação dos dados do processo em classes predeterminadas que incluem situações em estado de falha. 
- Técnicas estatísticas. Considerando operações reais em processos industriais, um problema consiste em tratar perturbações aleatórias que podem levar o sistema a um serviço ou produto defeituoso. Assim, algumas medidas podem ser obtidas a partir do sistema e ser analisadas para criar uma base de dados estatísticos. Nesse sentido, quando o processo não apresenta falhas as respectivas observações apresentam distribuições probabilísticas de acordo com as nominais. Entretanto, quando uma falha acontece, as distribuições apresentam mudanças características de cada falha. Por exemplo, quando um processo é caracterizado por uma distribuição normal, a média e a variância sofrem mudanças quando uma falha acontece. Uma técnica conhecida na indústria é o SPC (Statistical Process Contro) que permite a detecção de falhas em processos de uma única variável.

- Técnica ANN (artificial neural networks): nos últimos anos, as redes neurais têm recebido considerável atenção para o problema do diagnóstico de falhas. A sua capacidade de interpolação e aprendizado são qualidades que permitem que sua implementação seja bem sucedida. Entretanto, esta técnica tem comprovado ser efetiva apenas para sistemas de pequeno porte, já que o aprendizado para sistemas de grande porte aumenta as exigências de memória e o tempo de treinamento a níveis não aceitáveis.

\subsection{OBSERVAÇÕES DO CAPÍTULO}

Neste capitulo foram apresentados os principais conceitos e as principais teorias que servem como base para a presente pesquisa. Foi apresentado o conceito de sistema flexível de manufatura como uma solução de produção que visa atender a comportamentos em constante mudança por parte dos consumidores mediante a reconfiguração do que é feito e de como é feito. Foi discutida a complexidade que implica na adoção de tal solução e que não se pode desconsiderar a ocorrência de 
falhas e erros que podem inclusive ser as conseqüências de especificações indevidas e/ou incompletas do sistema. Além disso, foram apresentados os conceitos, as tipologias e a caracterização de falhas, erros e defeitos bem como também as principais técnicas de detecção e diagnóstico de falhas. Muitas das técnicas de diagnóstico de falhas tentam identificar as causas da falha realizando um tipo de raciocínio a partir de certas manifestações do sistema. Entretanto, nenhuma das técnicas citadas possui as características de indução, abdução e nãomonotonicidade simultaneamente.

Destaca-se então, que vários tipos de falhas e erros no sistema podem ser devidamente evitados na fase de desenvolvimento do sistema. Assim, fica evidente a necessidade de estabelecer um procedimento para a construção de modelos que permitam realizar a análise de sistemas de controle e que garantam a devida realização dos processos produtivos. Além disso, o levantamento realizado indica o potencial e ainda não devidamente explorado uso de técnicas de raciocínio probabilístico para o diagnóstico de falhas em sistemas de manufatura em operação, através de observações das operações envolvidas.

O capítulo a seguir apresenta assim teorias que serão consideradas para o desenvolvimento de uma proposta de procedimento de modelagem visando o diagnóstico e tratamento de falhas. 


\section{REDE DE PETRI E REDES BAYESIANAS}

Dentre as possíveis causas das falhas em um sistema de manufatura, uma que se destaca é uma especificação inadequada ou indevida das funcionalidades do sistema. Neste sentido, a escolha de modelos que representem o comportamento do sistema de controle tem papel fundamental na caracterização de propriedades que, sendo analisadas, permitem identificar processos que satisfaçam as funcionalidades desejadas. BOOCH et al., (1999) afirmam que a escolha do formalismo utilizado para a modelagem tem uma grande influência em como o problema é abordado e como sua solução é desenvolvida. Neste sentido, uma grande quantidade de trabalhos tem confirmado a rede de Petri como uma base teórica efetiva e eficaz na modelagem, sistematização, análise e implementação de sistemas de controle de FMS.

A rede de Petri é produto do trabalho do Prof. Carl Adam Petri que na sua tese apresentou um formalismo que permite descrever as relações existentes entre condições e eventos. Uma rede de Petri é um grafo bipartido composto por dois tipos de nós: lugares ${ }^{5}$, que são representados por círculos e transições, que são representados por barras. Arcos orientados conectam lugares com transições e viceversa. A dinâmica de um sistema é representada mediante o conceito de marcação que associa a cada lugar um conjunto de marcas representadas por pontos que indicam o estado atual do sistema e o conceito de disparo de transição que estabelece regras para a evolução da marcação.

Entre as principais vantagens da rede de Petri para a modelagem de sistemas de manufatura, encontram-se (DESROCHERS \& AL-JAAR; 1995), (ZHOU \& DICESARE, 1993):

- capacidade de representar de maneira simples, características próprias do sistema como assincronismo, paralelismo e concorrência;

\footnotetext{
${ }^{5}$ Neste trabalho os componentes da rede de Petri serão escritos em letra tipo arial de tamanho 10.
} 
- capacidade de identificar situações de conflito e bloqueio;

- capacidade de verificar propriedades tanto desejáveis como indesejáveis do sistema;

- capacidade de realizar uma análise sistemática do desempenho, mesmo em sistemas complexos;

- capacidade de gerar a partir da rede de Petri o código para controladores numa linguagem compatível com as funções de supervisão e gerenciamento de tarefas. Uma implementação em tempo real é também possível;

- capacidade de utilizar técnicas de simulação para a verificação de certas propriedades do sistema;

- possibilidade de estender o conceito da rede de Petri para realizar uma modelagem sistemática e hierárquica, como também análises quantitativas e qualitativas dos processos do sistema;

- possibilidade de uma modelagem baseado em refinamento sucessivo (bottom up) como também baseado em composição modular (top down).

Entretanto, uma das principais desvantagens da representação em rede de Petri é que ela pode gerar uma explosão no número de componentes (elementos de sua descrição gráfica) de acordo com o grau de complexidade do sistema sendo modelado. Isto dificulta tanto a concepção do modelo quanto a sua análise. Neste sentido MIYAGI (1988) propõe o PFS/MFG (Production Flow Schema/Mark Flow Graph) para realizar uma modelagem hierárquica e sistemática baseada no refinamento sucessivo dos componentes do sistema. O PFS e o MFG são ambos extensões interpretadas da rede de Petri e, portanto, herdam as características matemáticas da mesma, o que permite que a análise possa explorar as diversas técnicas e procedimento já existentes para a rede de Petri. 


\subsection{METODOLOGIA PFS/MFG}

Esta metodologia considera a modelagem do sistema através de um refinamento sucessivo e hierárquico de um modelo conceitual que representa o fluxo geral de itens (material e/ou informação) dentro do sistema até chegar a um modelo dinâmico que inclui na sua representação o comportamento no nível funcional de cada elemento do sistema.

A metodologia parte do conceito de que sistemas de manufatura podem ser descritos como um conjunto de atividades, de elementos distribuidores e da interrelação entre eles. Atividades são consideradas como processos que influem, modificam, transformam, agrupam ou separam os itens envolvidos na produção. Elementos distribuidores são encarregados de coletar, acumular, armazenar, mostrar à vista, e direcionar tais itens. Na prática, observa-se de que o início e fim das atividades envolvidas com a manufatura requerem que certas condições sejam previamente satisfeitas (chegada de material, disponibilidade de ferramenta, etc.). Além disso, observa-se de que é importante classificar o fluxo de itens numa atividade como fluxo principal e fluxo secundário (HASEGAWA, et al., 1988).

O modelo conceitual é representado em PFS que é uma representação de alto nível de abstração cuja finalidade é descrever o fluxo de dados através dos componentes do sistema. VILLANI (2000) acrescenta a utilização de tais redes para a representação de sistemas híbridos considerando uma classificação dos arcos com respeito ao fluxo discreto ou continuo de dados.

No entanto, para representar a dinâmica do sistema é introduzido o MFG, que permite modelar o funcionamento das várias partes e componentes de um sistema até chegar a um nível desejado (para casos de implementação é recomendado chegar até o nível de operação).

A metodologia PFS/MFG tem sido amplamente aplicada em sistemas de manufatura e neste campo tem demonstrado ser uma ferramenta útil para a modelagem, análise 
e implementação do programa de controle (MIYAGI, 1988), (SANTOS FILHO, 1993), (ARAKAKI, 1993), (LIU, 1993), (KAGOHARA, 1998).

\subsubsection{Production Flow Schema (PFS)}

O PFS é uma ferramenta que permite construir um modelo conceitual num nível relativamente alto de abstração sem considerar a dinâmica do sistema (HASEGAWA, 1988), (MIYAGI, 1988), (SILVA \& MIYAGI, 1996), (VILLANI, 2000). Ele aproveita o fato de que sistemas podem ser modelados como um conjunto de atividades, que realizam um processo ou uma função nos itens, que interagem com inter-atividades ou elementos distribuidores e que por sua vez realizam o direcionamento do fluxo de itens através do sistema ou processo.

O PFS, distintamente das redes de Petri, não possui o conceito de marcação. Ele permite uma descrição no qual podem ser observadas algumas características como (Figura 3.1):

- seqüência: indica relações de precedência entre as atividades, por ex., o inicio de uma atividade só pode ser concretizada a partir do final da atividade precedente;

- sincronização: indica o caso em que o inicio de uma atividade só pode ser ativada se as inter-atividades precedentes atendem certas condições. Isto implica no condicionamento de que certas atividades só podem ser realizadas quando as condições precedentes, chamadas de inter-atividades estão atendidas.

- paralelismo: indica que a finalização de uma atividade resulta no atendimento de condições correspondentes a mais inter-atividades. Possibilita-se assim, a ocorrência de duas ou mais atividades paralelas. 
- concorrência: que pode-se apresentar em duas formas: a primeira considera a convergência do fluxo de itens derivado de duas ou mais atividades numa única inter-atividade, introduzindo assim, incerteza sobre qual atividade dará inicio ao passo seguinte. A segunda, chamada de decisão, considera duas ou mais atividades que podem ser acionadas a partir de uma interatividade, introduzindo assim, incerteza sobre qual atividade será realizada. Portanto, elementos de decisão são necessários para abordar o problema de tais incertezas.

- compartilhamento de recursos: indica que duas ou mais atividades solicitam um mesmo recurso simultaneamente. Assim, um tipo especial de decisão é introduzido.

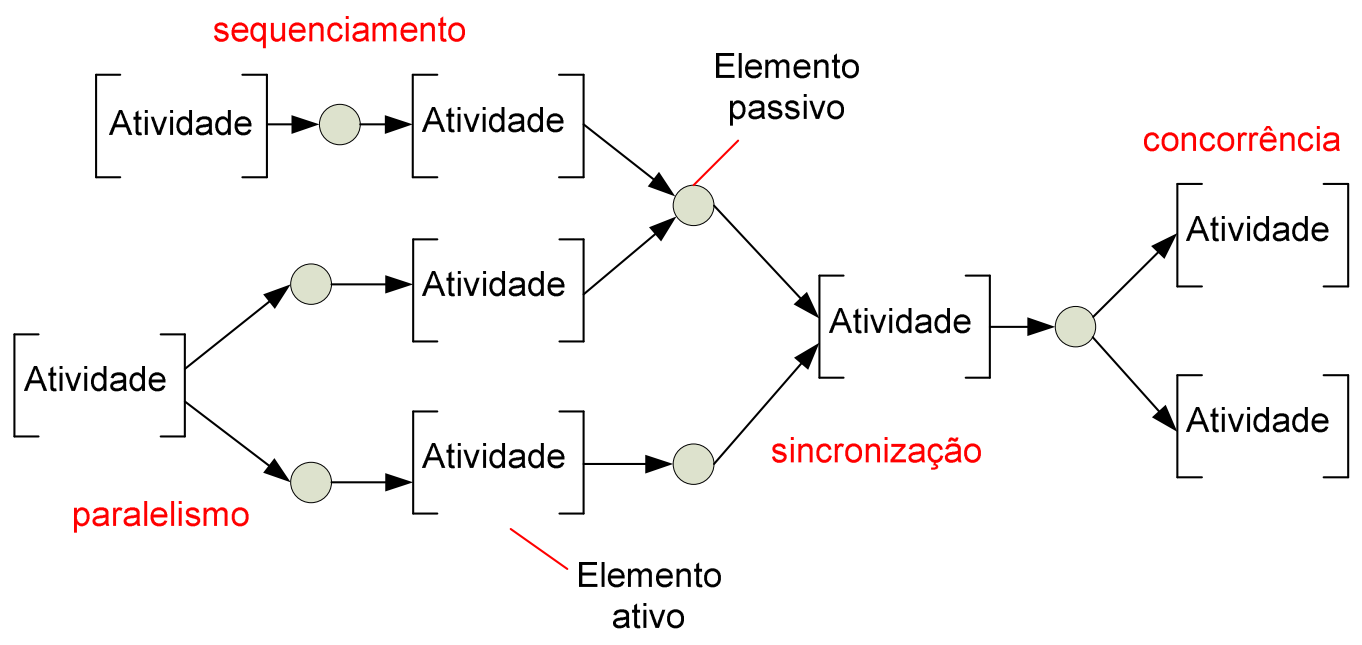

Figura 3.1. Elementos estruturais do PFS.

Neste sentido, as atividades de um sistema são representadas no PFS por colchetes que indicam um macro-elemento no qual uma inscrição é introduzida para descrever a atividade a ser realizada. $\mathrm{A}$ atividade pode ser refinada em sub-atividades considerando suas respectivas interações. Assim, um refinamento do modelo é possível, analisando as respectivas propriedades em cada nível de detalhamento.

Uma atividade pode ser iniciada ou finalizada pela ocorrência de um ou mais eventos exclusivos (Figura 3.2). 
No PFS as inter-atividades são representadas por círculos. Estes elementos podem distribuir ou direcionar o fluxo de itens (matérias ou dados) e torná-los visíveis.

Atividades e inter-atividades são conectadas mediante arcos orientados que representam o fluxo de itens através do modelo. Cada arco descreve uma relação lógica entre seus componentes, o que permite que a modelagem seja feita segundo uma descrição natural do processo.
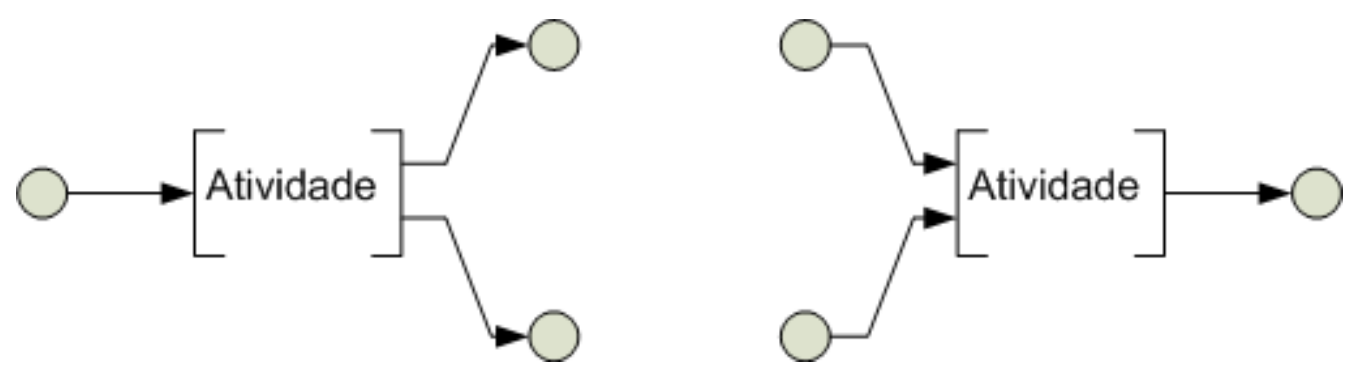

Figura 3.2. Inicio / Finalização de uma atividade por mais de um evento.

Deve-se observar que elementos do mesmo tipo não podem ser conectados diretamente já que isto contraria a relação lógica derivada da definição de redes bipartidas.

Um aspecto importante do PFS é que ele permite um refinamento sucessivo dos seus elementos ativos até chegar à representação detalhada da dinâmica do sistema mediante o uso do MFG ou até redes híbridas tipo PFS/MFG.

\subsubsection{Mark Flow Graph (MFG)}

O MFG é uma técnica derivada da rede de Petri devidamente interpretada, que permite a representação de sistemas tipo condição-evento (HASEGAWA et al., 1988). O MFG é uma solução para um dos problemas práticos de aplicação da rede de Petri que desconsidera elementos externos à rede. Isto é, de acordo com as premissas da rede de Petri, todo elemento que se considere parte do modelo teria que estar devidamente representado como um componente da própria rede, o que 
dificulta a consideração de sinais externas em sistemas de controle e supervisão. Neste contexto, o MFG além de representar a dinâmica do funcionamento do sistema, permite a representação de elementos externos como sinais de controle. Permite também a representação da dinâmica de situações como assincronismo, paralelismo, concorrência e intertravamentos. Assim, pode-se descrever funcionalmente todos os elementos estruturais que compõem um sistema de controle (Figura 3.3), (MIYAGI, 1996).

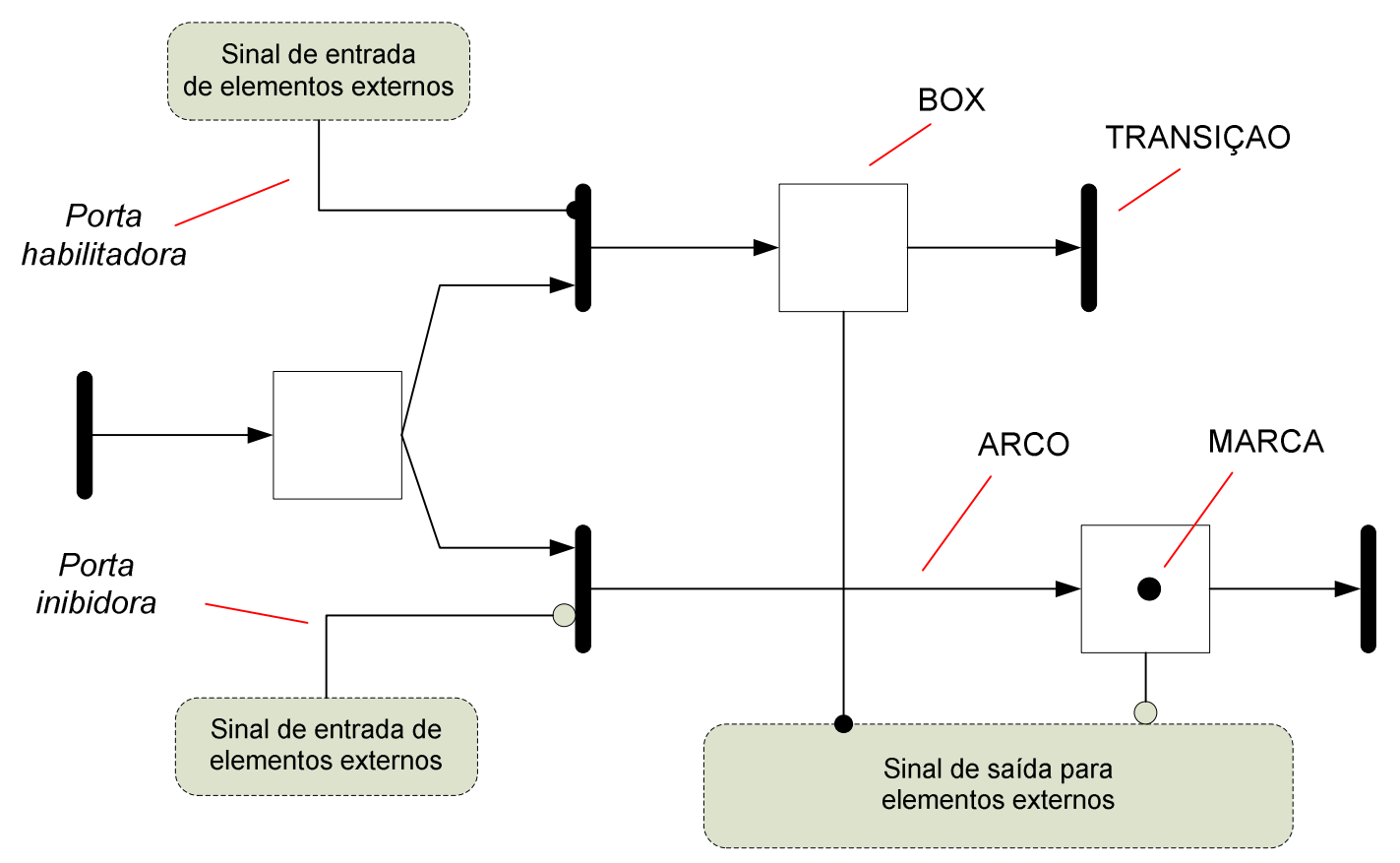

Figura 3.3. Elementos Estruturais do MFG.

TRANSIÇÕES são elementos que representam eventos que causam uma mudança no estado do sistema.

BOXES são elementos do MFG que representam estados dos componentes ou subprocessos, que por sua vez são pré- ou pós-condições dos eventos associados ao processo. Os boxes podem representar o estado, modo de operação ou a disponibilidade dos recursos do sistema. 
MARCAS no MFG são representadas por pontos dentro dos boxes. Estão associados a um valor binário atribuído aos boxes. A evolução das marcas pela rede define a dinâmica do funcionamento do sistema.

ARCOS ORIENTADOS representam relações causais entre os boxes e as transições, e vice-versa.

PORTAS que representam dois tipos de relações entre os boxes e as transições: (i) uma relação que inibe o disparo de uma transição (a evolução da marca por essa transição) mediante uma porta inibidora e, (ii) uma relação que habilita o disparo da transição afetada mediante uma porta chamada de habilitadora. A condição para a inibição ou habilitação é definida pela existência ou não de uma marca no box de onde 0 arco é originado.

ARCOS DE SINAL DE SAÍDA que envia um sinal binário (função de marcação) de um box para um dispositivo externo ao grafo.

O MFG é uma técnica derivada da rede de Petri tipo condição-evento, portanto, ele herda todas as características de funcionamento destas redes.

A seguir são apresentadas as definições formais do MFG (Miyagi, 1996):

O Mark Flow Graph é um grafo bipartido direcionado, representado por uma sêxtupla:

$M F G=\left(\mathbf{B}, \mathbf{T}, \mathbf{A}, \mathbf{G}_{\mathbf{l}}, \mathbf{G}_{\mathbf{E}}, \mathbf{S}\right)$

Onde,

$\mathbf{B}=\left\{B_{1}, \ldots, B_{i}\right\}$ com ( $\left.\mathrm{i} \geq 0\right)$ é um conjunto de boxes;

$\mathbf{T}=\left\{T_{1}, \ldots, T_{j}\right\}$ com $(\mathrm{j} \geq 0)$ é um conjunto de transições;

$\mathbf{A}=\left\{\mathbf{A}_{\mathbf{l}} \mathbf{U} \mathbf{A}_{\mathbf{O}}\right\}$ é um conjunto de arcos orientados onde:

$\mathbf{A} \mathbf{l}=\left\{A_{11}, \ldots, A_{l k}\right\} \operatorname{com}(\mathrm{k} \geq 0)$ é um conjunto de arcos de entrada para transições, e $\mathrm{AO}=\left\{A_{O 1}, \ldots, A_{O \mid}\right\} \operatorname{com}(\mathrm{I} \geq 0)$ é um conjunto de arcos de saída para transições; 

$G_{1}=\left\{G_{11}, \ldots, G_{l m}\right\}$ com (m $\left.\geq 0\right)$ é um conjunto de portas internas;
$G_{E}=\left\{G_{E 1}, \ldots, G_{E n}\right\} \operatorname{com}(n \geq 0)$ é um conjunto de portas externas;
$\mathbf{S}=\left\{S_{1}, \ldots, S_{p}\right\}$ com $(p \geq 0)$ é um conjunto de arcos de sinais de saída.

\subsection{REDES BAYESIANAS}

Os métodos Bayesianos provêem um formalismo que permite modelar um processo de raciocínio baseado em declarações parciais sobre condições de incerteza. Neste formalismo, são atribuídos às proposições parâmetros numéricos que representam o grau de crença sobre um espaço de conhecimento. Estes parâmetros são então manipulados de acordo com as regras da teoria da probabilidade (PEARL, 1988). Assim, redes Bayesianas são grafos direcionados acíclicos (abreviados por DAG directed acyclic graph) associados a um conjunto de distribuições de probabilidade. Nas redes Bayesianas cada nó representa uma variável de tipo aleatória. A existência de arcos direcionados entre dois nós representa uma influência causal entre as variáveis, e o peso desta influência é representada mediante probabilidades condicionais (PEARL, 2000). Uma rede Bayesiana é constituída por uma parte qualitativa (relações de nós interligados por arcos direcionados), e uma parte quantitativa, que são as distribuições de probabilidades associadas a cada uma das variáveis (nós) do grafo. As distribuições de probabilidade quantificam a relação de dependência entre as variáveis. Informalmente, a estrutura de uma rede Bayesiana pode ser construída mediante o seguinte procedimento: define-se um nó para cada variável $X_{i}$ do domínio e desenha-se um arco orientado a este nó a partir de cada uma das variáveis que possam ter uma influência sobre este. Este conjunto será chamado de conjunto de pais de $X_{i}, p a\left(X_{i}\right)$. O peso de cada arco orientado para $X_{i}$

é depois quantificado atribuindo através de uma matriz $\operatorname{Pr}\left(X_{i} \mid \operatorname{pa}\left(X_{i}\right)\right)$, que representa a estimativa subjetiva da probabilidade condicional $\operatorname{Pr}()$ do evento $X_{i}=x_{i}$, dado a combinação $p a\left(x_{i}\right)$ do domínio $p a\left(X_{i}\right)$. Para os nós que não possuem pais 
são atribuídos probabilidades marginais do tipo $\operatorname{Pr}\left(X_{i}\right)$. A conjunção de todos os conjuntos de probabilidades associadas à rede define uma função de distribuição conjunta sob a qual podem ser realizadas operações de inferência.

A propriedade básica das redes Bayesianas é que toda variável $X_{i}$ é independente de todos os antecessores de $X_{i}$, e condicional em relação aos pais de $X_{i}$. Isto garante que a distribuição conjunta seja definida por:

$$
\operatorname{Pr}(X)=\prod_{i} \operatorname{Pr} \quad\left(\mathrm{X}_{\mathrm{i}} \mid \mathrm{pa}\left(\mathrm{X}_{\mathrm{i}}\right)\right)
$$

onde $X_{i} \in \boldsymbol{X}$ é o conjunto de todas as variáveis. Essa expressão garante que uma distribuição conjunta, potencialmente complexa, possa ser representada através do produto de blocos menores (Figura 3.4).

\section{Inferência em redes Bayesianas}

O significado prático das probabilidades condicionais se reflete em três processos que todo sistema especialista procura emular (GEIGER et al., 1990): codificar o conhecimento de um especialista (elicitation), obter conclusões a partir de certas manifestações (inferência) e comunicar as conclusões obtidas do sistema para o usuário (explanação).

Em redes Bayesianas a inferência se resume em realizar os cálculos da probabilidade condicional em um conjunto de variáveis observadas. Por exemplo, a evidência $\mathrm{E}=\left\{X_{4}=0, X_{6}=1\right\}$ indica que as variáveis $X_{4}$ e $X_{6}$ foram observadas e apresentam valores fixos. Para calcular a distribuição condicional de uma variável qualquer $X_{Q}$, dadas as observações em $E$, é preciso computar: 


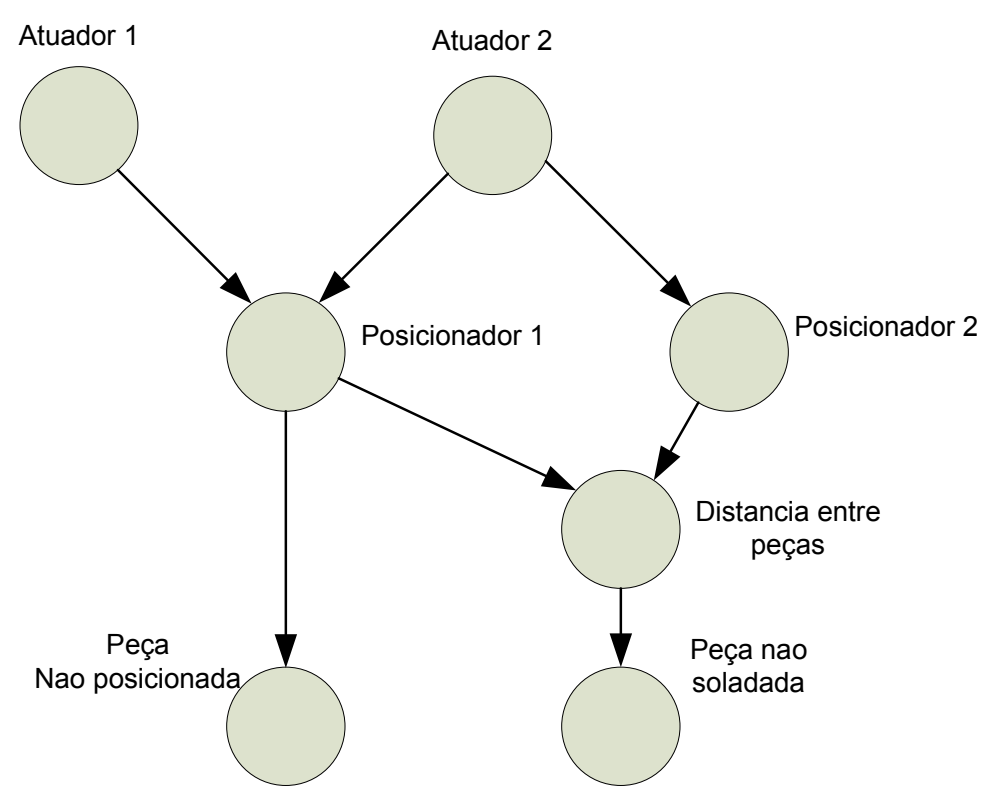

Figura 3.4. Exemplo de uma rede Bayesiana, adaptado de MORALES et al., (2007c).

$$
\operatorname{Pr}\left(X_{Q} \mid E\right)=\frac{\operatorname{pr}\left(\mathrm{X}_{\mathrm{Q}}, \mathrm{X}_{4}=0, \mathrm{X}_{6}=1\right)}{\operatorname{pr}\left(\mathrm{X}_{4}=0, \mathrm{X}_{6}=1\right)}
$$

A expressão geral para inferências em redes Bayesianas é:

$$
\operatorname{Pr}\left(X_{Q} \mid E\right)=\frac{\sum_{\mathrm{X} \backslash\left\{\mathrm{x}_{\mathrm{Q}, \mathrm{E}}\right\}}{ }^{\operatorname{pr}(\mathrm{X})}}{\sum_{\mathrm{X} \backslash\{\mathrm{E}\}} \operatorname{pr}(\mathrm{X})}
$$

onde $X_{Q}$ é a variável requerida (ou um conjunto de variáveis) e $E$ é um conjunto de variáveis observadas. $X \backslash\left\{X_{Q}, E\right\}$ representa o conjunto de todas as variáveis contidas em $X$, excluindo $X_{Q}$ e $E$.

Existem algoritmos relativamente eficientes para realizar estas operações em redes Bayesianas genéricas. Dois tipos de algoritmos são normalmente utilizados: algoritmos baseados em junction trees e algoritmos baseados em eliminação de variáveis. Todos esses algoritmos são exatos e podem crescer exponencialmente no tamanho e nos cálculos envolvidos em função do porte do grafo. Isto faz com que algoritmos exatos, dependendo do porte da rede, sejam potencialmente intratáveis. 
O caminho para realizar inferências em redes Bayesianas complexas são os algoritmos aproximados. As aproximações que ocupam menos memória são baseadas em amostragem, popularmente conhecidos por métodos de Monte Carlo.

A idéia fundamental do método de Monte Carlo é obter estimativas a partir de amostras da população geradas por simulação. Por se tratar de uma idéia geral, métodos de Monte Carlo são aplicados em diversas áreas. Uma explicação simples e intuitiva do método é encontrada em SOBOL (1994). 


\section{Procedimento para o Diagnóstico e Tratamento de Falhas em FMS}

Neste capítulo é introduzido o procedimento proposto para a construção de modelos do sistema de controle de FMS que inclui o processo de diagnóstico e tratamento de falhas. É considerado um procedimento seqüencial e iterativo que permita a revisão dos conceitos tratados em cada etapa do procedimento, minimizando assim, a possibilidade de erros e incongruências no modelo resultante com relação ao sistema real.

\subsection{PROCEDIMENTO PARA A CONSTRUÇÃO DO MODELO}

A proposta do procedimento geral para a construção do modelo do sistema de controle de FMS incluindo o diagnóstico e tratamento de falhas está ilustrado na Figura 4.1. É composto pelos seguintes passos:

- Construção do modelo do processo produtivo;

- Classificação dos componentes do modelo do processo produtivo com base nas suas características de representação;

- Construção do modelo do processo de diagnóstico;

- Definição das técnicas de tratamento de falhas. 


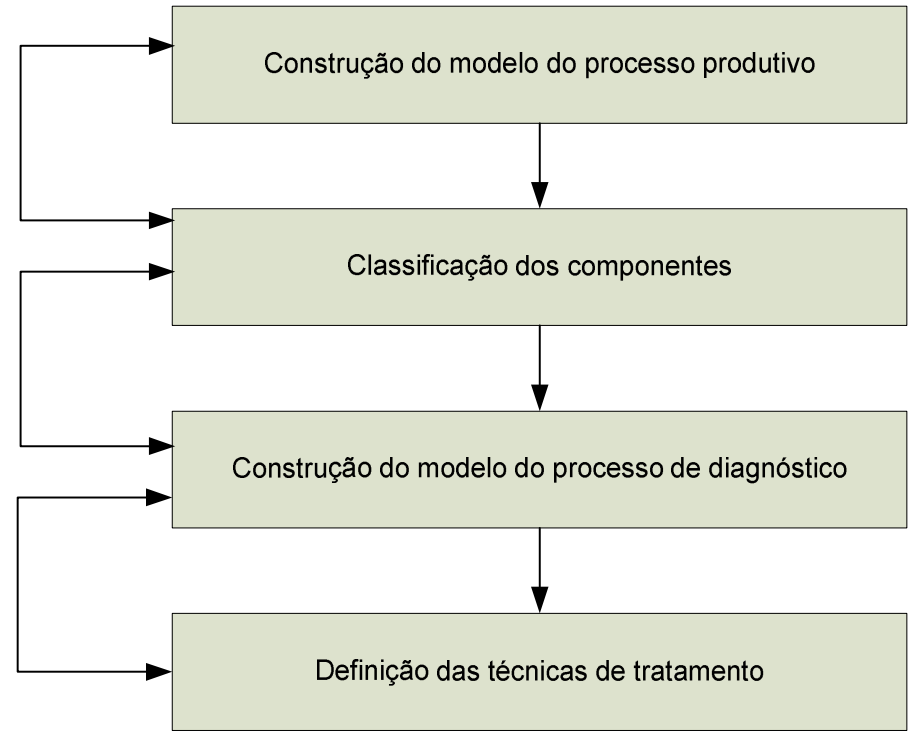

Figura 4.1. Procedimento geral para a construção de modelos.

Propõe-se que as revisões (de cada etapa de desenvolvimento do processo) sejam conduzidas dentro do conceito de prototipagem, onde o projeto e desenvolvimento são realizados repetindo-se o seguinte ciclo: concepção, operação e avaliação do protótipo (MIYAGI, 1996), (Figura 4.2):

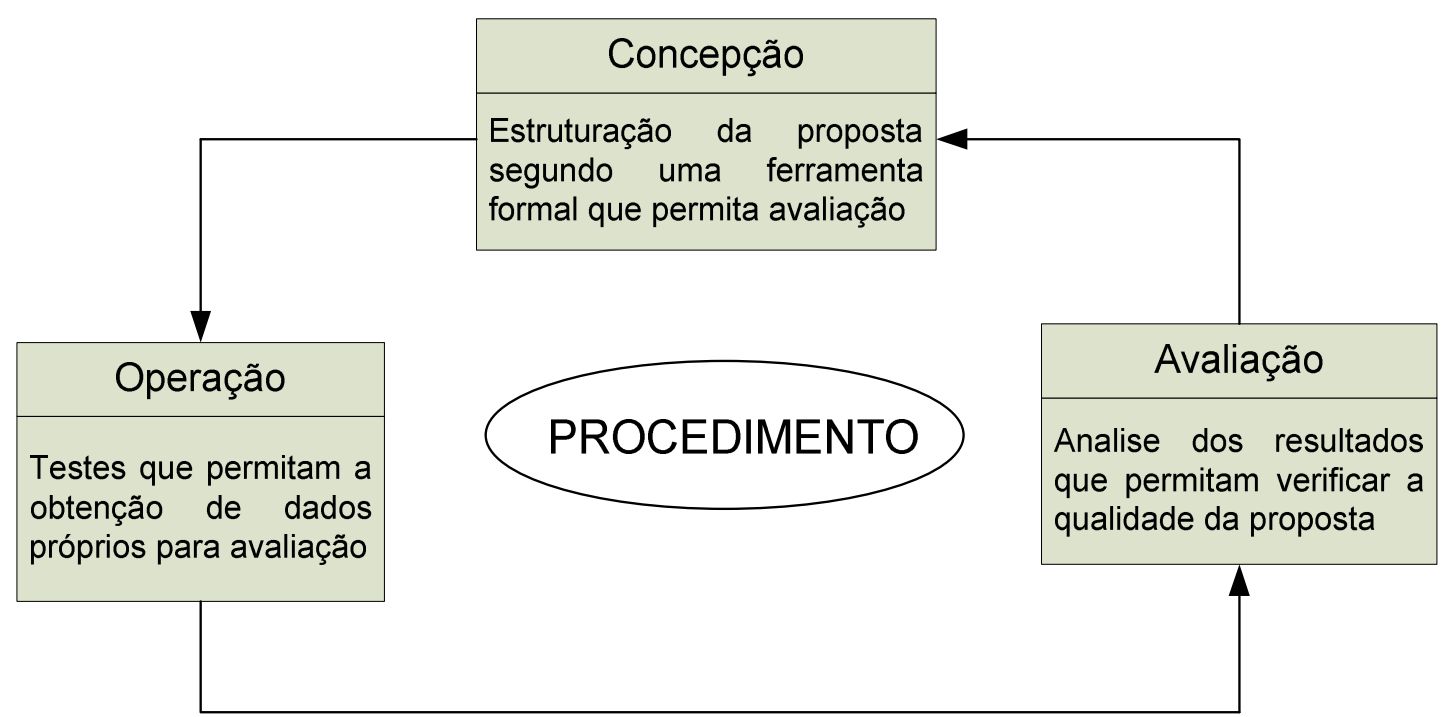

Figura 4.2. Ciclo de Prototipagem para o Procedimento (adaptado de MIYAGI, 1996). 
Nota-se que de na medida em que aumenta o porte e a quantidade de interações entre os componentes do FMS o procedimento torna-se também mais trabalhoso e propenso a erros. Portanto é necessária uma estruturação para que tais sistemas sejam abordados segundo uma lógica propriamente definida em cada etapa do procedimento.

A seguir apresenta-se uma discussão sobre cada um dos passos do procedimento proposto (Fig. 4.1)

\subsubsection{Construção do Modelo do Processo Produtivo}

A rede de Petri tem demonstrado ser uma ferramenta útil para a modelagem de SED, com características de concorrência, paralelismo, e assincronismo (ZHOU et al., 1992), (DESROCHERS \& AL-JAAR, 1995), (ZHOU \& VENKATESH, 1999), (VILLANI, 2004). Entretanto, na prática nota-se que a construção de modelos baseados em rede de Petri é uma tarefa não trivial já que, um dos problemas na modelagem de FMS consiste na explosão do número de elementos da rede com relação aos estados possíveis dos inúmeros dispositivos físicos, lógicos e restrições envolvidas. $\mathrm{Na}$ presente proposta propõe-se que a construção do modelo do processo produtivo seja feita segundo a metodologia PFS/MFG (MIYAGI, 1996). Considera-se ainda que a rede que modela o sistema de controle seja construída hierarquicamente segundo níveis estruturais, gerando redes com características próprias, em níveis distintos de representação (vide Figura 2.4). Assim, o primeiro passo consiste na construção de uma rede num nível que representa a evolução dos processos produtivos do sistema considerando propriedades como vivacidade, segurança e reversibilidade, (MURATA, 1989). Este nível é chamado de nível de supervisão e é também utilizado para representar a alocação de recursos do transporte do sistema. Na estrutura da Fig. 2.4, dependendo do FMS isto pode corresponder ao nível 4 ou nível 3. A evolução dos processos deve satisfazer as especificações que indicam como o sistema deve-se comportar e impedir que ele atinja estados indevidos não pertencentes às especificações iniciais. 
O segundo passo consiste no refinamento sucessivo dos elementos da rede no nível de supervisão. Isto gera uma rede que representa o comportamento funcional da planta, detalhando os componentes envolvidos no processo de operações presentes no sistema. Nesta rede devem ser verificadas propriedades como vivacidade e alcançabilidade dos estados desejáveis do processo produtivo e impedimento dos estados indesejáveis. Este nível é chamado de nível de controle, e dependendo dos equipamentos e dispositivos que compõem o FMS considerado isto pode corresponder ao nível 4 ou nível 5 da estrutura da Fig. 2.4. O nível de controle local representa a implementação das estratégias de controle, e contém elementos que representam as operações envolvidas na produção, bem como o comportamento e a disponibilidade dos dispositivos utilizados para tais operações.

Tem-se assim uma abordagem de tipo top-down para a construção de modelos que representa o processo produtivo do sistema. No nível de supervisão, desenvolve-se um modelo baseado nas especificações do sistema, segundo o seqüenciamento dos sub-processos necessários para realizar as tarefas de produção e cujo refinamento conduz a uma descrição detalhada do comportamento do sistema. A motivação para adotar tal divisão consiste na dificuldade que existe na construção de modelos com uma grande quantidade de componentes. Isto dificulta a síntese de modelos gráficos para sistemas de manufatura, que conseqüentemente, dificulta também a sua análise. ZHOU \& VENKATESH, (1990) apresentam no seu trabalho uma técnica baseada no refinamento tipo top-down, integrada à técnica bottom-up para a construção de modelos em rede de Petri para FMS. Os resultados motivam a adoção da divisão proposta no presente estudo.

A divisão de modelos em níveis de supervisão e controle para FMS também foi adotada em COMBACAU \& COURVOUSIER (1990), ESTEBAN \& COURVOISIER (1991) para tarefas de monitoração. Neste trabalho, funções de monitoração estão inerentemente consideradas e devidamente estruturadas na divisão do modelo do sistema numa rede de processo, que trata dos recursos do sistema, e outra que trata das partes manipuladas pelo sistema. 
A rede de Petri, sendo uma ferramenta matemática, possui um conjunto de propriedades que, sendo devidamente interpretadas para um sistema real, representam as características funcionais do FMS. Neste sentido, a análise das propriedades na rede de Petri que modela o sistema, é uma forma de avaliar o comportamento do próprio sistema. Em MURATA (1989), PETERSON (1981) são detalhadas as principais propriedades que são possíveis de serem analisadas com a rede de Petri. Neste ponto do procedimento, é feito uma avaliação de tais propriedades para assim garantir que falhas não aconteçam na fase de desenvolvimento do FMS. Uma interpretação para tais propriedades no caso de FMS é apresentada a seguir, (PETERSON, 1981), (MURATA, 1989), (CARDOSO \& VALLETE, 1997), (ZHOU \& VENKATESH, 1999):

Alcançabilidade (reachability): esta propriedade permite que seja verificado se os estados desejáveis do FMS são, de fato, alcançados a partir da evolução do processo e se os estados indesejáveis são evitados. Esta propriedade é particularmente importante já que, distintamente de sistemas de informação, os FMS que atingem um estado particular em geral não têm condições ou não podem mais voltar para os estados anteriores.

Limitabilidade e segurança (boundeness \& safeness): num FMS, é importante verificar se os lugares que representam o armazenamento de itens, que têm por definição capacidade finita, têm esse limite respeitado. Assim, a propriedade de limitabilidade permite identificar os componentes propensos a saturação. Quando o lugar representa uma operação, a propriedade de segurança garante que uma nova operação não seja acionada enquanto existe outra em execução.

Vivacidade (liveness): a vivacidade em FMS garante que o sistema não entre num estado de travamento. As situações de travamento em FMSs correspondem a uma alocação inapropriada de recursos compartilhados. No ambiente de FMS que, devido à sua própria natureza, apresenta compartilhamento de recursos, as seguintes 4 situações têm que apresentar-se simultaneamente para a ocorrência de travamento (COFFMAN et al., 1971), (SANTOS FILHO, 2000), (NAKAMOTO et al., 2002): 
- mútua exclusão - cada recurso está ou disponível ou alocado a um processo que tem o uso exclusivo deste recurso;

- retenção enquanto aguarda - enquanto aguarda a liberação de um recurso, o processo está livre de requisitar outro recurso;

- não há preempção - um recurso pode ser liberado somente pelo processo que o alocou;

- espera circular - dois ou mais processos formam uma cadeia circular fechada, no qual cada processo espera pelos recursos alocados em outros processos da mesma cadeia.

NAKAMOTO et al., (2002) propõe que para evitar estados de travamentos, é suficiente controlar a condição de espera circular, já que as outras três condições são características próprias de sistemas produtivos e, portanto de FMS. Entretanto, CHU \& XIE (1996) apresentam no seu trabalho uma técnica baseada em sifões. Esta técnica permite aplicar um conjunto de regras na construção da rede de Petri que garanta a ausência de lugares propensos a travamentos.

Reversibilidade (reversibility): Numa rede de Petri, quando a partir de qualquer marcação é possível retornar ao estado inicial, a rede é dita de reversível. Esta propriedade é particularmente importante porque em muitas situações, é desejável voltar para o estado inicial. Esta situação acontece em especial quando são consideradas falhas no modelo, e cujo tratamento implica no reset total do sistema.

\section{Processo de Síntese da Rede de Controle}

O procedimento apresentado na presente proposta segue a seqüência de primeiro estruturar a rede de Petri no nível de supervisão para depois construir a rede de Petri no nível de controle. No presente estudo propõe-se que tal processo seja realizado com base na técnica PFS/MFG apresentado no capítulo anterior. A rede de Petri no nível de supervisão descreve o processo produtivo como uma seqüência de sub-processos que junto com a representação da alocação de recursos de transporte descreve o processo de produção. Entretanto, o PFS descreve 0 
processo produtivo conceitual do sistema aproveitando o conceito de fluxo de itens através da planta. Portanto, é necessário definir a seqüência de passos a serem realizados para construir a rede de Petri no nível de controle a partir da rede de Petri no nível de supervisão utilizando a técnica PFS/MFG.

O FMS é um sistema complexo que é formado por vários sub-processos que respondem a eventos para serem inicializados ou finalizados. Devido ao indeterminismo sobre o instante de ocorrência de tais eventos, o inicio e a finalização de tais sub-processos não pode ser definida a partir da variável tempo. Assim, é aproveitado o conhecimento da seqüência de sub-processos que têm que ser realizados para atender à produção e, nesse sentido utilizam-se transições que representem o início e a finalização de tais operações. A rede de Petri no nível de supervisão utiliza os lugares para representar os sub-processos envolvidos no processo produtivo. Cada lugar representa um conjunto de tarefas pelas quais as peças e informações têm que ser transformadas e manipuladas antes de passar para o lugar seguinte, onde novas tarefas serão realizadas. Entretanto, o início e a finalização de tais operações são representados como transições de entrada e saída para o respectivo lugar. Assim, cada lugar na rede de Petri junto com as suas respectivas transições de início e finalização de atividade no nível de supervisão podem ser devidamente descritas como uma rede tipo PFS. A partir desta representação, através de um refinamento sucessivo tem-se a rede de Petri no nível de controle representado em MFG. A Figura 4.3 ilustra esta seqüência.

A rede MFG de controle, considera a interação entre o dispositivo de controle e os objetos de controle como um conjunto de portas de entrada e saída que permite a comunicação com os dispositivos externos responsáveis pela manipulação dos itens de produção (MIYAGI, 1996). Entretanto, para a construção de modelos de controle tolerantes a falhas é necessário que tais dispositivos sejam devidamente representados na rede de controle em MFG. Neste sentido, cada porta de entrada/saída é substituído por um box que represente o funcionamento do dispositivo respectivo. 

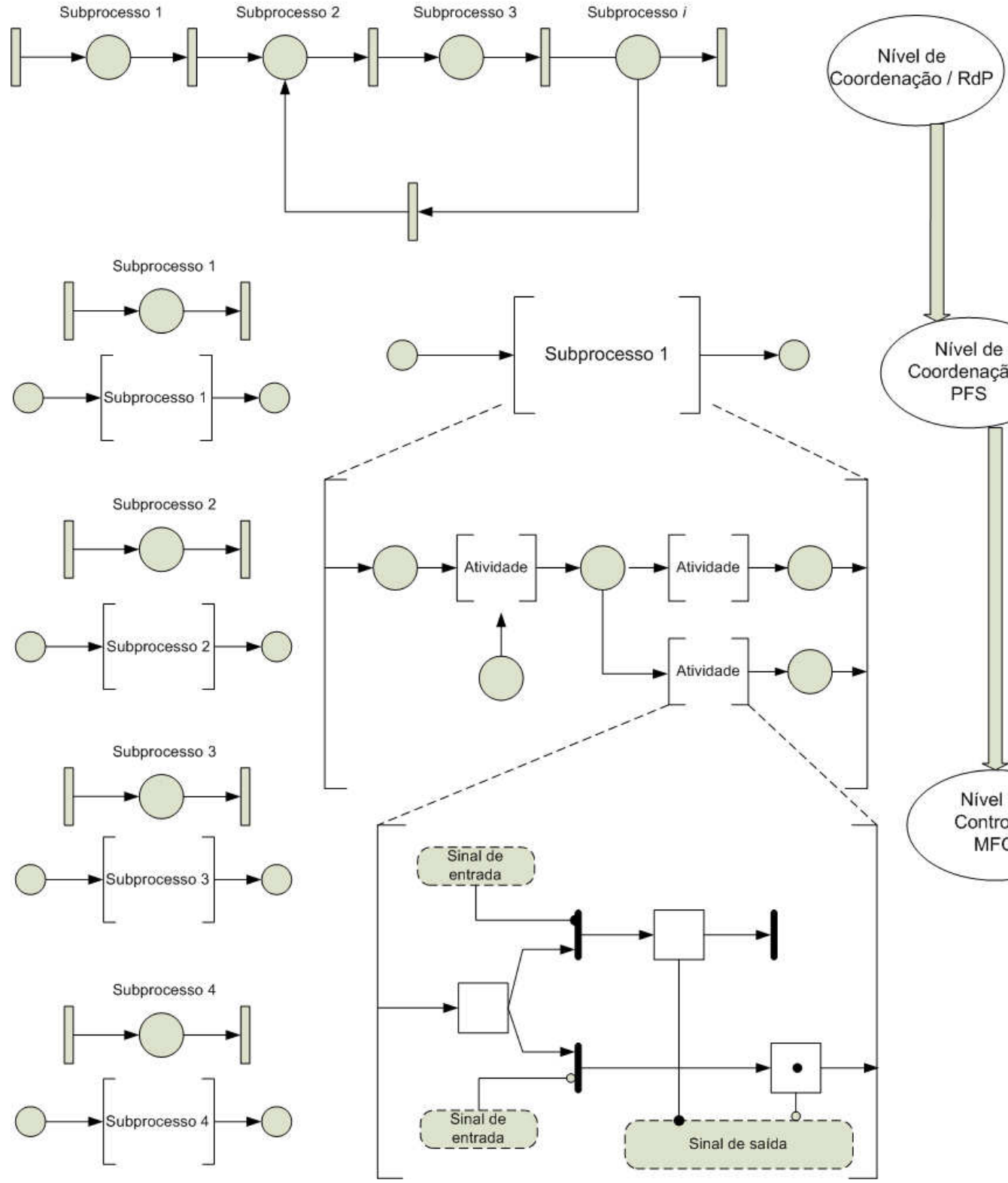

Nivel de

Coordenação / PFS

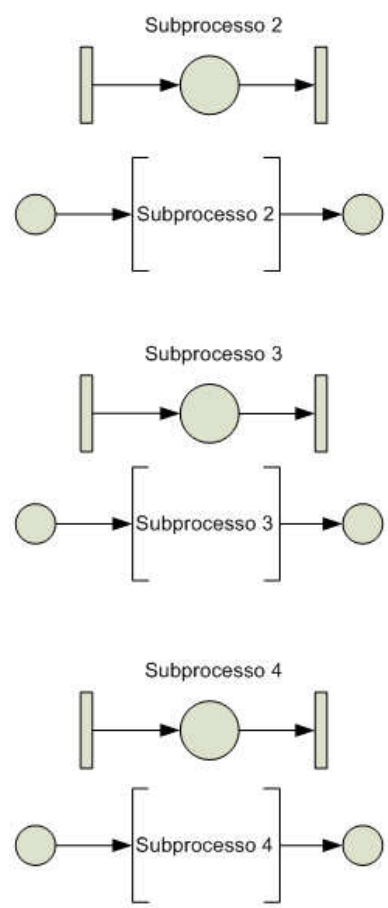

Nivel de

Controle/ MFG

Figura 4.3. Seqüência de construção de modelos de processos produtivos baseado em redes de Petri no nível de supervisão e de controle.

\subsubsection{Classificação dos componentes do modelo do processo produtivo com base nas suas características de representação}

Com o objetivo de obter e identificar o conjunto de variáveis que serão consideradas como nós tipo componentes (nós que representam dispositivos propensos a falhas) 
na rede Bayesiana, é necessário realizar uma classificação dos lugares da rede de Petri no nível de controle representado em MFG. Esta classificação é feita segundo as características representativas de cada box. Assim, são identificados dois tipos de boxes, isto é, boxes tipo $A$, e boxes tipo $B$. Os boxes tipo $A$, são componentes que representam operações, processos, e alocação de recursos. Estes boxes representam os elementos envolvidos na realização das tarefas de controle para atingir os objetivos de produção concebidos em níveis superiores de planificação. Exemplos destes tipos de boxes são inicio/finalização da operação de uma máquina, inicio/finalização de movimentação de um robô, estado do estoque, disponibilidade de máquinas, etc. Devido a sua própria natureza, os boxes tipo A normalmente apresentam uma marcação inicial nula.

Os boxes tipo B representam o funcionamento dos dispositivos de conversão de sinais envolvidos com os processos de produção. Isto é, eles representam o estado dos dispositivos de detecção e atuação do sistema de controle. Todos os componentes que devem ser considerados como possíveis causas de uma falha têm que ser devidamente representados e identificados como boxes tipo B. Boxes tipo B apresentam a característica de segurança, devido à sua natureza binária de funcionamento (isto é, estados 'ativo', 'inativo'). A Figura 4.4 ilustra esta classificação.

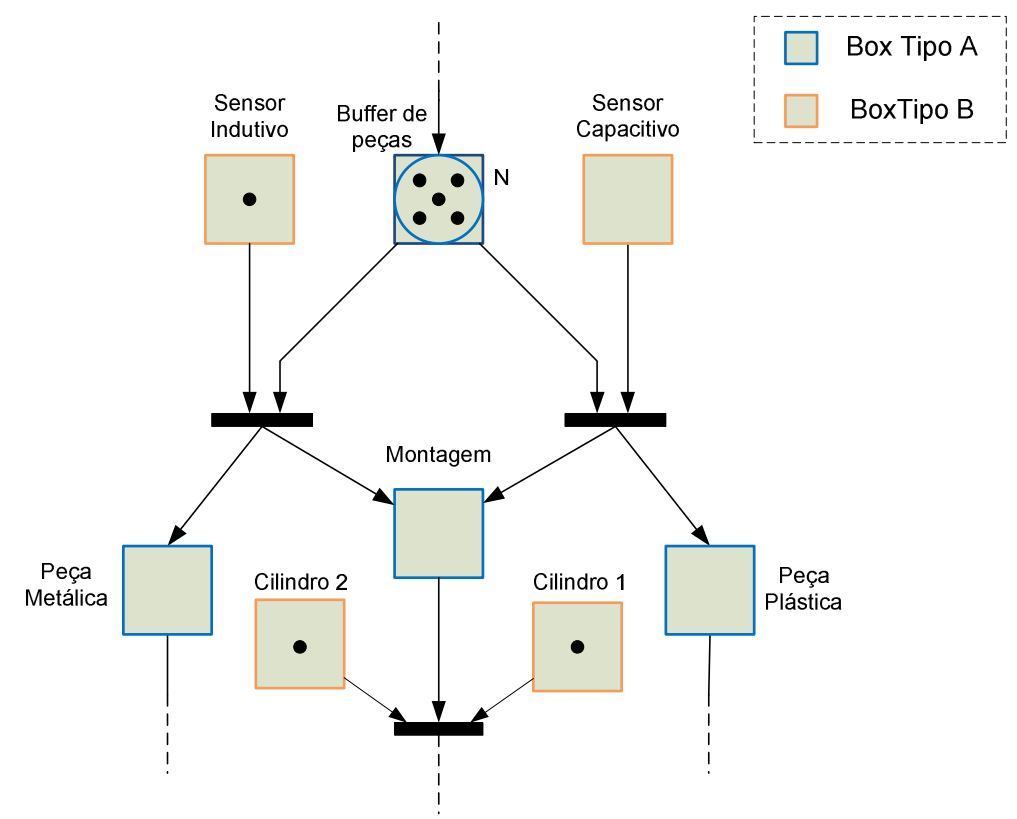

Figura 4.4. Lugares Tipo A e Lugares Tipo B (Adaptado de MORALES et al., 2007b). 
Nota-se que ao contrario dos boxes tipo A, alguns dos boxes tipo B podem apresentar uma marcação inicial não nula.

ZHOU \& DiCESARE (1990) propõem uma classificação de lugares em três categorias com respeito à marcação inicial. Isto é feito com o objetivo de definir um procedimento para a síntese de rede de Petri que represente um FMS. Entretanto, na presente proposta limita-se a classificação em duas categorias já que o foco aqui são os componentes que possam apresentar falhas no sistema real.

Uma última consideração com respeito à classificação de boxes no nível de controle consiste na forma como esta informação é usada na construção da rede Bayesiana. Uma das dificuldades que se apresenta é definir o número adequado de nós da rede Bayesiana. Observa-se na prática, que o nível de detalhamento representado na rede Bayesiana influencia de maneira decisiva a efetividade do diagnóstico. Por outro lado, quanto maior o número de nós na rede Bayesiana, e em particular, quanto maior o número de pais existentes, o processo de inferência torna-se mais complexo. Deve-se considerar assim, um refinamento que permita um efetivo diagnóstico sem sobrecarregar a rede Bayesiana. A classificação dos boxes no MFG ajuda, neste sentido, a identificar quais os possíveis nós a serem adicionados na rede Bayesiana, além dos nós tipo componentes.

\subsubsection{Construção do modelo do processo de diagnóstico}

Nos últimos anos, a utilização de redes Bayesianas, também chamadas de redes de crença, para o diagnóstico de falhas tornou-se atraente devido à capacidade de lidar com vários tipos de informações (quantitativas e qualitativas) do sistema e à capacidade de realizar inferência sobre as causas que derivam de uma certa manifestação, considerando incertezas nos dados do processo (PRZYTULA \& THOMPSON, 2000), (PRZYTULA \& THOMPSON, 2001), (PRZYTULA et al., 2003), (MEHRANBOD et al., 2003), (SAHIN et al., 2007), (MORALES, et al., 2007a), (MORALES, et al., 2007b), (MORALES, et al., 2007c). Entre outras aplicações, as 
redes Bayesianas têm sido utilizadas amplamente para realizar diagnósticos médicos, pois os resultados de testes nesta área freqüentemente apresentam grande incerteza (COZMAN, 2001). Redes Bayesianas também têm sido utilizadas para sistemas de processamento de imagens e sistemas de tomada de decisão (LUO, J. et al., 2005). As redes Bayesianas constituem uma ferramenta útil para representar relações causais entre as suas variáveis, em especial quando estas incluem o conceito de incerteza dentro das relações entre os nós da rede representado pelo peso de cada relação como um conjunto de probabilidades condicionais. Assim, o problema do diagnóstico de falhas em FMS baseado em redes Bayesianas consiste em encontrar as variáveis com maior probabilidade de ser responsáveis pelas manifestações que apresentam tais falhas. Utilizando o conceito da matriz de dependência (LUO, et al., 2005) pode ser demonstrado que as redes Bayesianas têm a mesma capacidade de diagnóstico de falhas que a rede de Petri para diagnóstico (behavioral Petri nets) (PORTINALE, 1997) e que as redes multisignal flow graphs (DEB, et al., 1994). Entretanto, as principais vantagens que apresentam as redes Bayesianas para o diagnóstico de falhas em FMS são:

- capacidade de representar vários tipos de informações, tanto quantitativas (testes estatísticos do processo), quanto qualitativas (conhecimento de especialista sobre o sistema);

- capacidade de lidar com incertezas nos dados do processo;

- capacidade de atualizar o modelo sem necessidade da construção de um novo modelo;

- capacidade de reduzir o grafo que representa a rede Bayesiana de diagnóstico conforme as manifestações observadas.

Embora tais vantagens tornem as redes Bayesianas uma ferramenta muito atraente para o diagnóstico de falhas, algumas desvantagens também são identificadas:

- os algoritmos de inferência são de tipo NP-Hard;

- as redes Bayesianas são limitadas a estruturas tipo acíclicas; 
- as redes Bayesianas não provêem mecanismos para a representação de dependência temporal, o que limita a sua aplicação em processos produtivos;

- tanto a construção da estrutura da rede Bayesiana quanto a elicitação dos seus parâmetros é uma tarefa difícil que envolve vários tipos de informação.

Com respeito à primeira dificuldade PEARL, (1988), LAURITZEN \& SPIEGEHALTER (1988), GEIGER, et al., (1990) introduzem alguns métodos para facilitar a inferência em redes Bayesianas. PEARL, (1988) introduz métodos que variam de acordo com o tipo da rede sendo analisada. LAURITZEN \& SPIEGEHALTER (1988) definem um algoritmo aproximado que em geral pode ser aplicado a qualquer tipo de rede. GEIGER, et al., (1990), aproveita do conceito de $D$ - separação (PEARL, 1988) para reduzir a rede e facilitar assim o processo de inferência.

$\mathrm{Na}$ segunda dificuldade, o fato das redes Bayesianas serem limitadas a estruturas tipo acíclicas pode ser tratado com a introdução de nós auxiliares que permitam que os ciclos sejam quebrados.

Com respeito à terceira consideração, no caso de FMS, o fato das redes Bayesianas não prover mecanismos de dependência temporal não adiciona maior dificuldade devido a que em geral, as dependências entre as falhas e suas causas são de tipo estáticas (não variam no tempo).

Com respeito à quarta dificuldade, na literatura consultada, são poucos os trabalhos onde podem ser encontrados procedimentos eficientes para a construção das redes Bayesianas para diagnóstico de sistemas de alta complexidade (PRZYTULA et al., 1999), (HENRION, 1989). De fato, a construção de tais redes é uma tarefa que envolve o conhecimento de especialistas sobre o sistema, engenheiros de manutenção e operação, manuais técnicos, bases de dados sobre falhas passadas, etc. Assim, a integração de tais conhecimentos num único modelo não é trivial e justifica o estudo da sistematização de um procedimento eficaz para a construção de tais modelos. Um dos problemas é que os encarregados da operação dos equipamentos têm uma visão muito diferente da visão dos engenheiros de manutenção. Portanto, muitas vezes a serem consideradas por uns são distintas das 
falhas consideradas por outros. Além disso, muitas vezes o conhecimento individual (humano) do processo e do sistema muitas vezes é limitado. Na prática, nota-se que ao solicitar aos operadores que descrevam as principais falhas do sistema, estes consideram unicamente as últimas falhas que aconteceram excluindo assim, falhas menos freqüentes mas eventualmente de grande severidade. Neste sentido, é necessário considerar uma técnica que garanta que todos os componentes envolvidos no processo serão considerados na hora de construir o modelo do diagnóstico, razão pela qual foi introduzida a classificação dos boxes no MFG que representa o funcionamento normal do processo.

O procedimento geral proposto em PRZYTULA \& THOMPSON (2000) para a construção de redes Bayesianas para diagnóstico é apresentado na Figura 4.5.

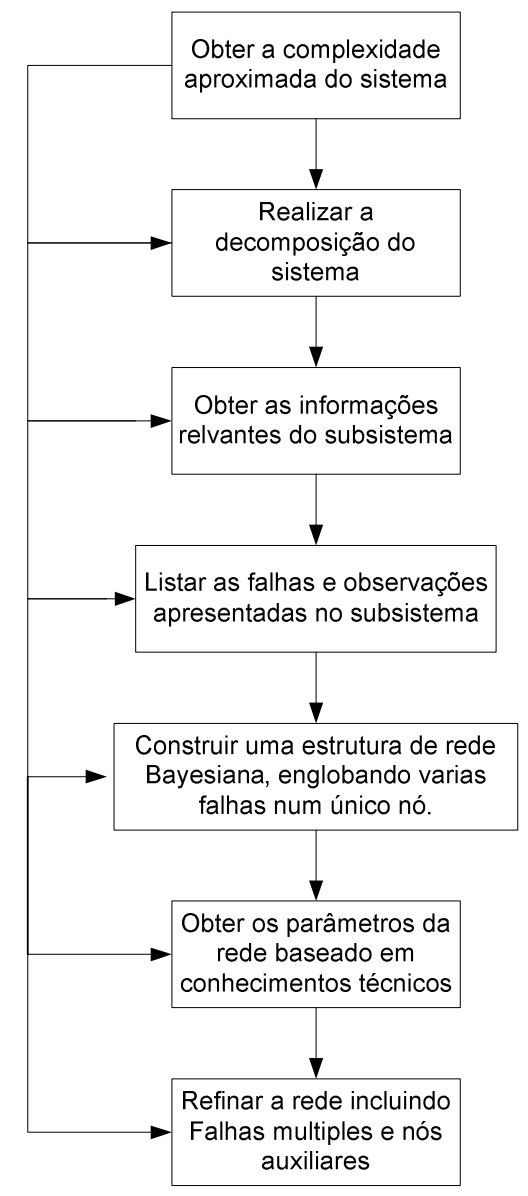

Figura 4.5. Procedimento para a construção de modelos de diagnóstico baseado em redes Bayesianas (adaptado de PRZYTULA \& THOMPSON, 2000). 
A construção do modelo começa com a definição aproximada da complexidade do sistema. Esta complexidade é função da quantidade de componentes propensos a falhas somadas com o número de observações que poderão ser obtidas do sistema. Note que a quantidade de componentes propensos a falha requer que seja previamente definido o número falhas a ser considerado, o que resulta uma tarefa difícil em especial na etapa inicial da construção do modelo.

Em PRZYTULA \& THOMPSON (2000) a decomposição do sistema em subsistemas menores é feita segundo as divisões em setores dos equipamentos de manufatura ou dos sub-processos pertencentes ao processo produtivo global. Isto apresenta a desvantagem de que na prática, têm-se vários recursos sendo compartilhados por vários sub-processos representados o que demanda um gerenciamento adicional para assegurar a devida comunicação entre o sistema de controle e o sistema de diagnóstico exclusivo dos recursos compartilhados. Entretanto, as manifestações de uma falha de tais recursos em um sub-processo dado, serão distintas das manifestações do mesmo recurso num outro sub-processo.

Além disso a construção de uma estrutura simples que englobe várias falhas num só nó para depois ser refinado em vários nós segundo o poder representativo da rede, é uma tarefa iterativa que apresenta o risco de perda da objetividade do modelo.

Neste sentido, no presente trabalho tem-se uma nova proposta para o procedimento de construção de modelos aptos para o diagnóstico de falhas que considera o nível de controle propriamente representado no MFG. A Figura 4.6 apresenta tal procedimento.

Cada box tipo B é representado como um nó na rede Bayesiana e, em geral pode apresentar dois estados, normal e em condição de falha. Não obstante, alguns outros estados podem ser incluídos considerando modos de falha, por exemplo, modo de falha severo, modo de falha parcial, e modo normal de funcionamento. Note que a probabilidade de não considerar componentes propensos a falha é reduzido devido ao fato de que são considerados todos os componentes envolvidos no processo produtivo do FMS. 


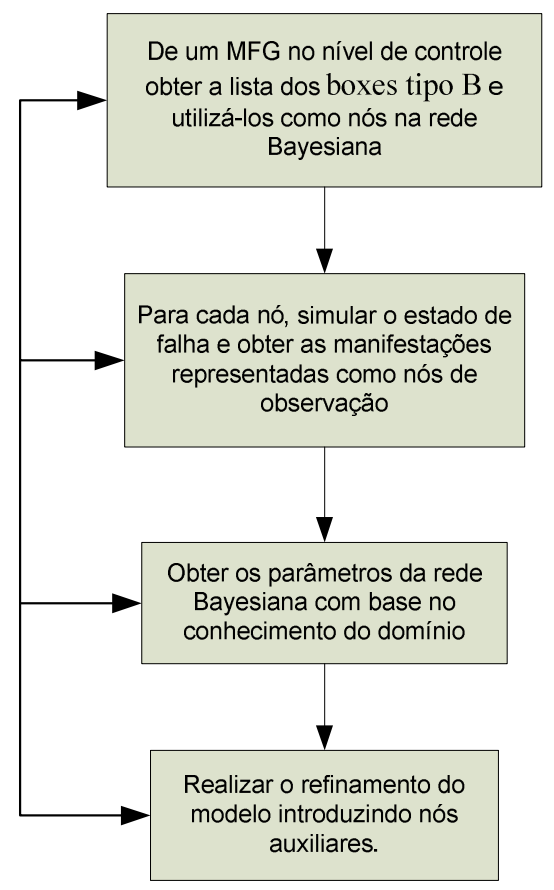

Figura 4.6. Procedimento proposto para a construção de modelos de diagnóstico.

Como no MFG no nível de controle pode ser observado o comportamento dos componentes propensos a falha, as conseqüências de falha nestes casos são de fácil dedução, já que em geral, elas afetam as tarefas subseqüentes representadas no nível de controle. No entanto, é necessário incluir neste ponto o conhecimento do pessoal de operação e manutenção para verificar se todas as possíveis manifestações das falhas estão sendo consideradas. Assim, a caracterização das falhas (item 2.3.1) é fundamental já que permite mediante as 5 perguntas, identificar e detectar a procedência da falha e assim determinar seus possíveis históricos.

Os parâmetros do processo são obtidos de forma iterativa simulando a cada conjunto de probabilidades definidas se o modelo realiza diagnósticos corretos. Este procedimento começa com a definição de um conjunto de observações conhecidas de uma falha a partir das quais são realizadas inferências para determinar se a causa com maior probabilidade é de fato a falha esperada. A obtenção destes parâmetros é feita baseada em dados estatísticos dos componentes e no 
conhecimento de especialistas. Quando se trata de nós sem pais, é simplesmente baseado em dados estatísticos das falhas de tais componentes.

Finalmente o refinamento da rede é conduzido de acordo com os resultados obtidos na verificação da rede resultante.

\subsubsection{Definição das técnicas de tratamento}

Na prática, existem muitas aplicações nas quais não é possível parar o processo de produção para realizar tarefas de manutenção imediata. No entanto, não é desejável que o processo continue a produzir itens com problemas. Neste sentido, apresentase aqui as principais técnicas de tratamento de falhas junto com a definição das características tanto operacionais quanto físicas, das situações onde podem ser aplicadas tais técnicas. Os métodos de tratamento são: método de entrada condicional, método de caminho alternativo, método de recuperação inverso, e método de recuperação complementar.

Método de entrada condicional (ZHOU \& DiCESARE, 1993)

O método de entrada condicional consiste em realizar uma operação auxiliar a partir de uma tarefa em estado de falha. Isto permite que tal tarefa volte a um estado normal de funcionamento mediante a realização de tarefas complementares ao processo produtivo (Figura 4.7).

Note na Figura 4.7 que o processo produtivo normal de funcionamento é representado por $Z$, enquanto que o processo complementar para a recuperação do erro é representado pela seqüência $S$. Esta técnica é utilizada por exemplo, na calibração das ferramentas que envolvem o processo $Z$, na introdução no processo produtivo normal de operações de acabamento, no requerimento de novas ferramentas, etc. Além disso, esta técnica exige o reprocesso da operação $p$, portanto a seqüência $S$ simplesmente pode representar o pedido de uma nova execução da operação p. 


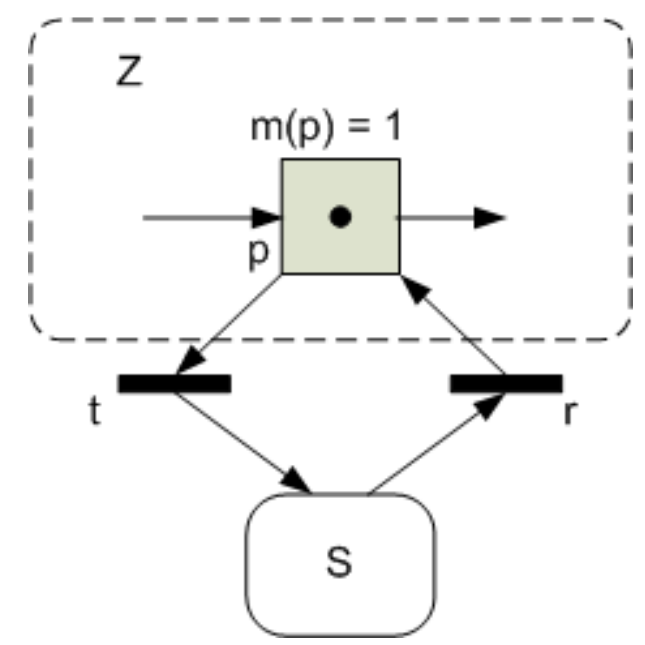

Figura 4.7. Método de entrada condicional.

Método de caminho alternativo (ZHOU \& DiCESARE, 1993)

O método de caminho alternativo consiste utilizar uma seqüência de processos alternativos ao processo produtivo habitual. Neste sentido, se evita utilizar as operações onde a falha foi detectada, o que por sua vez permite que programas de manutenção possam ser utilizados para recuperar tal processo. A Figura 4.8 ilustra esta técnica.

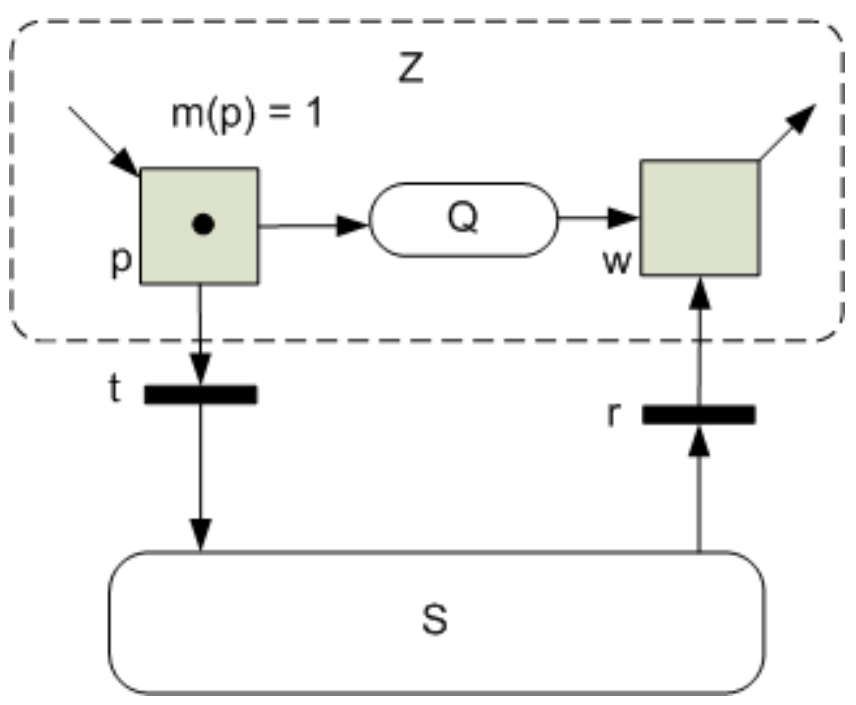

Figura 4.8. Método de caminho alternativo. 
Este método deve ser utilizado quando se dispõe de recursos/equipamentos redundantes, já que ele exige que a seqüência alternativa envolva as mesmas tarefas realizadas pela seqüência normal de funcionamento.

A implementação desta técnica é recomendada em processos produtivos críticos cuja parada gera perdas significativas de recursos físicos e/ou humanos.

Método de recuperação inversa (ZHOU \& DiCESARE, 1993)

O método de recuperação inversa consiste em realizar uma seqüência de passos que reiniciem o processo produtivo normal, com o intuito de melhorar os resultados obtidos por tal seqüência. A Figura 4.9 ilustra este método, onde após a realização de uma seqüência de tarefas $Q$ no box w é observado que houve alguma falha. Assim, mediante uma reconfiguração na seqüência $S$ é feito um reprocesso para obter um melhor resultado.

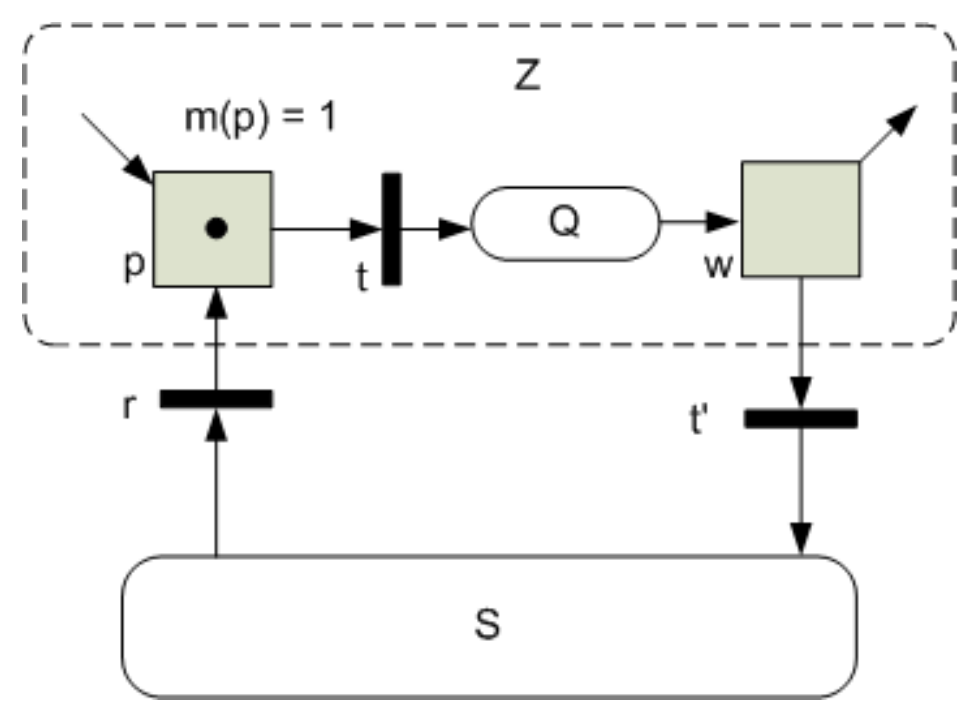

Figura 4.9. Método de recuperação inversa.

Como uma aplicação em FMS tem-se, por exemplo, quando a seqüência $Q$ representa a montagem de certo tipo de peça que exige uma alimentação ordenada de sub-partes e cujo resultado só pode ser observado numa estação de inspeção w. 
Assim, após um reordenamento das tarefas que pode inclusive considerar a desmontagem da peça é feita uma nova montagem.

Método de recuperação complementar

O método de recuperação complementar assume que algumas tarefas que se encontram em estado de falha podem se tornar tarefas normais com a introdução de tarefas complementares que sejam processadas em paralelo com a produção. Neste sentido é utilizado um conjunto de transições que modelam a sincronização das tarefas sendo realizadas em paralelo. A Figura 4.10 ilustra esta técnica.

Algumas aplicações desta técnica incluem a utilização de recursos que realizem tarefas complementares como, por exemplo, a utilização de robôs para auxiliar a fixação de peças sob processos que envolvem vibração.

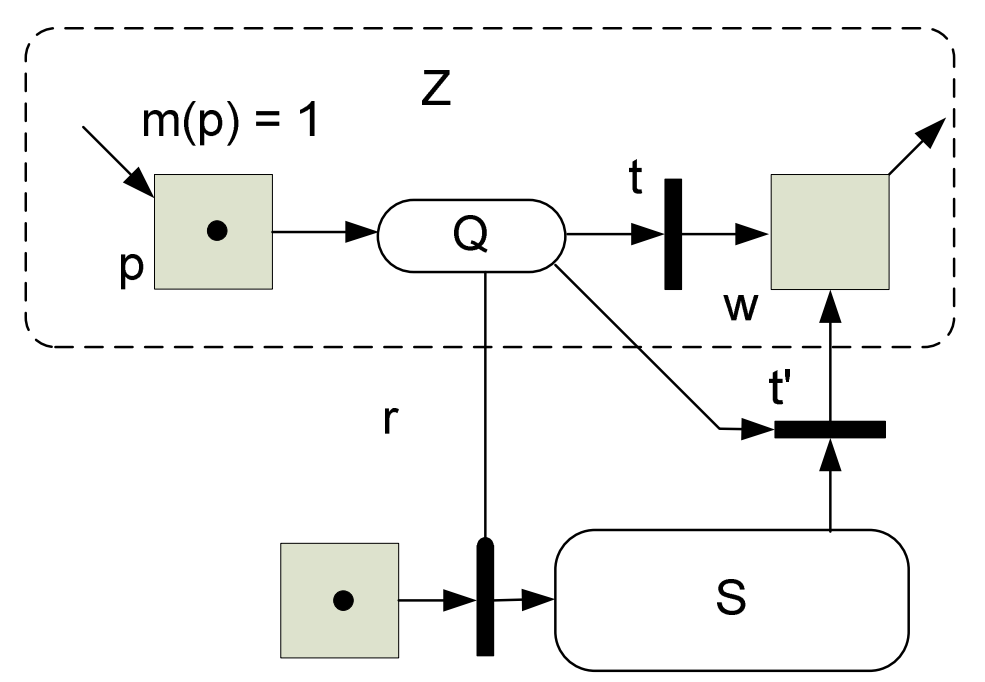

Figura 4.10. Método de recuperação complementar.

\subsection{CONSIDERAÇÕES SOBRE O MODELO DE SUPERVISÃO}

O modelo resultante do procedimento descrito na seção anterior permite o estudo e especificação da estratégia de supervisão e controle de processos de manufatura considerando não só comportamentos normais, mas também comportamentos 
anormais ou em estado de falha. Entretanto, para a implementação do controle baseado na utilização de tais modelos é necessário definir o tipo de comunicação que será utilizado entre o modelo da parte de controle (MFG) e o modelo da parte de diagnóstico (rede Bayesiana). Os modelos desenvolvidos para o controle e para o diagnóstico são de formalismos distintos, e não é possível estabelecer uma comunicação direta utilizando uma junção dos componentes ou elementos de cada modelo (JUNQUEIRA, 2006). Portanto, é necessário definir algum mecanismo adicional que permita que o modelo de controle informe um estado de falha para que o respectivo diagnóstico seja inicializado.

Neste sentido define-se que o conjunto de transições pertencentes ao MFG no nível de controle seja composto por dois tipos de transições, um conjunto de transições tipo normais, e outro conjunto de transições que permita a inspeção das condições do processo a partir de elementos externos e que permita também o diagnóstico baseado em rede Bayesiana através de uma chamada de método de diagnóstico.

Definição. O conjunto de transições $T=\left\{T_{\mathrm{op}} \cup T_{\text {diag }}\right\}$ do MFG no nível de controle local é composta por um conjunto de transições operacionais $\mathrm{T}_{\mathrm{op}}$ e um conjunto de transições de diagnóstico $\mathrm{T}_{\text {diag. }}$.

Enquanto as transições operacionais representam simplesmente os eventos relativos à execução das operações normais do sistema, as transições de diagnóstico são os eventos relacionados com a verificação de condições externas que podem indicar se o sistema modelado encontra-se em estado de falha ou não. Estas condições externas são as observações do sistema sob estudo baseado em dispositivos independentes instalados no chão de fábrica e nos próprios sinais de controle. Notese que os sinais dirigidos a estas transições podem ser gerados a partir de outros MFG que modelam o comportamento de outros parâmetros do sistema, ou podem ser gerados a partir de observações de um operador humano sobre a evolução do processo. Note também que tais observações têm que estar devidamente consideradas na rede Bayesiana que modela tal processo como o conjunto de nós que representam as manifestações dos estados de falha. A Figura 4.11 ilustra as transições $T_{o p} e$ as transições $T_{\text {diag. Para facilitar a visualização, as transições }}$ 
operacionais são ilustradas como barras pretas e as transições de diagnóstico são ilustradas como barras brancas.

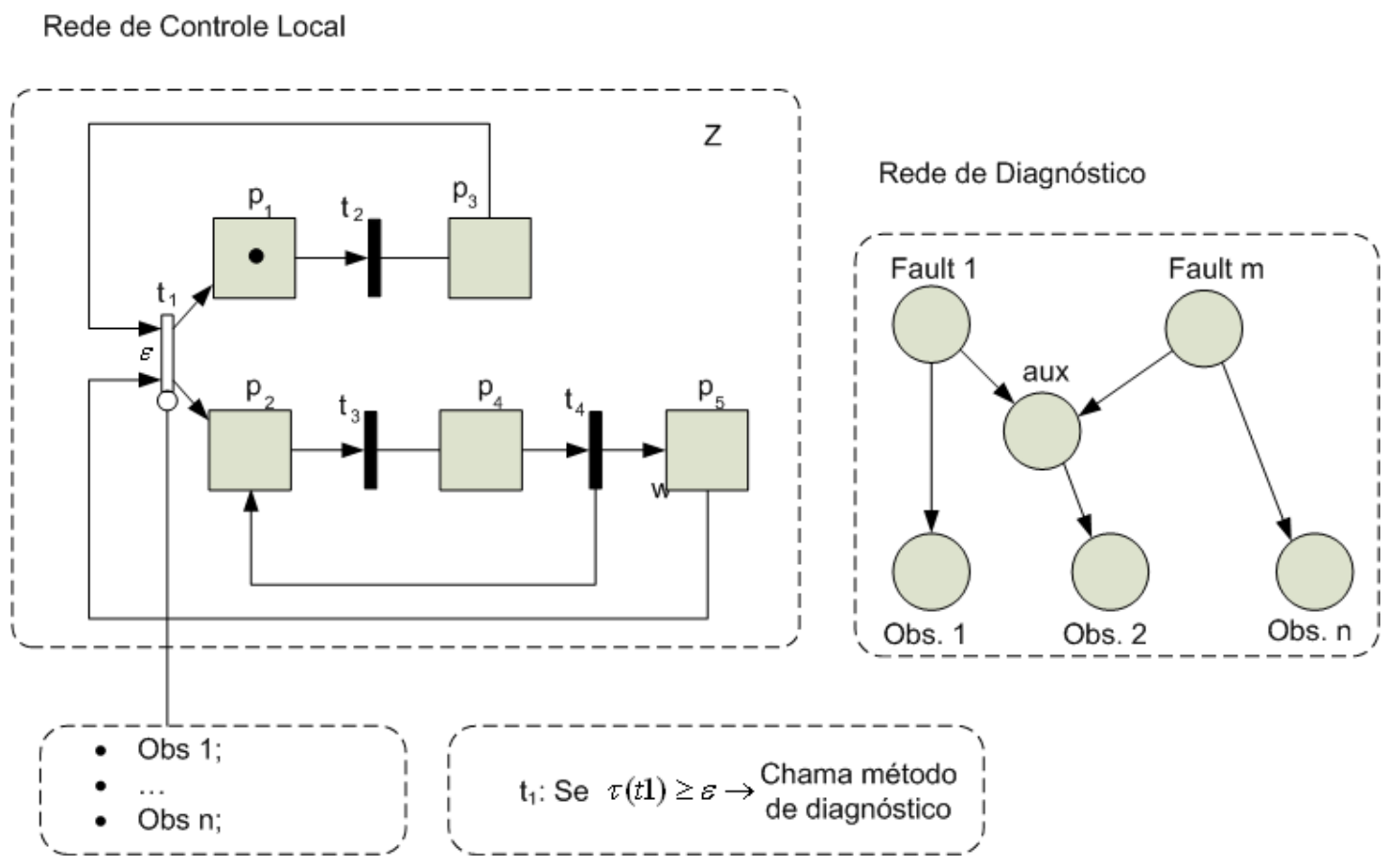

Figura 4.11. Definição das transições $T_{o p} \in T_{\text {diag }}$.

É necessário definir ainda, quando é solicitado o método de diagnóstico realizado pela rede Bayesiana. Neste sentido, define-se que as transições de diagnóstico possuem uma variável de tempo $\varepsilon$, que representa o valor máximo de tempo que a transição pode estar habilitada sem ser disparada. Assim, quando uma falha ocorre e uma observação é informada à rede, a transição de diagnóstico respectiva apresentará um tempo de habilitação $\tau(t)$ maior do que a variável $\varepsilon$, o que indica por sua vez que a rede de diagnóstico tem que ser inicializada.

Definição. Para toda transição $t_{i} \in T_{\text {diag }}$ é associado uma variável $\varepsilon_{i}$ que representa o tempo máximo que a transição ti pode estar habilitada sem ser disparada. Se o tempo de habilitação $\tau\left(t_{i}\right)$ é maior do que a variável $\varepsilon_{i}$ então efetua-se o método de diagnóstico.

Finalmente, é necessário definir uma vez realizado o diagnóstico, qual será ou serão as tarefas de tratamento de falhas que serão realizadas pelo controlador. Neste 
sentido definem-se um conjunto de regras atribuídas aos nós primitivos da rede de diagnóstico (nós componentes) que estabelecem a seqüência de tarefas necessárias para o tratamento. Note que o nó componente ao qual é atribuído a falha, é também um box na rede MFG de controle. Neste sentido, a transição que habilita o processo de tratamento seguinte ao box (representado na rede MFG de controle) ou da seqüência de boxes seguintes será disparada inicializando o processo de tratamento. Esta transição só será habilitada mediante uma regra atribuída ao nó componente do modelo de diagnóstico. A Figura 4.12 ilustra este processo.

Definição. Para cada nó primitivo (nó componente) do modelo de diagnóstico, representado por rede Bayesiana, é atribuído um conjunto de regras que habilitam o disparo da transição de entrada respectivo ao box componente (tipo B) que inicializa o processo de tratamento de falha.

Hayes-Roth (1985) define os sistemas baseados em regras como sistemas modulares baseados em conhecimentos. È possível, mediante este tipo de sistemas, representar técnicas situação-ação baseados em regras de disparo através de um conjunto de condições satisfeitas.

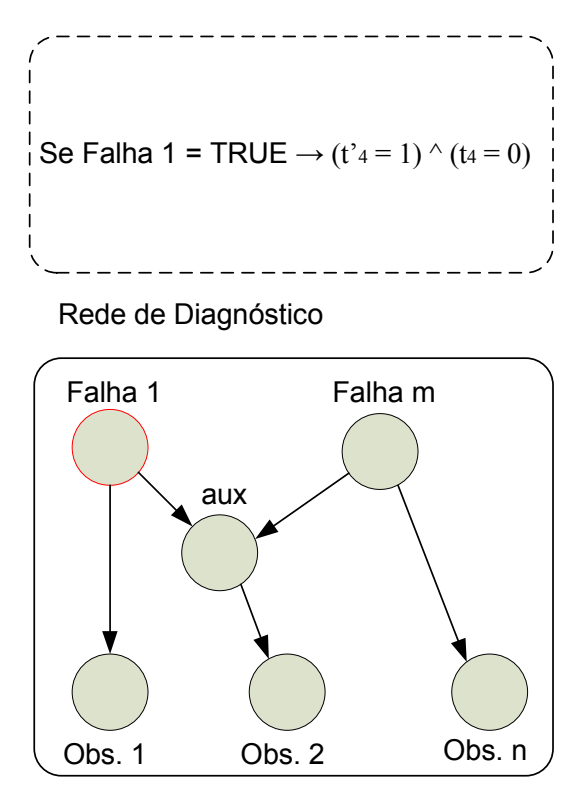

Rede de Controle Local

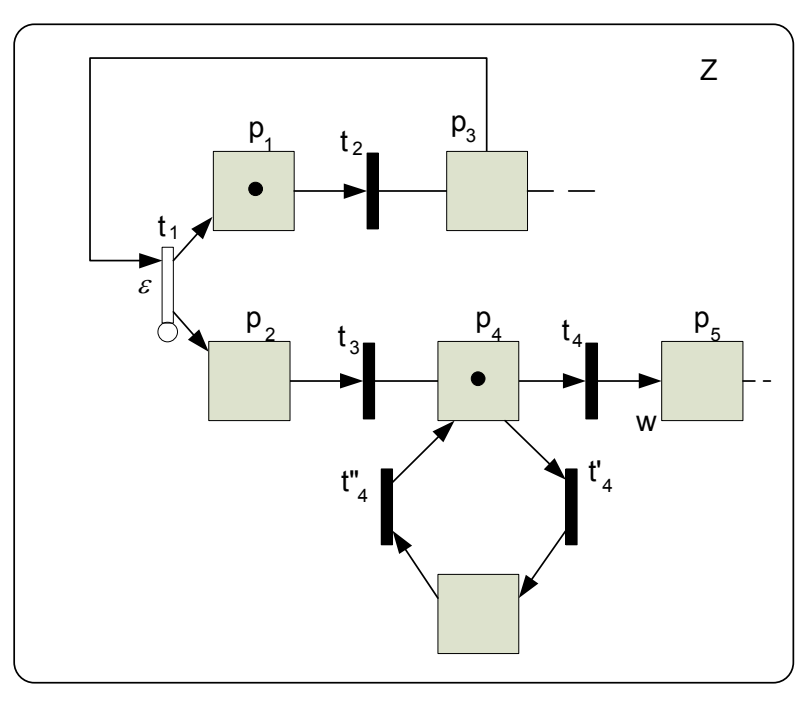

Figura 4.12. Definição de regras de disparo das transições de tratamento de falhas. 
Existem sistemas nos quais o conjunto de operações e atividades próprias de cada sub-processo (vide Figura 4.3) da produção não são visíveis e nem podem ser monitorados. Assim, o correto funcionamento de tais atividades só pode ser verificado no final de cada etapa e mediante a observação do produto obtido. Neste sentido, a definição anterior não permite a realização da detecção de falhas presentes no sistema quando não podem ser obtidas as manifestações de tais falhas no respectivo sub-processo. Assim, é necessário definir um procedimento que considere tal situação.

Define-se neste sentido, que no modelo do nível de supervisão, existem certas transições das quais podem ser obtidas as informações relacionadas a cada subprocesso mediante a observação dos defeitos do produto parcial obtido. Devido a que a rede de Petri no nível de supervisão acompanha o seqüenciamento dos subprocessos, assume-se que podem ser identificados defeitos entre o final de uma atividade e o inicio da seguinte atividade.

Definição. A rede de Petri no nível de supervisão possui um conjunto de transições $t_{\text {inss }} \subseteq T$, chamadas de transições de inspeção, que indicam se a atividade precedente encontra-se em estado de falha ou não.

A Figura 4.13 ilustra este caso. Para melhor visualização as transições de inspeção são representadas por barras vazias.

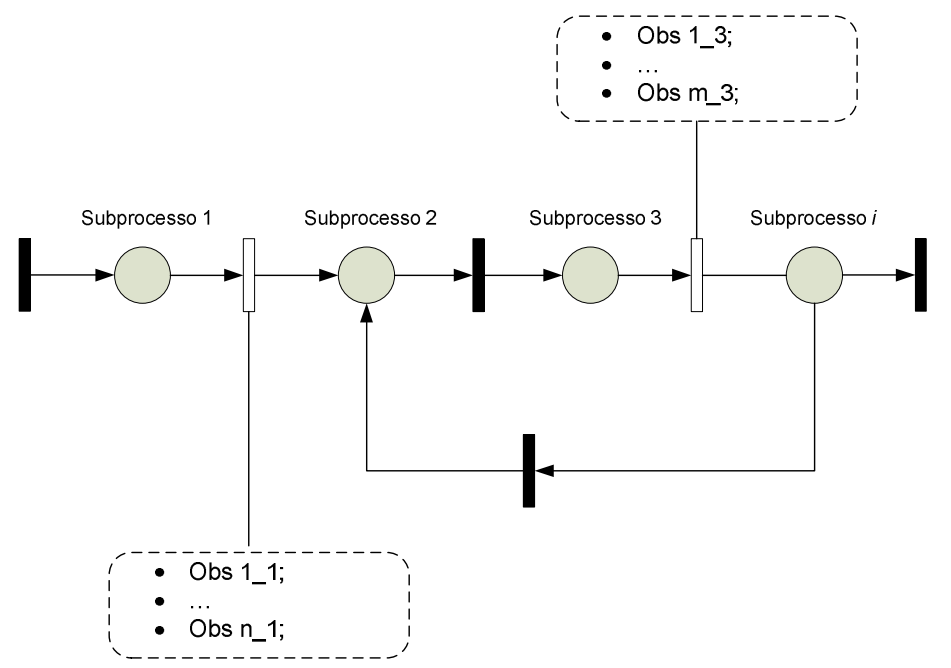

Figura 4.13. Transições de inspeção na rede de Petri no nível de supervisão. 
As observações pertinentes à rede de Petri no nível de supervisão são observações baseadas no produto parcial obtido. Portanto, as informações obtidas a partir de tais observações são limitadas e o diagnóstico pode ser impreciso. Em geral, uma vez observado um produto defeituoso, é necessário uma inspeção da maior quantidade possível de componentes envolvidos em cada operação, de modo que se possa alimentar a rede Bayesiana com a maior quantidade possível de informação para obter diagnósticos mais precisos.

Uma vez identificada a falha ou o conjunto de falhas, podem ser tomadas medidas com respeito às técnicas de tratamento definidas na seção anterior.

Finalmente é apresentada na Figura 4.14 a seqüência de construção de modelos para FMS considerando não só o comportamento normal do processo produtivo mas também as situações de falha.

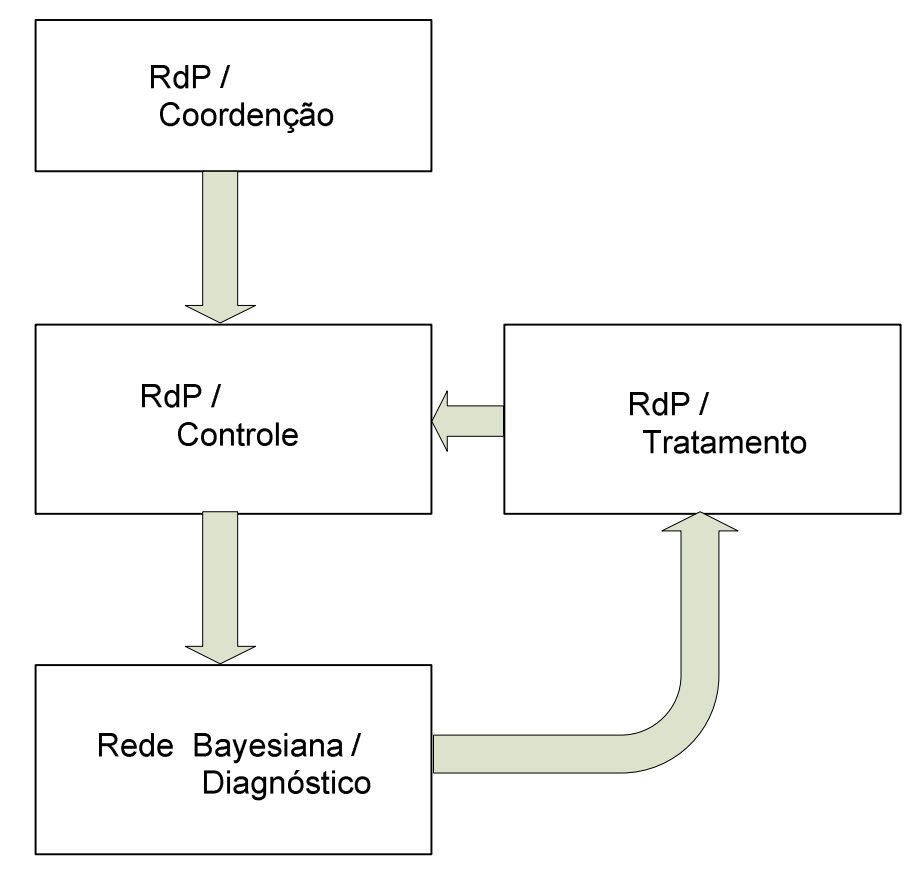

Figura 4.14. Representação da seqüência de construção de modelos. 


\section{EXEMPLO}

No presente capítulo é apresentado um exemplo que permite demonstrar a funcionalidade da presente proposta. Considera-se particularmente o caso que representa o ambiente atual de um processo de montagem automatizado e real, o que possibilita concluir que o procedimento é aplicável a situações reais.

\subsection{SISTEMA FLEXÍVEL DE MONTAGEM}

Com a finalidade de ilustrar a aplicabilidade da presente proposta dentro de um ambiente real, o exemplo aqui apresentado considera um sistema flexível de montagem instalado no laboratório de automação e controle do Departamento de Mecatrônica da Escola Politécnica da USP. Este laboratório apresenta todas as características de um FMS encontrado na indústria.

O sistema flexível de montagem possui duas células de produção e um sistema de transporte (Figura 5.1). A função principal deste sistema flexível é a montagem de um produto composto por uma peça "corpo" (rosa, prata e preto), uma peça "embolo" (preto e prata), uma mola e uma tampa (Figura 5.2). Existem algumas combinações de montagem que têm que ser respeitadas, por exemplo, 'corpo' prata e rosa somente podem ser montadas com um êmbolo preto, enquanto que o corpo prata unicamente pode ser montado com êmbolo prata. 


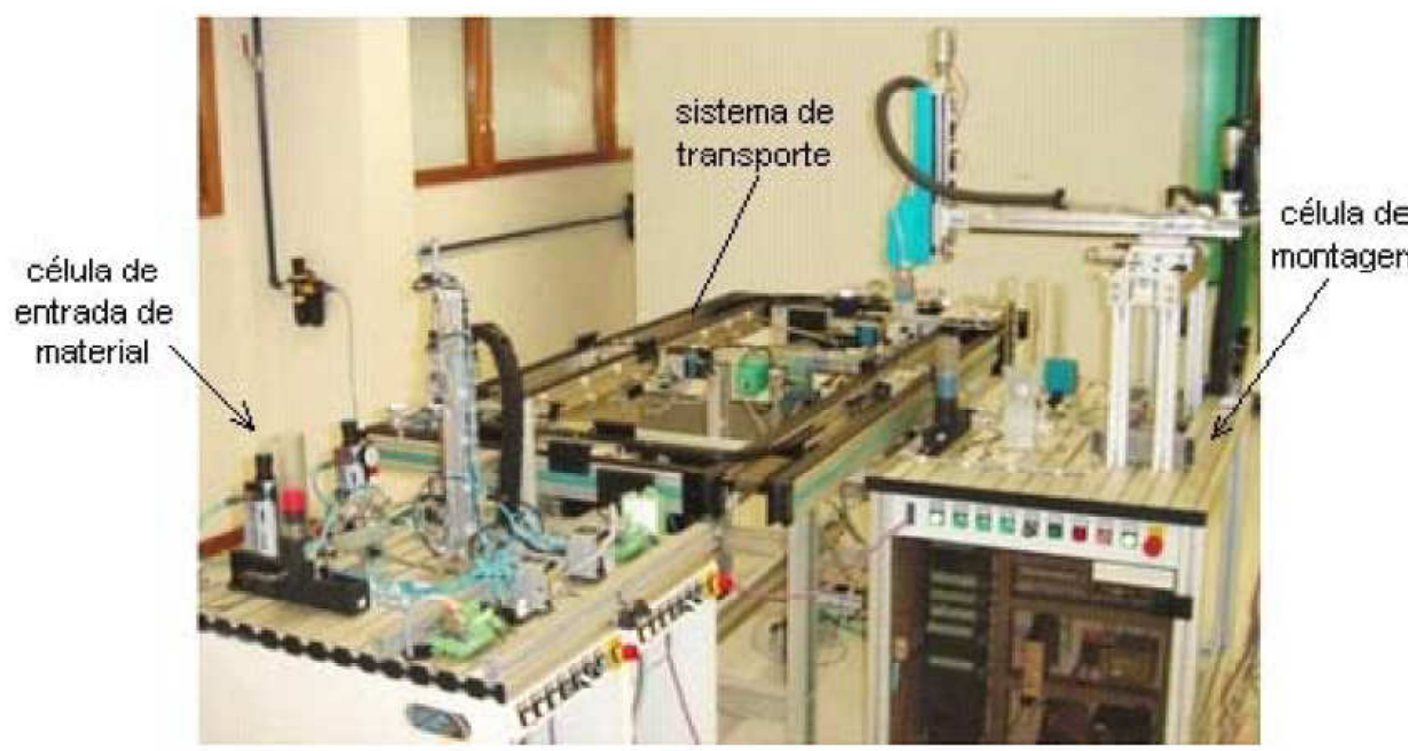

Figura 5.1. Sistema Flexível de Montagem.

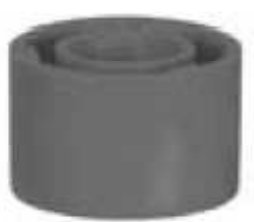

corpo

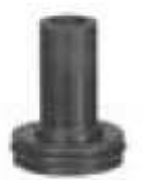

êmbolo

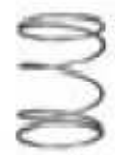

mola

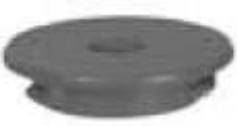

tampa

Figura 5.2. Peças montadas pelo Sistema Flexível de Montagem.

O sistema flexível de montagem é composto por um conjunto de células que incluem (Figura 5.3):

- Uma célula de entrada de Material (I) que é composta por uma estação de alimentação (Su) e uma estação de teste (Te);

- Uma célula de montagem (A) que é composta pela estação de montagem (As) e a estação de Robô (Ro);

- Um sistema flexível de transporte $(T)$ que interliga as células citadas e que transporta o produto final (peça montada) para uma área de armazenagem. 


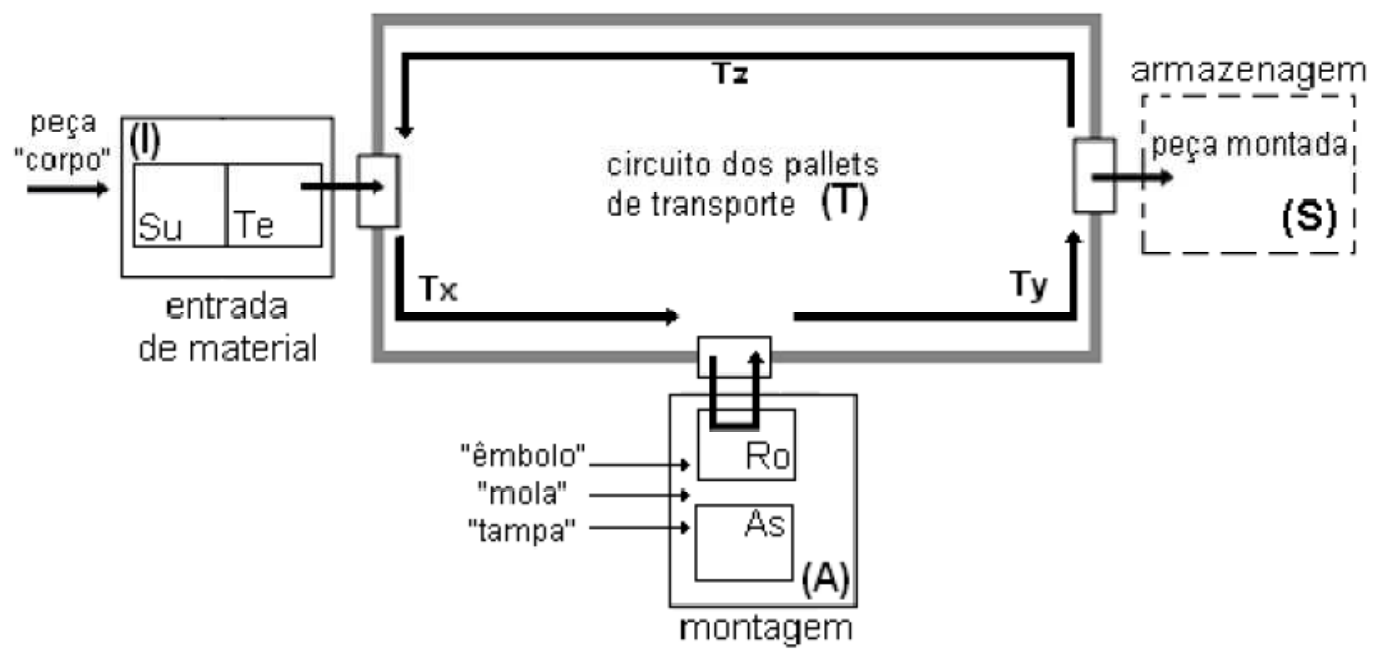

Figura 5.3. Esquema das Estações do Sistema Flexível de Montagem.

Para a identificação dos dispositivos físicos de cada célula, é seguida a norma DIN/ISSO 1219-2:1996-11 (DIN - Deutsches Institut für Normung)/(ISSO International Organization for Standarization) que identifica o dispositivo conforme a seguinte codificação, começando pela extrema esquerda: um número que é designado para um equipamento (objeto de controle), um código designado de acordo ao tipo de dispositivo, e um número seqüencial designado para o dispositivo do equipamento, conforme ilustrado na Figura 5.4. Dentro da nomenclatura adotada, os códigos dos dispositivos, ou letras, seguem a norma IEC 61346-2:2000-12 (IEC International Electrothecnical Commission).

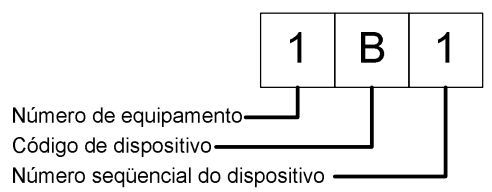

Figura 5.4. Nomenclatura de identificação.

Para os dispositivos pneumáticos é preciso de ar comprimido (ou energia pneumática) com uma pressão mínima de funcionamento de 6 bar (87 PSI). Para os dispositivos eletro-mecânicos é preciso energia de $110 \mathrm{~V} \mathrm{AC}, 22-\mathrm{V} \mathrm{AC}$ e/ou $380 \mathrm{~V}$ AC dependendo do dispositivo. Nas tabelas 5.1, 5.2, 5.3, 5.4, 5.5, 5.6, 5.6, 5.7, 5.8, 
$5.9,5.10,5.11,5.12,5.13,5.14$, e 5.15 estão os principais dispositivos conforme cada uma das estações das células descritas que compõem o sistema flexível de montagem.

Tabela 5.1. Lista dos dispositivos de atuação da estação de alimentação.

\begin{tabular}{|l|l|l|}
\hline Código & Tipo & Função \\
\hline 1_A & Cilindro pneumático & retira peça corpo \\
\hline 2_A & gerador de vácuo & Captura peça corpo \\
\hline 3_A & Cilindro pneumático & transporte peça corpo \\
\hline
\end{tabular}

Tabela 5.2. Lista dos dispositivos de controle da estação de alimentação.

\begin{tabular}{|l|l|l|}
\hline Código & Tipo & Função \\
\hline 1 Y1 & Solenóide & controla válvula $1^{\underline{a}}$ \\
\hline $2 Y 1$ & Solenóide & controla válvula 2 ${ }^{\underline{a}}$ \\
\hline $2 Y 2$ & Solenóide & controla válvula 2 ${ }^{\underline{a}}$ \\
\hline $3 Y 1$ & Solenóide & controla válvula $3^{\underline{a}}$ \\
\hline $3 Y 2$ & Solenóide & controla válvula $3^{\underline{a}}$ \\
\hline
\end{tabular}

Tabela 5.3. Lista dos dispositivos de detecção da estação de alimentação.

\begin{tabular}{|l|l|l|}
\hline Código & Tipo & Função \\
\hline 1B1 & Sensor magnético de proximidade & Detecta pistão recuado \\
\hline 1B2 & Sensor magnético de proximidade & Detecta pistão estendido \\
\hline 1B3 & sensor ótico & Detecta falha de peça corpo \\
\hline 2B1 & Vacuostato & detecta garra ventosa \\
\hline 3S1 & sensor fim de curso & detecta braço basculante \\
\hline 3S2 & sensor fim de curso & detecta braço basculante \\
\hline
\end{tabular}

Tabela 5.4. Lista dos dispositivos de atuação da estação de teste.

\begin{tabular}{|l|l|l|}
\hline Código & Tipo & Função \\
\hline 4_A & Cilindro pneumático & sobe a peça corpo para o teste \\
\hline 5_A & Cilindro pneumático & expulsa peça corpo \\
\hline 6_A & Cilindro pneumático & mede altura da peça corpo \\
\hline
\end{tabular}

Tabela 5.5. Lista dos dispositivos de controle da estação de teste.

\begin{tabular}{|c|c|c|}
\hline Código & Tipo & Função \\
\hline $4 \mathrm{Y} 1$ & Solenóide & controla válvula $4^{\mathrm{a}}$ \\
\hline $4 Y 2$ & Solenóide & controla válvula $4^{\underline{a}}$ \\
\hline $5 Y 1$ & Solenóide & controla válvula $5^{\mathrm{a}}$ \\
\hline $6 Y 1$ & Solenóide & controla válvula $6^{a}$ \\
\hline
\end{tabular}


Tabela 5.6. Lista dos dispositivos de detecção da estação de teste.

\begin{tabular}{|l|l|l|}
\hline Código & Tipo & Função \\
\hline 4B1 & Sensor magnético de proximidade & deteta modulo elevador \\
\hline 4B2 & Sensor magnético de proximidade & deteta modulo elevador \\
\hline 4B3 & sensor indutivo & deteta peça corpo prata \\
\hline 4B4 & sensor capacitivo & deteta peça corpo preta, prata e rosa \\
\hline 4B5 & sensor ótico & deteta peça corpo prata e rosa \\
\hline 5B1 & Sensor magnético de proximidade & deteta pistão recuado \\
\hline 6B1 & Sensor magnético de proximidade & deteta pistão estendido \\
\hline 6B2 & potenciômetro de deslocamento lineal & Confere altura do corpo \\
\hline
\end{tabular}

Tabela 5.7. Lista dos dispositivos de atuação da estação de montagem.

\begin{tabular}{|l|l|l|}
\hline Código & Tipo & Função \\
\hline 12_A & Cilindro pneumático & retém peça corpo para montagem \\
\hline 13_A & Cilindro pneumático & fornece embolo \\
\hline 14_A & Cilindro pneumático & fornece mola \\
\hline 15_A & Cilindro pneumático & fornece tampa \\
\hline
\end{tabular}

Tabela 5.8. Lista dos dispositivos de controle da estação de montagem.

\begin{tabular}{|l|l|l|}
\hline Código & Tipo & Função \\
\hline $12 Y 1$ & Solenóide & controla válvula $12^{\underline{a}}$ \\
\hline $13 Y 1$ & Solenóide & controla válvula $13^{\underline{a}}$ \\
\hline $13 Y 2$ & Solenóide & controla válvula $13^{\underline{a}}$ \\
\hline $14 Y_{1}$ & Solenóide & controla válcula $14^{\underline{a}}$ \\
\hline $15 Y 1$ & Solenóide & controla válvula $15^{\underline{a}}$ \\
\hline $15 Y 2$ & Solenóide & controla válvula $15^{\underline{a}}$ \\
\hline
\end{tabular}

Tabela 5.9. Lista dos dispositivos de detecção da estação de montagem.

\begin{tabular}{|l|l|l|}
\hline Código & Tipo & Função \\
\hline 13B1 & Sensor magnético de proximidade & detecta cilindro giratório \\
\hline 13B2 & Sensor magnético de proximidade & detecta cilindro giratório \\
\hline 13B3 & sensor ótico & detecta presença de embolo \\
\hline 14B1 & Sensor magnético de proximidade & detecta pistão da mola \\
\hline 14S2 & sensor fim de curso & detecta pistão da mola \\
\hline 15B1 & Sensor magnético de proximidade & detecta pistão da tampa \\
\hline 15B2 & Sensor magnético de proximidade & detecta pistão da tampa \\
\hline 15B3 & sensor ótico & detecta pistão da tampa \\
\hline
\end{tabular}

Tabela 5.10. Lista dos dispositivos de atuação do Robô. 


\begin{tabular}{|l|l|l|}
\hline Código & Tipo & Função \\
\hline 7_A & cilindro pneumático & alimenta pallet e peças para montagem \\
\hline 8_A & cilindro pneumático & gira a garra \\
\hline 9_A & braço robótico em $X$ & movimenta o braço no eixo $X$ \\
\hline 10_A & braço robótico em $\mathrm{Y}$ & movimenta o braço no eixo $\mathrm{Y}$ \\
\hline 11_A & braço robótico em $Z$ & movimenta o braço no eixo $Z$ \\
\hline
\end{tabular}

Tabela 5.11. Lista dos dispositivos de controle do Robô.

\begin{tabular}{|c|c|c|}
\hline Código & Tipo & Função \\
\hline $7 Y 1$ & Válvula solenóide & controla válvula $7^{a} \underline{a}$ \\
\hline $7 Y 2$ & Válvula solenóide & controla válvula $7^{a \underline{a}}$ \\
\hline $8 Y 1$ & Válvula solenóide & controla válvula $8^{\underline{a}}$ \\
\hline $8 Y 2$ & Válvula solenóide & controla válvula $8^{\underline{a}}$ \\
\hline $9 \mathrm{M} 1$ & servo-motor & altera giro do motor $9 \mathrm{~A}$ sentido horário \\
\hline $9 \mathrm{M} 2$ & servo-motor & altera giro do motor $9 \mathrm{~A}$ sentido anti-horário \\
\hline $10 \mathrm{M} 1$ & servo-motor & altera giro do motor $10 \mathrm{~A}$ sentido horário \\
\hline $10 \mathrm{M} 2$ & servo-motor & altera giro do motor $10 \mathrm{~A}$ sentido anti-horário \\
\hline $11 \mathrm{M} 1$ & servo-motor & altera giro do motor $11 \mathrm{~A}$ sentido horário \\
\hline $11 \mathrm{M} 2$ & servo-motor & altera giro do motor $11 \mathrm{~A}$ sentido anti-horário \\
\hline
\end{tabular}


Tabela 5.12. Lista dos dispositivos de detecção do Robô.

\begin{tabular}{|l|l|l|}
\hline Código & Tipo & Função \\
\hline 7B1 & Sensor magnético de proximidade & detecta garra aberta \\
\hline 7B2 & Sensor magnético de proximidade & detecta garra fechada \\
\hline 8B1 & Sensor magnético de proximidade & detecta giro da garra \\
\hline 8B2 & Sensor magnético de proximidade & detecta giro da garra \\
\hline 9D2 & encoder incremental & detecta posição do braço em $X$ \\
\hline 10D2 & encoder incremental & detecta posição do braço em $Y$ \\
\hline 9D3 & encoder incremental & detecta posição do braço em $X$ \\
\hline 10D3 & encoder incremental & detecta posição do braço em $Y$ \\
\hline 9D4 & encoder incremental & detecta posição do braço em $X$ \\
\hline 10D4 & encoder incremental & detecta posição do braço em $Y$ \\
\hline 9D5 & encoder incremental & detecta posição do braço em $X$ \\
\hline 10D5 & encoder incremental & detecta posição do braço em $Y$ \\
\hline 9D6 & encoder incremental & detecta posição do braço em $X$ \\
\hline 10D6 & encoder incremental & detecta posição do braço em $Y$ \\
\hline 9D7 & encoder incremental & detecta posição do braço em $X$ \\
\hline 10D7 & encoder incremental & detecta posição do braço em $Y$ \\
\hline 9D8 & encoder incremental & detecta posição do braço em $X$ \\
\hline 10D8 & encoder incremental & detecta posição do braço em $Y$ \\
\hline 9D9 & encoder incremental & detecta posição do braço em $X$ \\
\hline 10D9 & encoder incremental & detecta posição do braço em $Y$ \\
\hline 9D10 & encoder incremental & detecta posição do braço em $X$ \\
\hline 10D10 & encoder incremental & detecta posição do braço em $Y$ \\
\hline 9D11 & encoder incremental & detecta posição do braço em $X$ \\
\hline 10D11 & encoder incremental & detecta posição do braço em $Y$ \\
\hline 11B1 & Sensor magnético de proximidade & detecta posição do braço em $Z$ \\
\hline 11B2 & Sensor magnético de proximidade & detecta posição do braço em $Z$ \\
\hline 11B3 & Sensor magnético de proximidade & detecta posição do braço em $Z$ \\
\hline 11B4 & Sensor magnético de proximidade & detecta posição do braço em $Z$ \\
\hline 11S1 & Sensor fim de curso & detecta posição do braço em $Z$ \\
\hline 11S2 & Sensor fim de curso & detecta posição do braço em $Z$ \\
\hline
\end{tabular}


Tabela 5.13. Lista dos dispositivos de atuação da estação de transporte.

\begin{tabular}{|l|l|l|}
\hline Código & Tipo & Função \\
\hline 16_A & cilindro pneumático & detém pallet na primeira plataforma \\
\hline 17_A & cilindro pneumático & eleva pallet para verificar presença \\
\hline 18_A & cilindro pneumático & detém pallet na primeira plataforma \\
\hline 19_A & cilindro pneumático & detém pallet na segunda plataforma \\
\hline 20_A & cilindro pneumático & eleva pallet para verificar presença \\
\hline 21_A & cilindro pneumático & detém pallet na segunda plataforma \\
\hline 22_A & cilindro pneumático & detém pallet na terceira plataforma \\
\hline 23_A & cilindro pneumático & eleva pallet para verificar presença \\
\hline 24_A & cilindro pneumático & detém pallet na terceira plataforma \\
\hline 25_A & esteira transportadora de pallets & desloca os pallets \\
\hline
\end{tabular}

Tabela 5.14. Lista dos dispositivos de controle da estação de transporte.

\begin{tabular}{|l|l|l|}
\hline Código & Tipo & Função \\
\hline $16 Y 1$ & Solenóide & controla válvula 16 \\
\hline $17 Y 1$ & Solenóide & controla válvula 17 \\
\hline $18 Y 1$ & Solenóide & controla válvula 18 \\
\hline $19 Y 1$ & Solenóide & controla válvula 19 \\
\hline 20 Y1 & Solenóide & controla válvula 20 \\
\hline $21 Y 1$ & Solenóide & controla válvula 21 \\
\hline $22 Y 1$ & Solenóide & controla válvula 22 \\
\hline $23 Y 1$ & Solenóide & controla válvula 23 \\
\hline $24 Y 1$ & Solenóide & controla válvula 24 \\
\hline $25 \mathrm{M} 1$ & motor trifásico & desloca pallet \\
\hline $25 \mathrm{M} 2$ & motor trifásico & desloca pallet \\
\hline $25 \mathrm{M} 3$ & motor trifásico & desloca pallet \\
\hline
\end{tabular}


Tabela 5.15. Lista dos dispositivos de detecção da estação de transporte.

\begin{tabular}{|l|l|l|}
\hline Código & Tipo & Função \\
\hline 16B1 & Sensor magnético de proximidade & detecta pallet na primeira plataforma \\
\hline 16B2 & Sensor magnético de proximidade & detecta pallet passando a primeira plataforma \\
\hline 17B1 & sensor indutivo & detecta primeira plataforma \\
\hline 17B2 & sensor capacitivo & detecta primeira plataforma acima \\
\hline 17B3 & sensor capacitivo & detecta pallet na primeira plataforma \\
\hline 17B4 & sensor indutivo & identifica pallet \\
\hline 18B1 & Sensor magnético de proximidade & detecta pallet saíndo da primeira plataforma \\
\hline 19B1 & Sensor magnético de proximidade & detecta pallet na segunda plataforma \\
\hline 19B2 & Sensor magnético de proximidade & detecta pallet passando a segunda plataforma \\
\hline 20B1 & sensos indutivo & detecta segunda plataforma \\
\hline 20B1 & sensor capacitivo & detecta segunda plataforma acima \\
\hline 20B3 & sensor capacitivo & detecta pallet na segunda plataforma \\
\hline 20B4 & sensor capacitivo & identifica pallet \\
\hline 21B1 & Sensor magnético de proximidade & detecta pallet saíndo da segunda plataforma \\
\hline 22B1 & Sensor magnético de proximidade & detecta pallet na terceira plataforma \\
\hline 22B2 & Sensor magnético de proximidade & detecta pallet passando a terceira plataforma \\
\hline 23B1 & sensor indutivo & detecta terceira plataforma \\
\hline 23B2 & sensor capacitivo & detecta terceira plataforma acima \\
\hline 23B3 & sensor capacitivo & detecta pallet na terceira plataforma \\
\hline 23B4 & sensor capacitivo & identifica pallet \\
\hline 24B1 & Sensor magnético de proximidade & detecta pallet saíndo da terceira plataforma \\
\hline & &
\end{tabular}

\subsection{Construção do Modelo do Processo Produtivo}

Conforme descrito no item 4.1 o primeiro passo do procedimento proposto é a construção do modelo do processo produtivo que é realizado em duas etapas, uma considerando o a descrição conceitual do sistema onde se gera o modelo em PFS e uma outra baseada no funcionamento dinâmico onde se gera o modelo em MFG.

Na Fig. 5.4 é apresentada a rede de coordenação descrita em PFS do sistema flexível de montagem. 


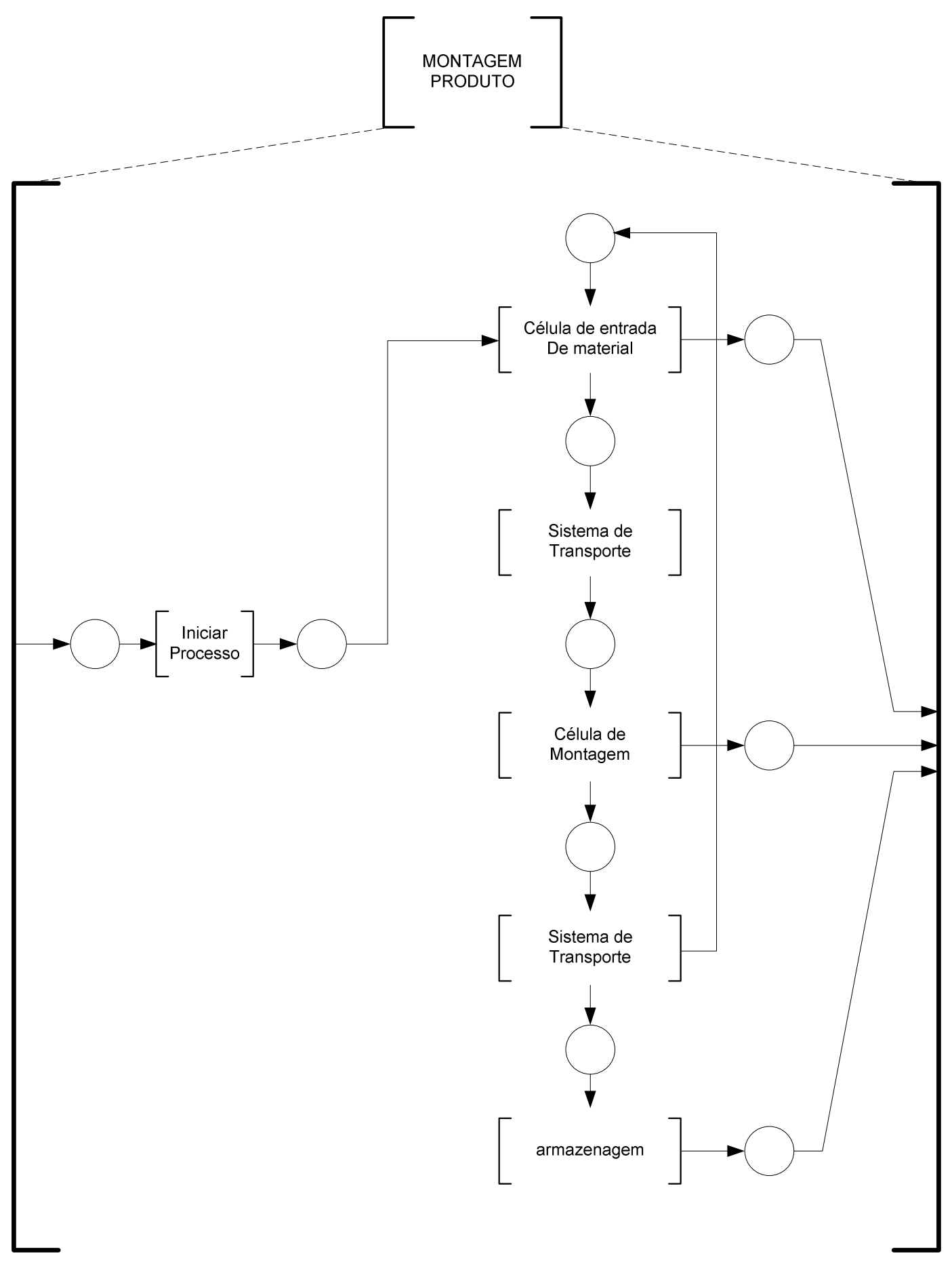

Figura 5.4. Rede de coordenação em PFS do Sistema flexível de montagem.

Na Fig. 5.5 é apresentada a rede de coordenação da célula de entrada de material. Esta rede é composta pelas atividades de alimentação da peça corpo do produto e a atividade de teste respectiva. Na Fig. 5.6 é apresentado a rede de coordenação da 
célula de entrada de material onde são representadas as atividades de retirada de peça corpo da estação de teste e o respectivo transporte.

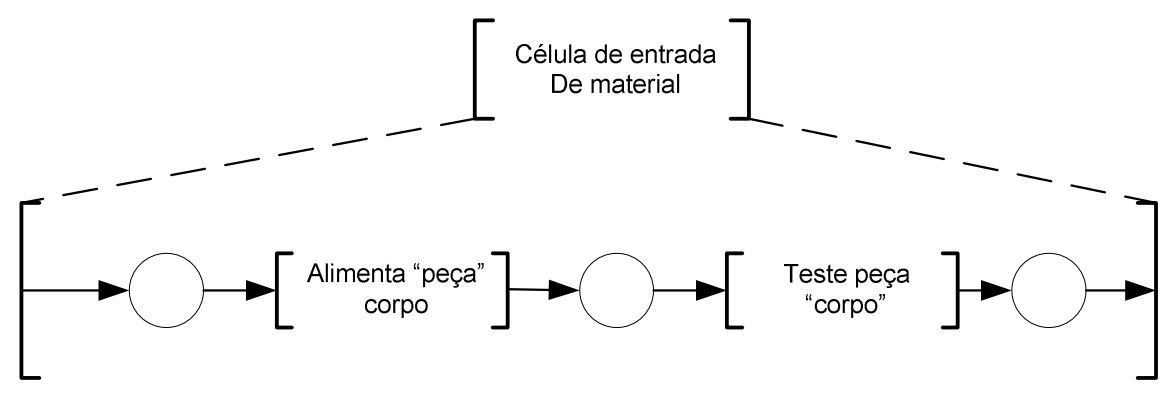

Figura 5.5. Rede de Coordenação em PFS da célula de entrada de material (I).

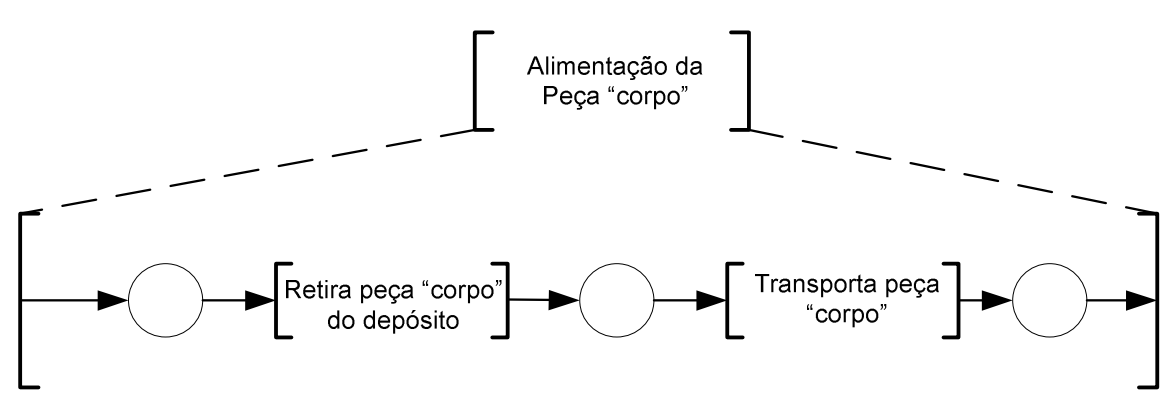

Figura 5.6. Rede de Coordenação em PFS da estação de alimentação (Su).

A partir da Fig. 5.7 são detalhadas as atividades da atividade representada na Fig. 5.6 "Retira Peça Corpo". As atividades de este processo incluem a movimentação do braço da estação de teste e a retirada do pino de retenção da peça.

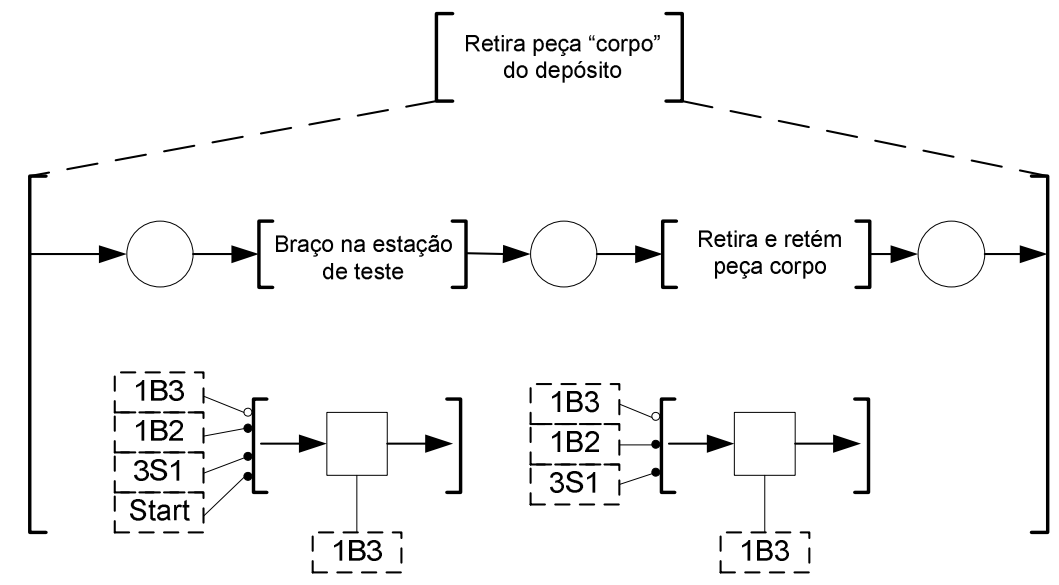

Figura 5.7. Rede de Coordenação em PFS da estação de alimentação (Su). 


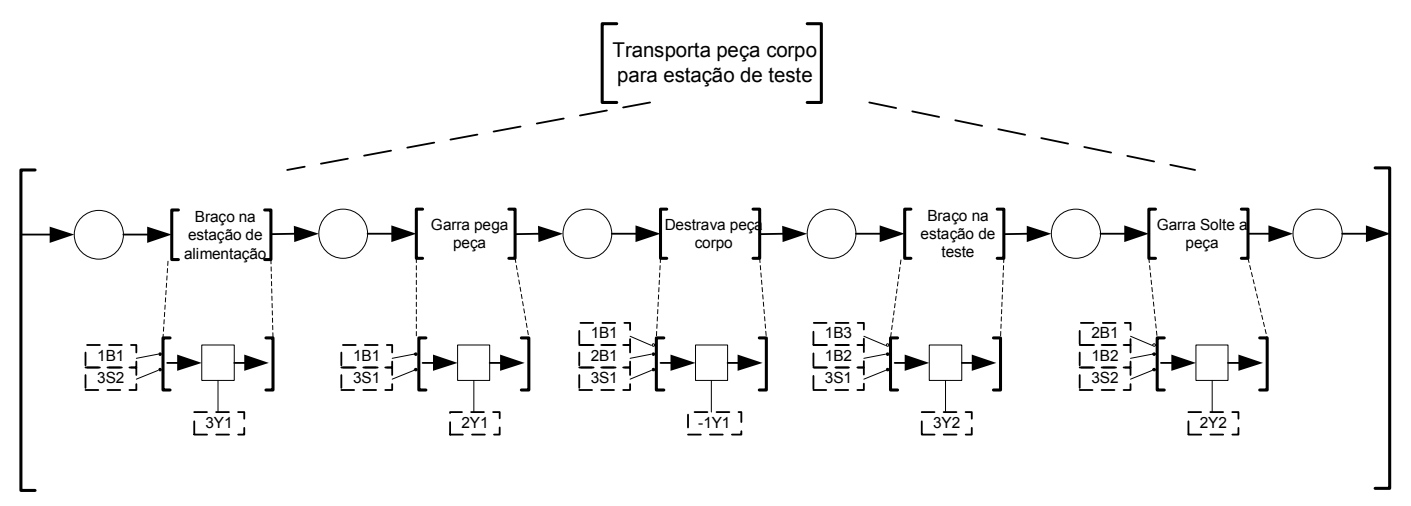

Figura 5.8. Rede de Coordenação em PFS da estação de alimentação (Su).

$\mathrm{Na}$ Fig. 5.8 são detalhadas as operações referentes à atividade "transporta peça corpo". Estão incluídas as operações de movimentação do braço robótico e da garra.

Na Fig. 5.9 é apresentada a rede no nível de coordenação da estação de teste. Nesta rede estão incluídas as atividades de identificação do tipo de peça (preto, metal ou rosa) e a verificação da altura da peça. Na Fig. 5.10 é apresentada o a rede que representa a operação do Box de identificação do corpo do produto. São detalhadas as atividades de identificação da peça preta, metal e rosa considerando o funcionamento dos sensores indutivo e capacitivo.

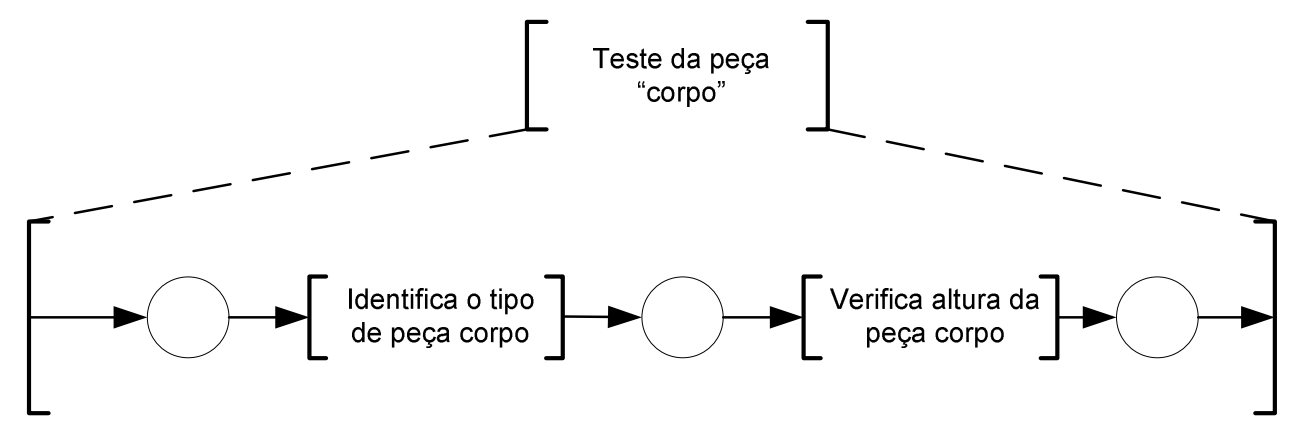

Figura 5.9. Rede de Coordenação em PFS da estação de teste (Te). 


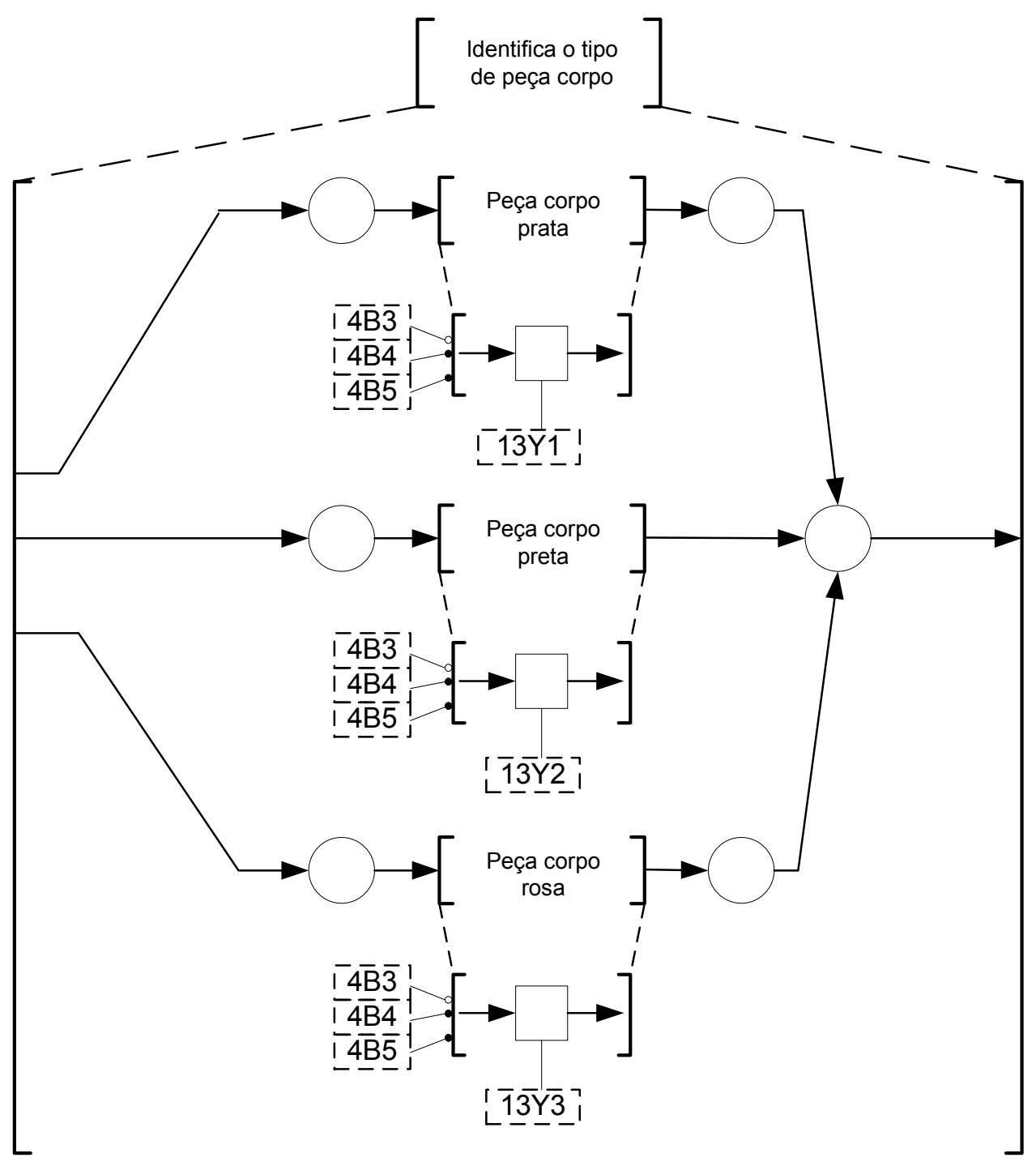

Figura 5.10. Rede de Coordenação em PFS da estação de teste (Te).

A rede de coordenação da estação do Robô está representada na Fig. 5.11. São incluídas as atividades da movimentação do braço robótico para pegar o pallet da esteira, a liberação da peça por parte do braço no equipamento de fixação, o transporte da peça corpo do pallet e a movimentação respectiva até o ponto de retenção. Neste ponto são detalhadas as atividades de alimentação do embolo no corpo, da mola e da tampa do produto. Finalmente estão representadas a devolução do produto ao pallet e do pallet à esteira de movimentação. 


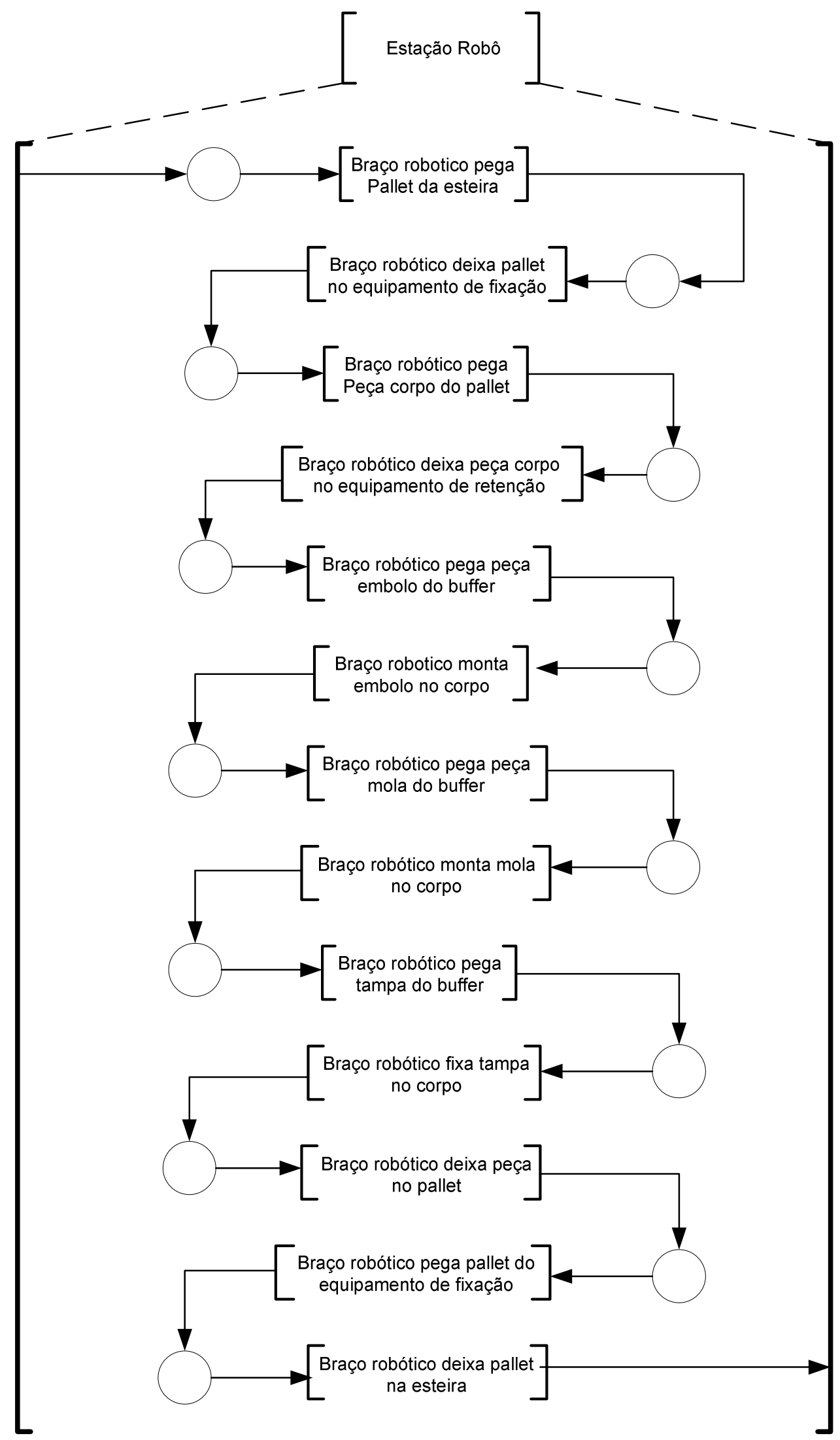

Figura 5.11. Rede de Coordenação em PFS da estação do Robô (Ro). 
É apresentada na Fig. 5.12 a rede de coordenação da estação de montagem, incluindo as atividades de retenção da peça corpo e as movimentações das peças embolo, mola e tampa. Já na Fig. 5.13, 5.14 e 5.15 estão representados os refinamentos dos Boxes "Prove Peça Embolo" "Prove Peça Mola" e "Prove Peça Tampa" respectivamente.

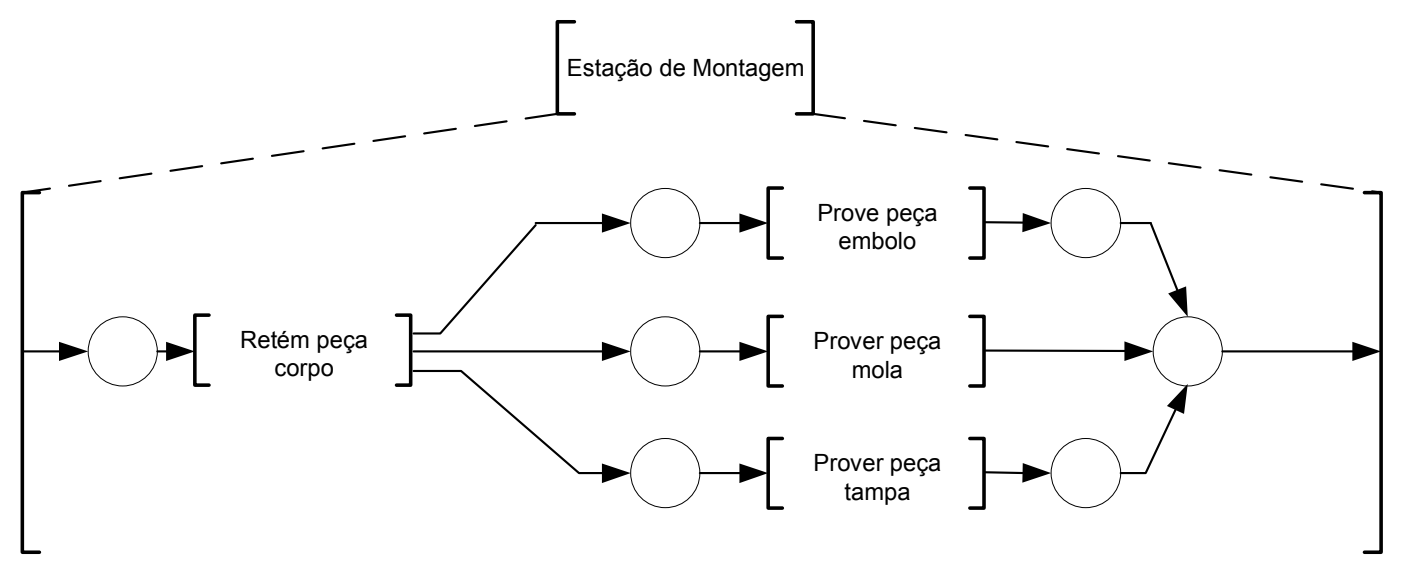

Figura 5.12. Rede de Coordenação em PFS da estação de Montagem (As).

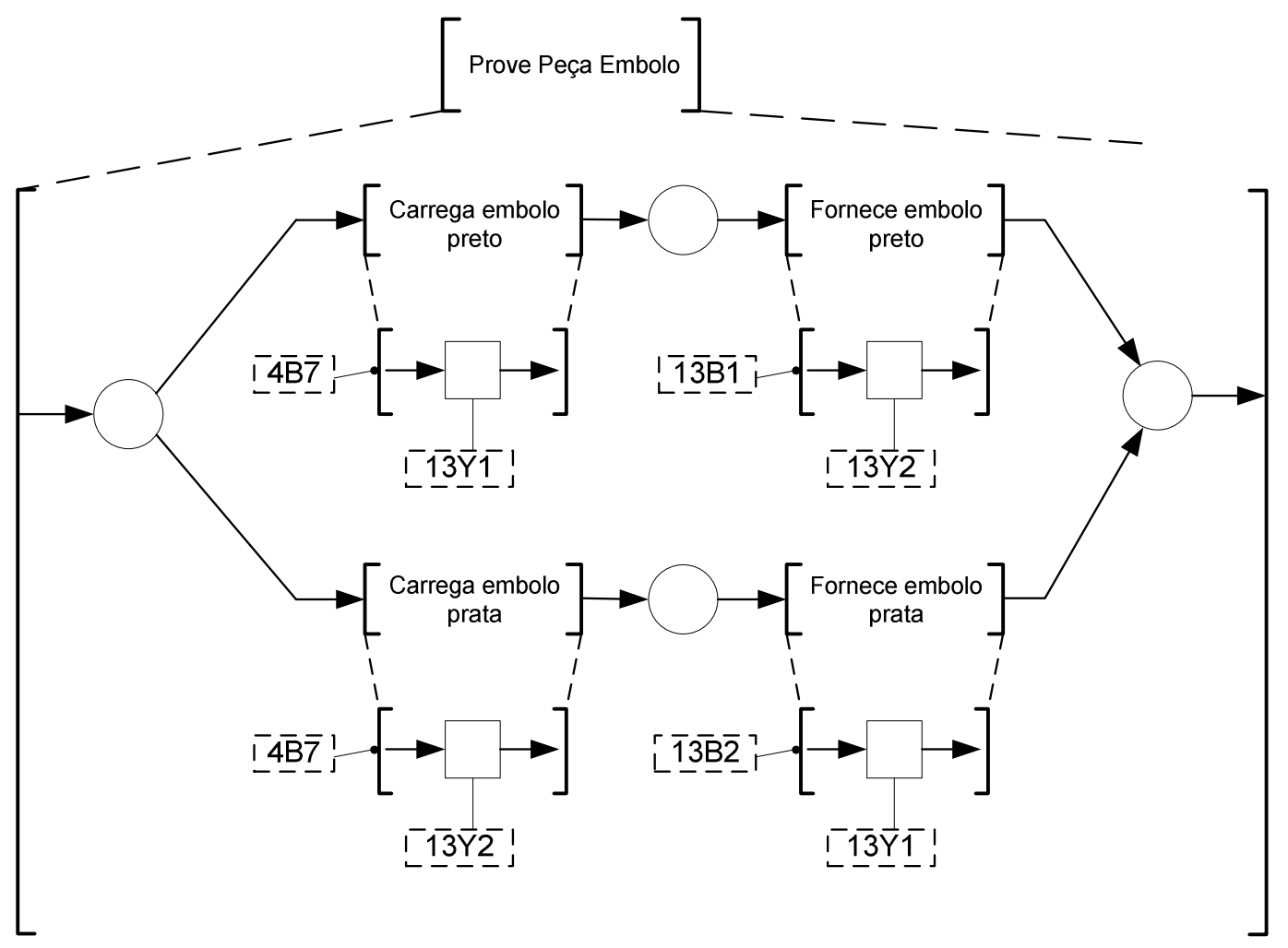


Figura 5.13. Rede de Coordenação em PFS da estação de Montagem (As).

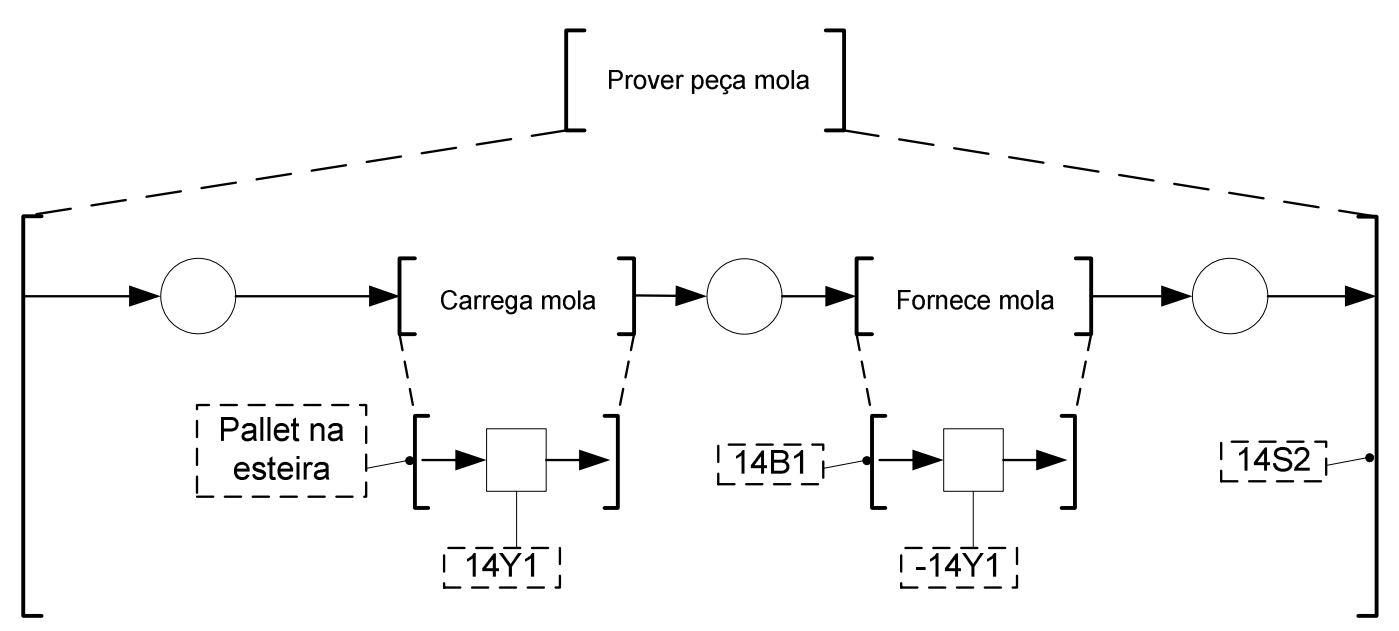

Figura 5.14. Rede de Coordenação em PFS da estação de Montagem (As).

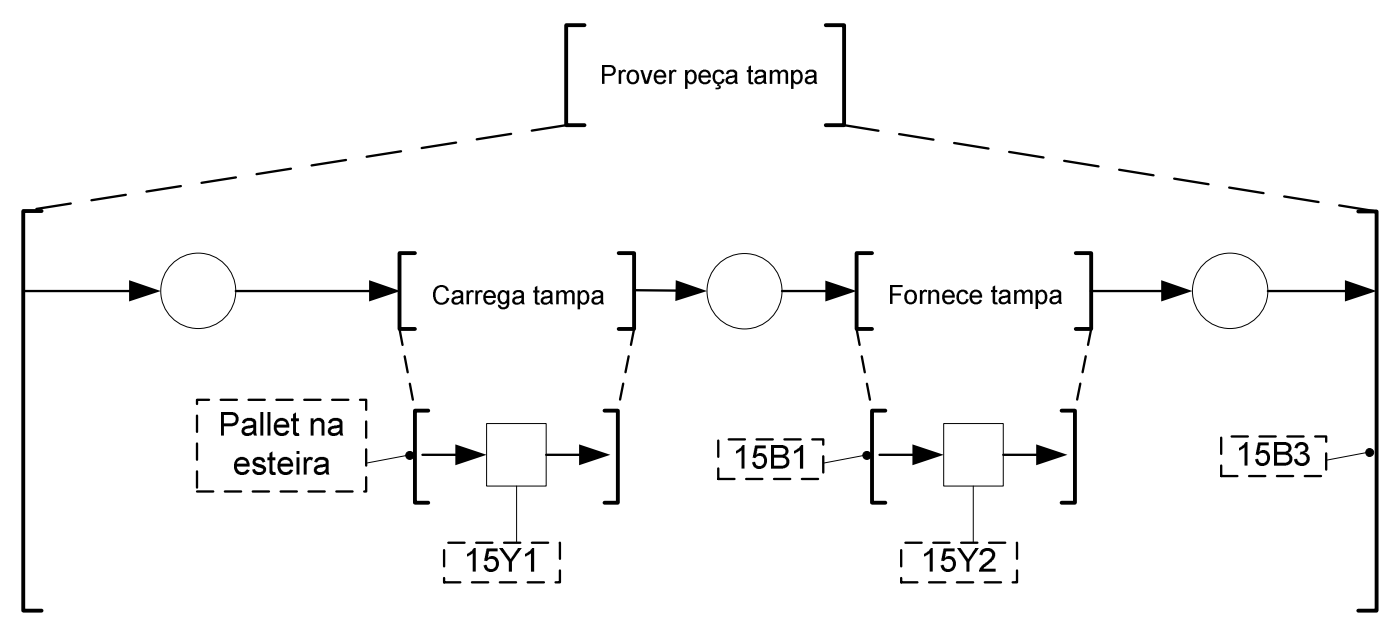

Figura 5.15. Rede de Coordenação em PFS da estação de Montagem (As).

$\mathrm{Na}$ Fig. 5.16 é apresentada a rede de coordenação em PFS da estação de transporte, que inclui as atividades de recebimento de pallet, identificação do pallet, carregamento e descarregamento de peças, e envio de pallet à estação seguinte. $\mathrm{Na}$ Fig. 5.17 encontra-se detalhada a atividade de recebimento de pallet enquanto que na Fig. 5.8 encontra-se detalhada a operação de carregamento e descarregamento de peças. 


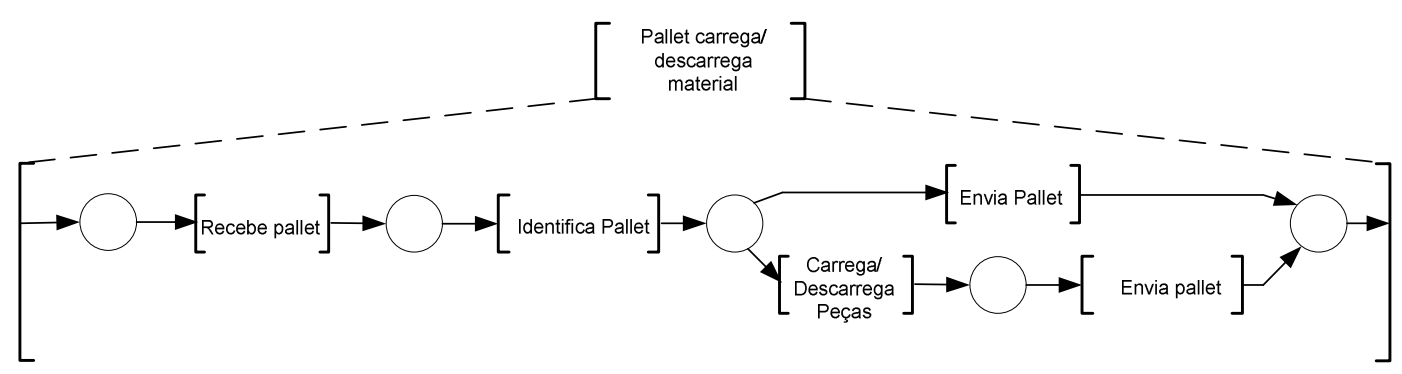

Figura 5.16. Rede de Coordenação em PFS da estação de Transporte(T).

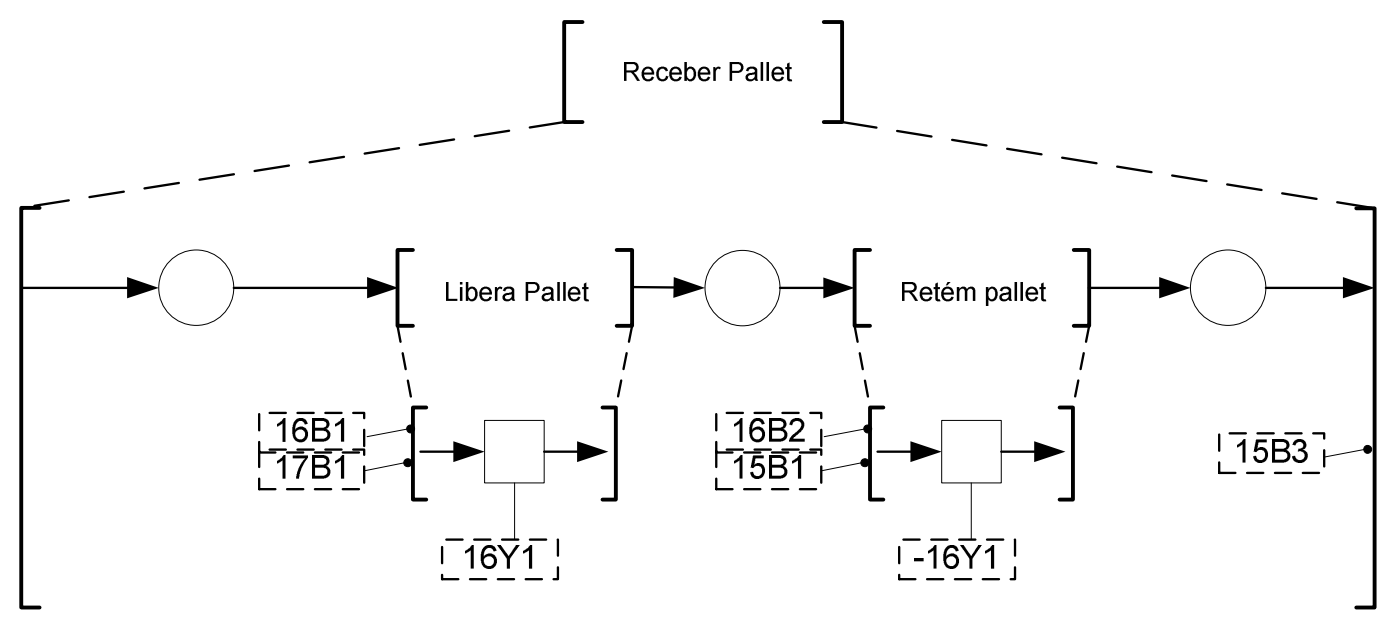

Figura 5.17. Rede de Coordenação em PFS da estação de Transporte(T).

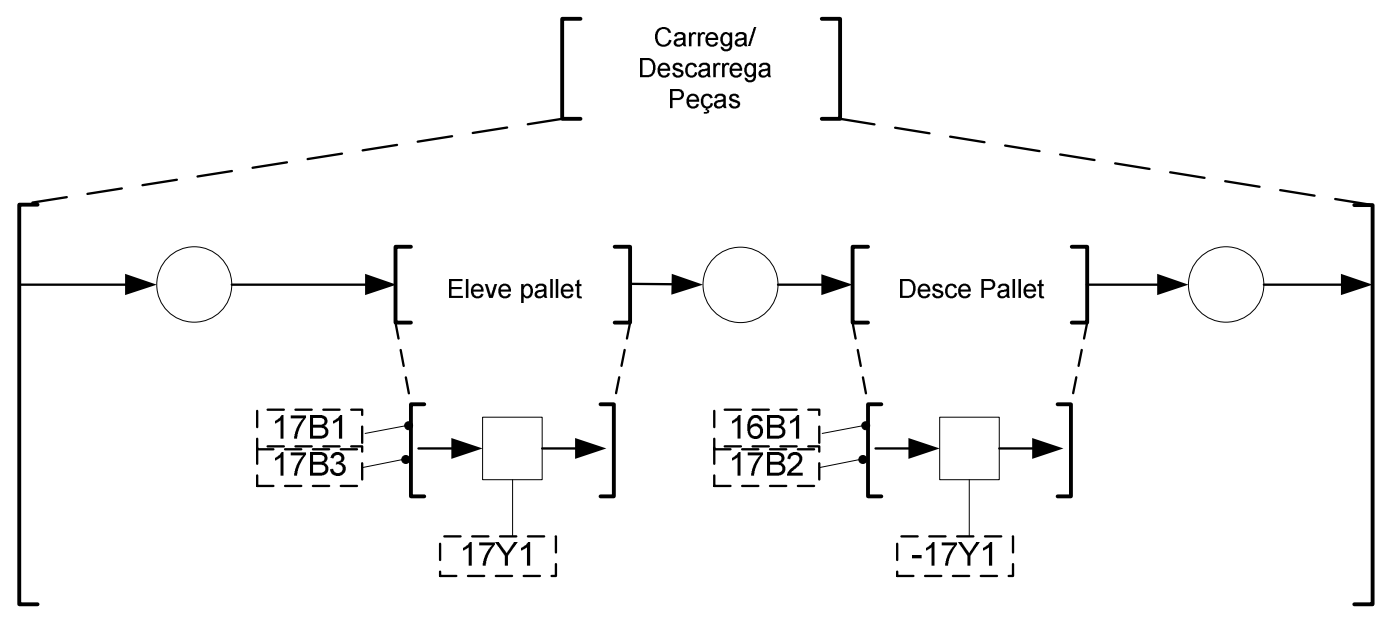

Figura 5.18. Rede de Coordenação em PFS da estação de Transporte(T). 
A partir da Fig. 5.19 até a Fig. 5.34 são apresentadas as redes de controle local descritas mediante redes MFG. A presença de peça na área de carregamento envia sinal ao solenóide que ativa o processo de carregamento mediante o braço na estação de teste através do solenóide $3 \mathrm{Y}$. O solenóide 2 Y liga/desliga o gerador de vácuo para segurar a peça a ser transportada. A operação 'alimenta peça' recebe sinais do solenóide $1 Y 1$ que identifica presença da peça na área de alimentação.

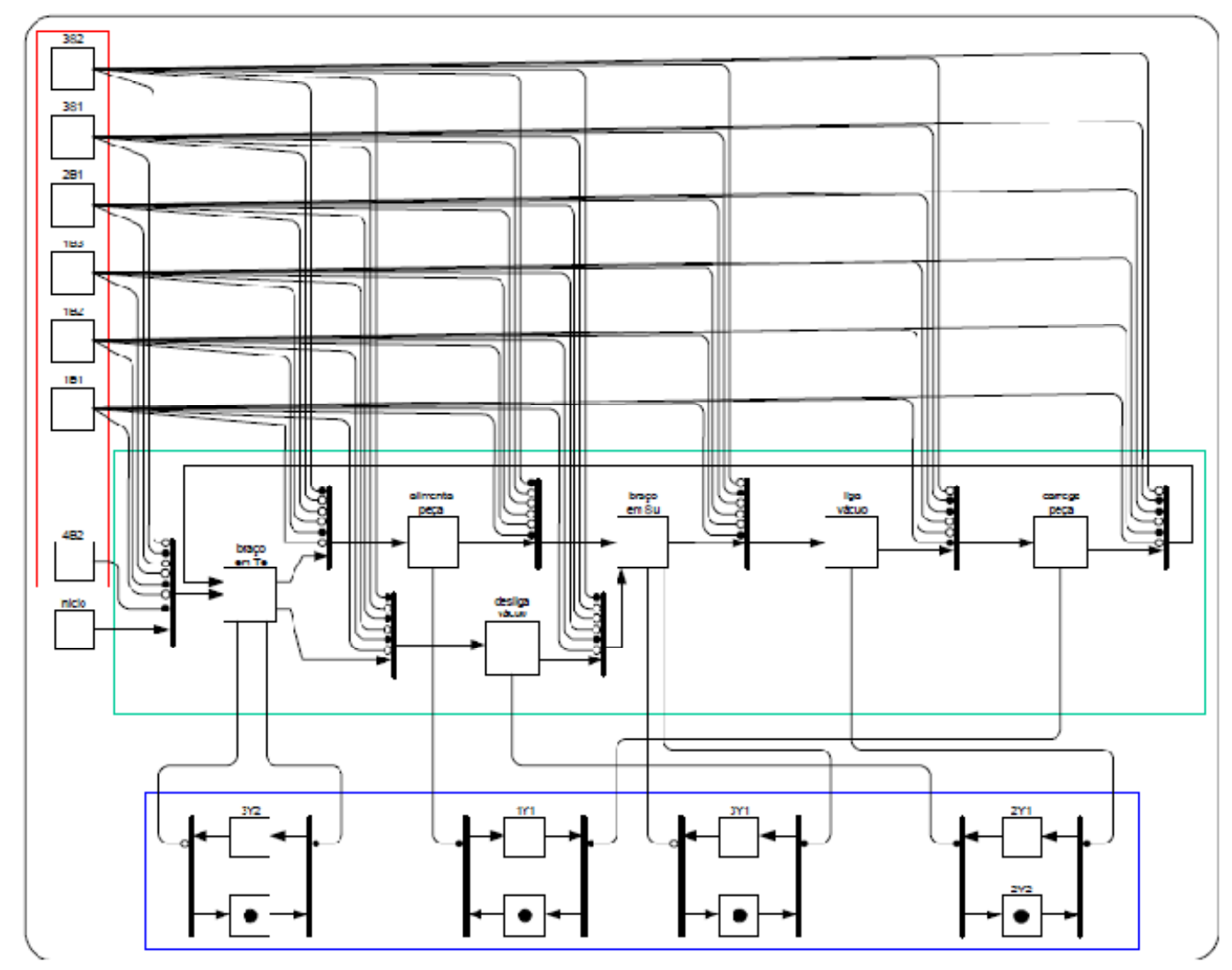

Figura 5.19. Rede de Controle Local da estação de Alimentação (Su).

Na Fig. 5.20 é apresentada a rede de controle local da estação de teste. O solenóide $4 Y$ ativa os atuadores respectivos que sobem o elevador até o ponto de teste de altura da peça. $\mathrm{O}$ solenóide $6 \mathrm{Y}$ controla o sistema de elevação do medidor de altura e o solenóide $5 \mathrm{Y}$ controle o cilindro que empurra a peça para a área de carregamento da peça no pallet. A presença das peças em cada operação da rede é 
detectada mediante o sensor fim de curso 351 , o sensores magnéticos de proximidade 6B1, 4B1, 4B2 e 5B1 e o sensor potenciômetro de deslocamento $6 \mathrm{~B} 2$.

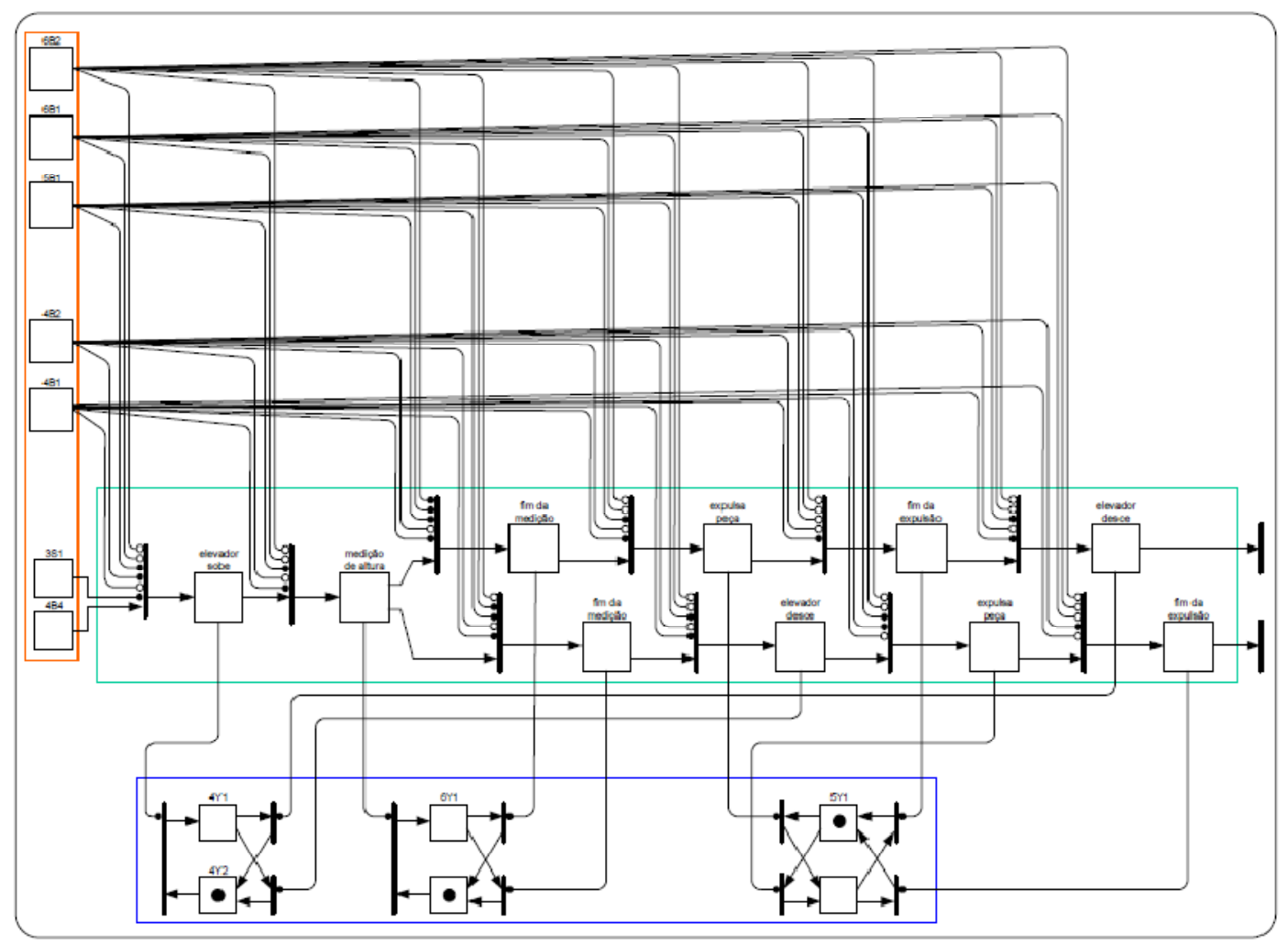

Figura 5.20. Rede de Controle Local da estação de Teste (Te).

Na Fig. 5.21 detalha-se a rede de controle local da estação de robô na atividade de pegar o pallet. Os servo-motores $11 \mathrm{M} 1$ e $11 \mathrm{M} 2$ são ativados para a movimentação do braço robótico, enquanto que a válvula solenóide $7 Y$ controla a apertura e fechamento da garra do robô. O servo-motor $10 \mathrm{M}$ controla o deslocamento do braço no eixo $\mathrm{X}$ e o servo-motor $9 \mathrm{M}$ controle o deslocamento do braço no eixo $\mathrm{Y}$.

Na Fig. 5.22 encontra-se detalhada a rede de controle local na operação transportar pallet pelo robô. Os atuadores que atuam na movimentação do pallet atuam também nesta operação. 


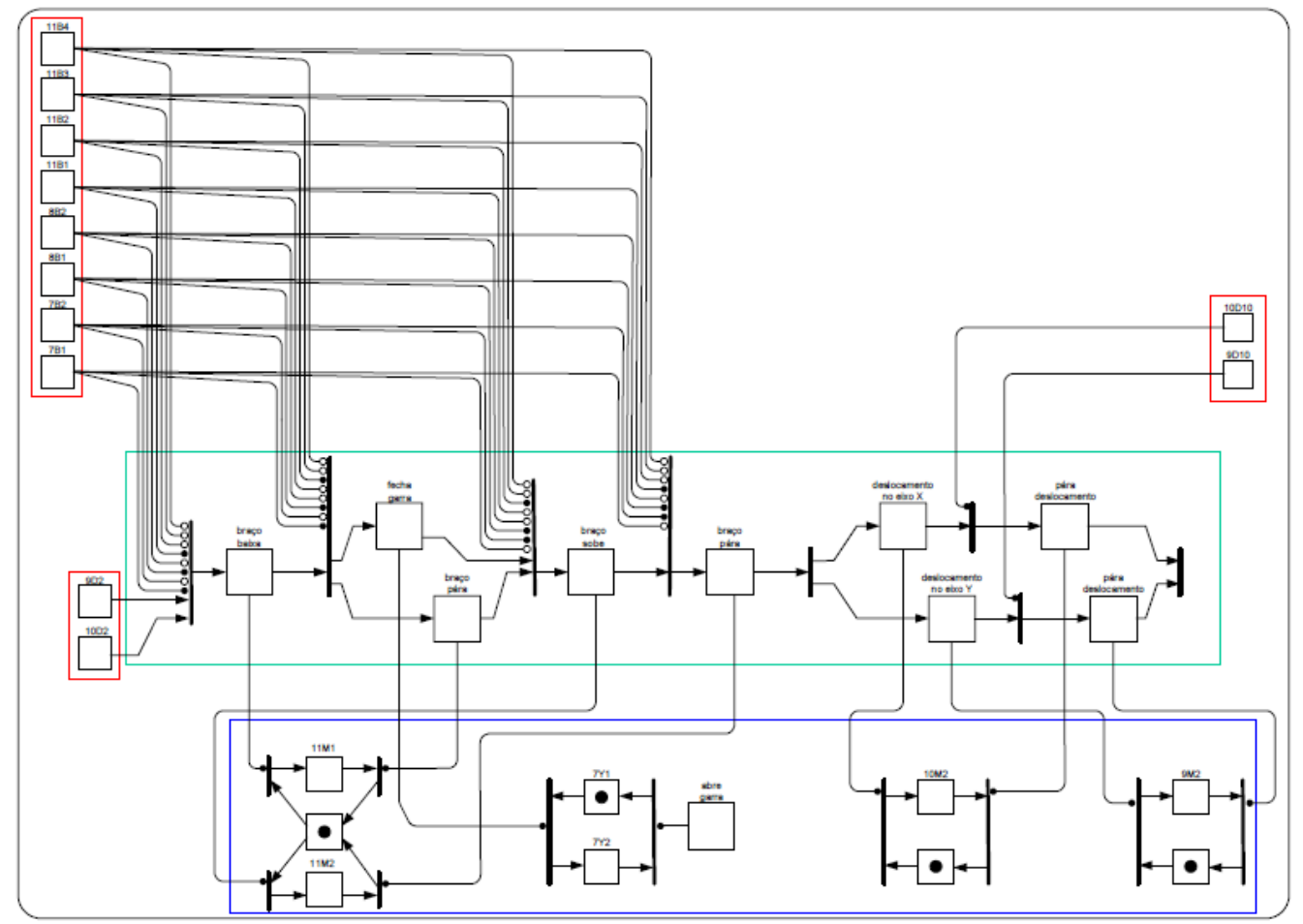

Figura 5.21. Rede de Controle Local da estação de Robô na atividade "pegar pallet" (Ro).

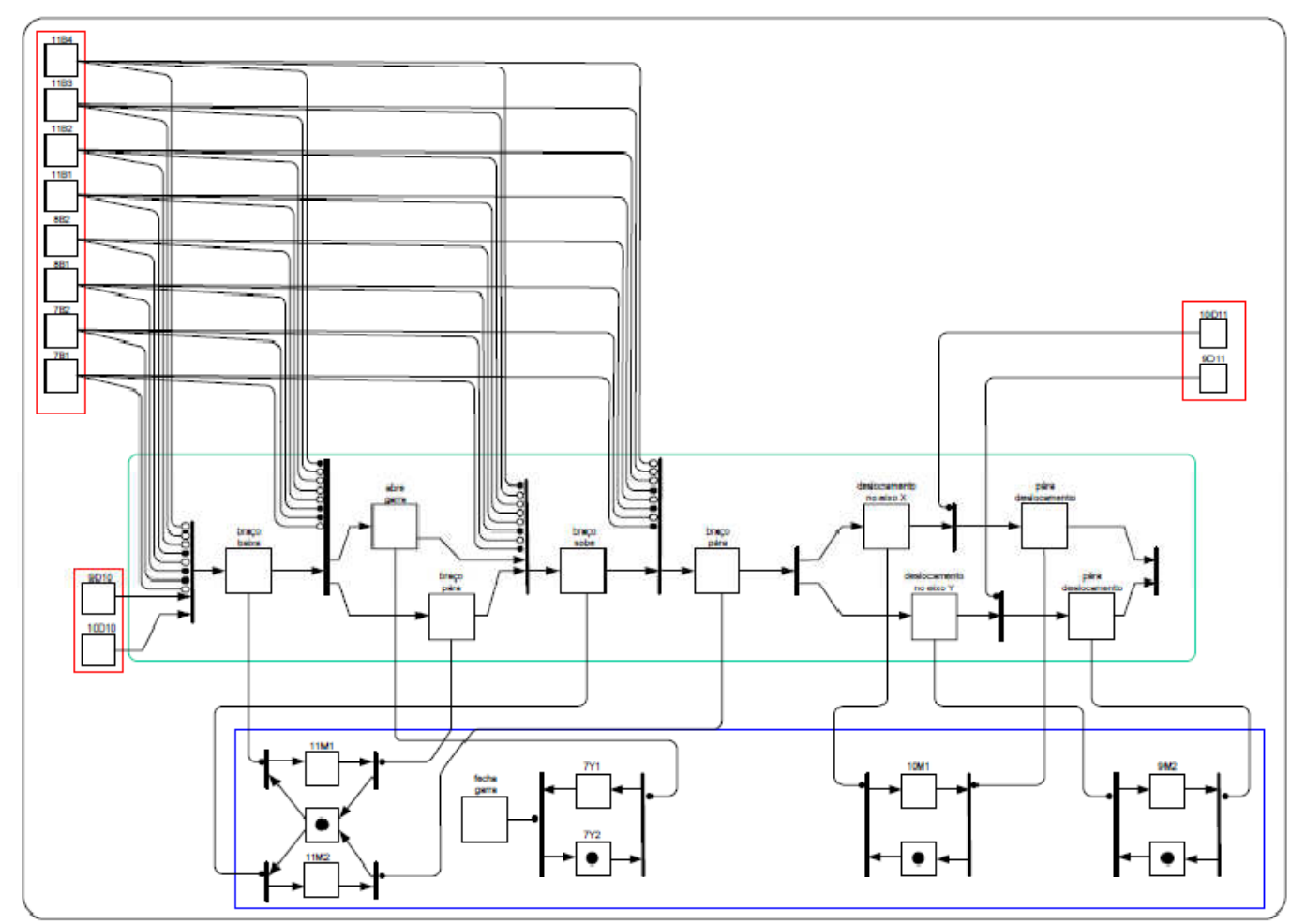

Figura 5.22. Rede de Controle Local da estação de Robô na atividade "transportar pallet” (Ro). 
A Fig. 5.23 detalha as operações do robô referentes à atividade 'pegar peça corpo'. Nestas operações são utilizados os sensores magnéticos de proximidade 11B, 8B, e 7B para identificar a posição da peça. Os servo-motores 9M, 10M e 11M são utilizados para controlar a movimentação do braço.

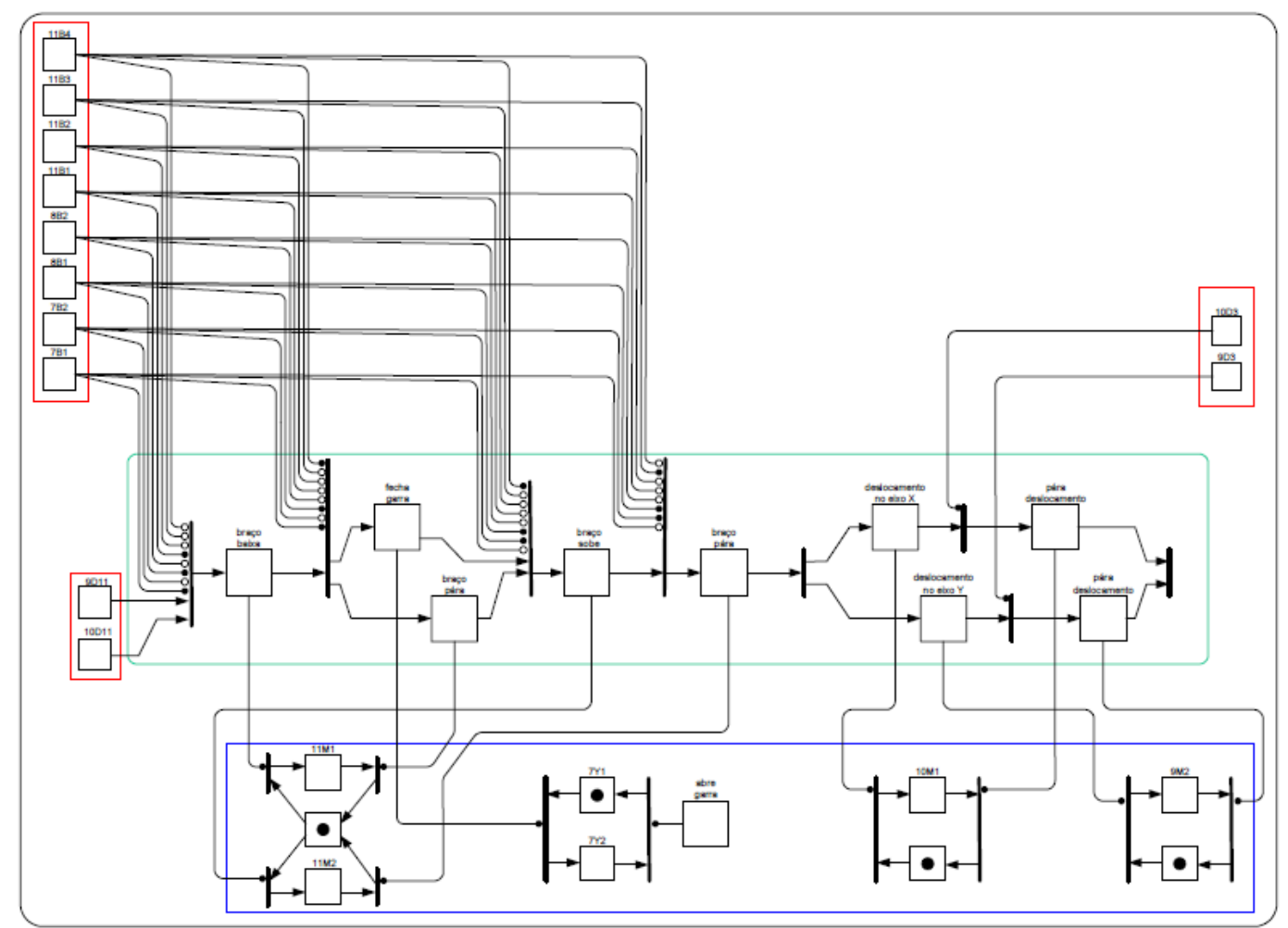

Figura 5.23. Rede de Controle Local da estação de Robô na atividade "pegar peça corpo" (Ro).

$\mathrm{Na}$ Fig. 5.24 encontra-se representada a rede de controle local na atividade transportar 'peça corpo enquanto que na Fig. 5.25 encontra-se representada rede de controle local na atividade de movimentação do embolo até a base. Os atuadores nestas duas redes são as mesmas representadas na rede da Fig. 5.23 na atividade pegar peça corpo. A diferença encontra-se nos sensores que identificam os estados e as posições dos componentes do produto final. 


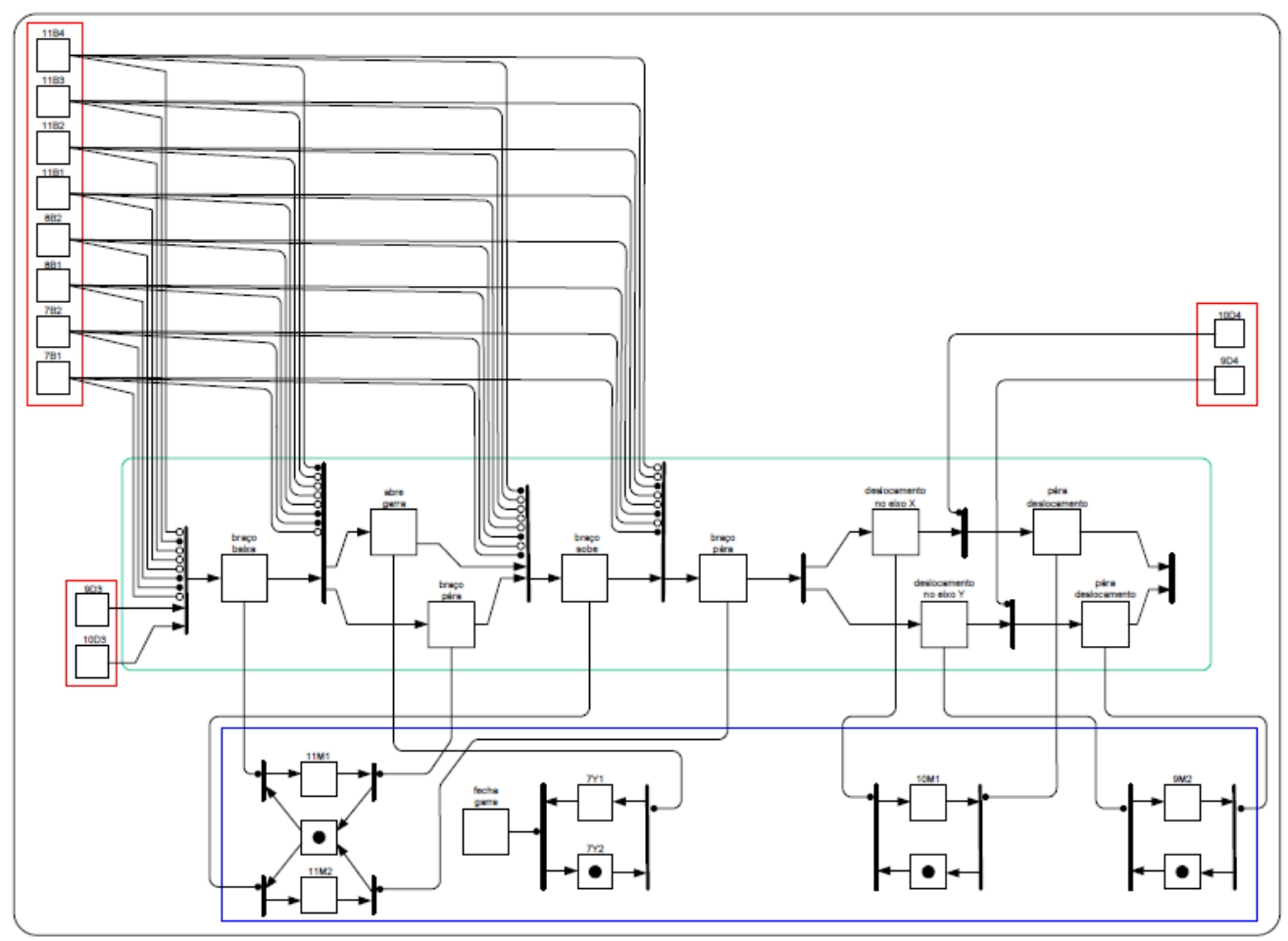

Figura 5.24. Rede de Controle Local da estação de Robô na atividade "transporte peça corpo" (Ro).

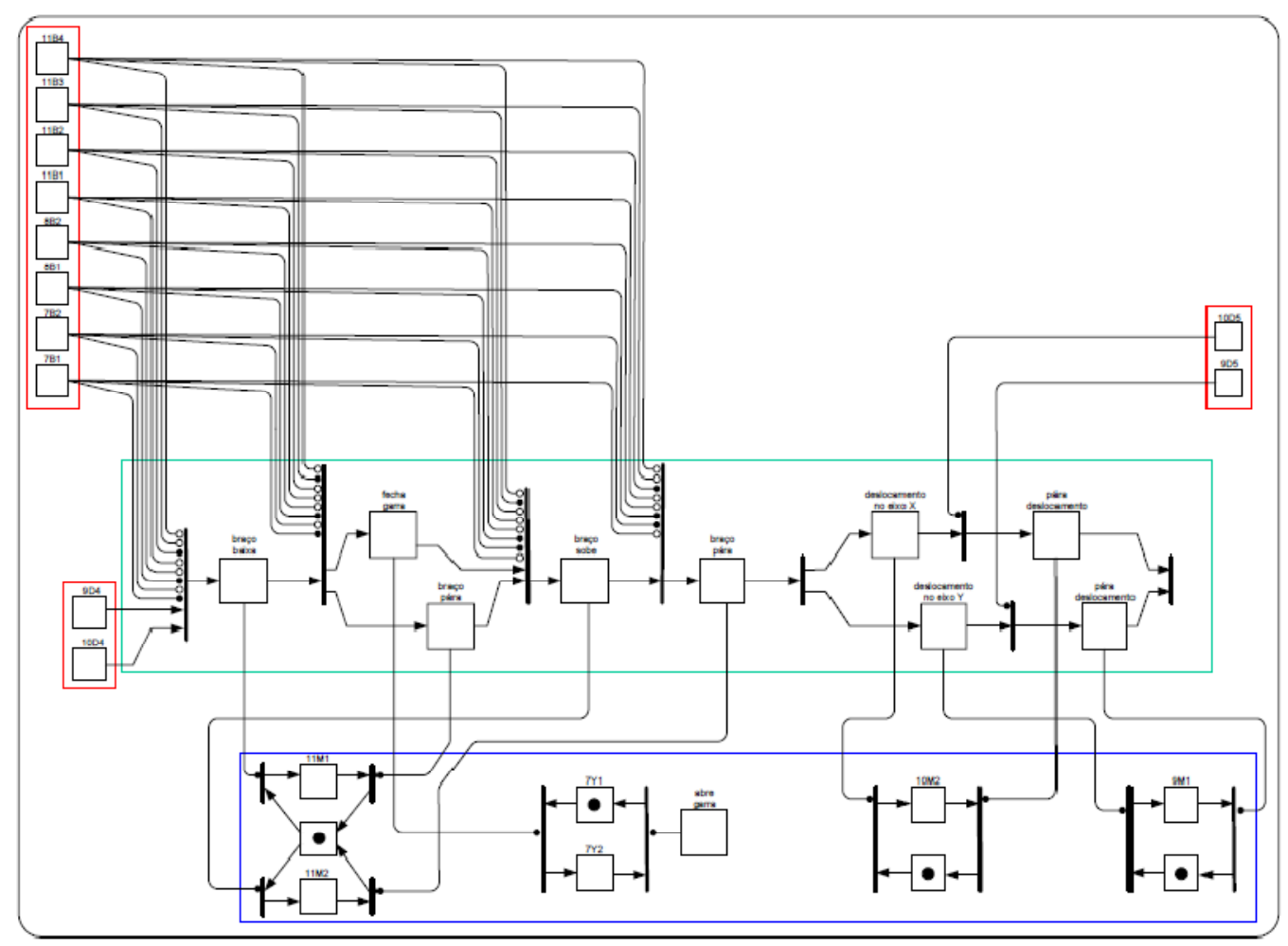

Figura 5.25. Rede de Controle Local da estação de Robô na atividade "pega embolo" (Ro). 


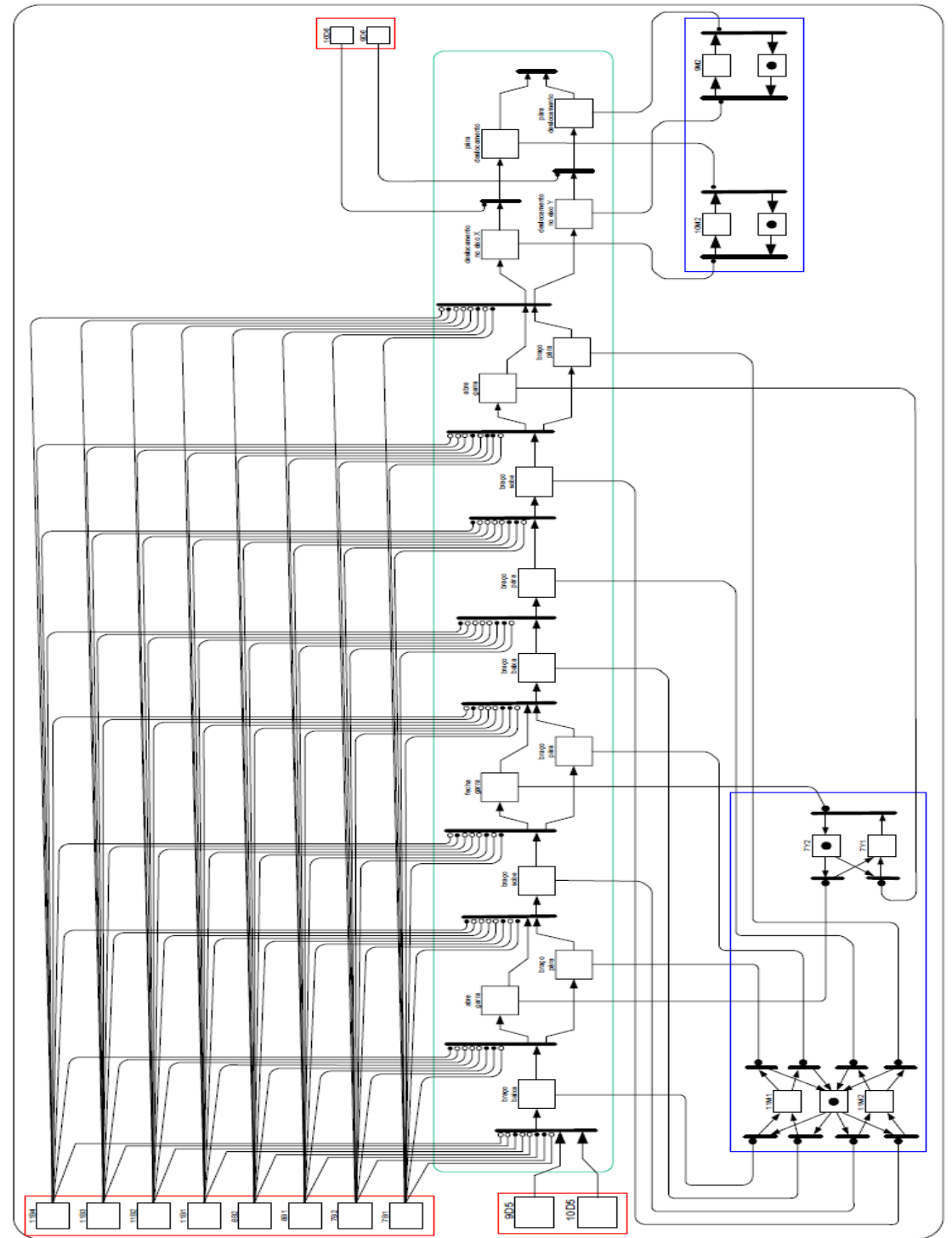

Figura 5.26. Rede de Controle Local da estação de Robô na atividade "montagem de embolo" (Ro).

A Fig. 5.26 detalha as operações referentes à atividade montagem do embolo. Nesta rede encontram-se representadas as sinais dos sensores que identificam a presença do embolo e do braço mediante os enconders 9D e 10D. 


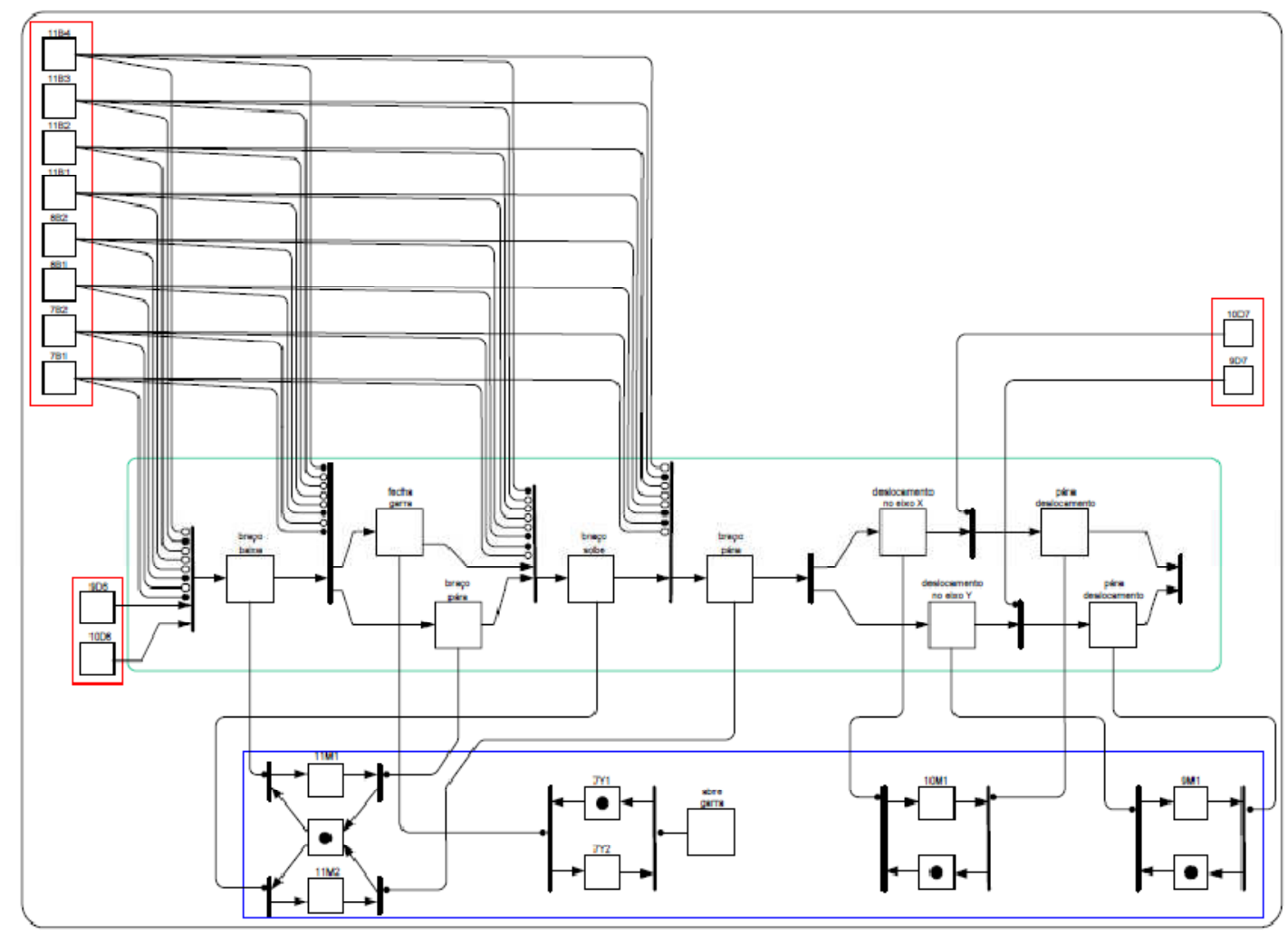

Figura 5.27. Rede de Controle Local da estação de Robô na atividade "pegar mola" (Ro).

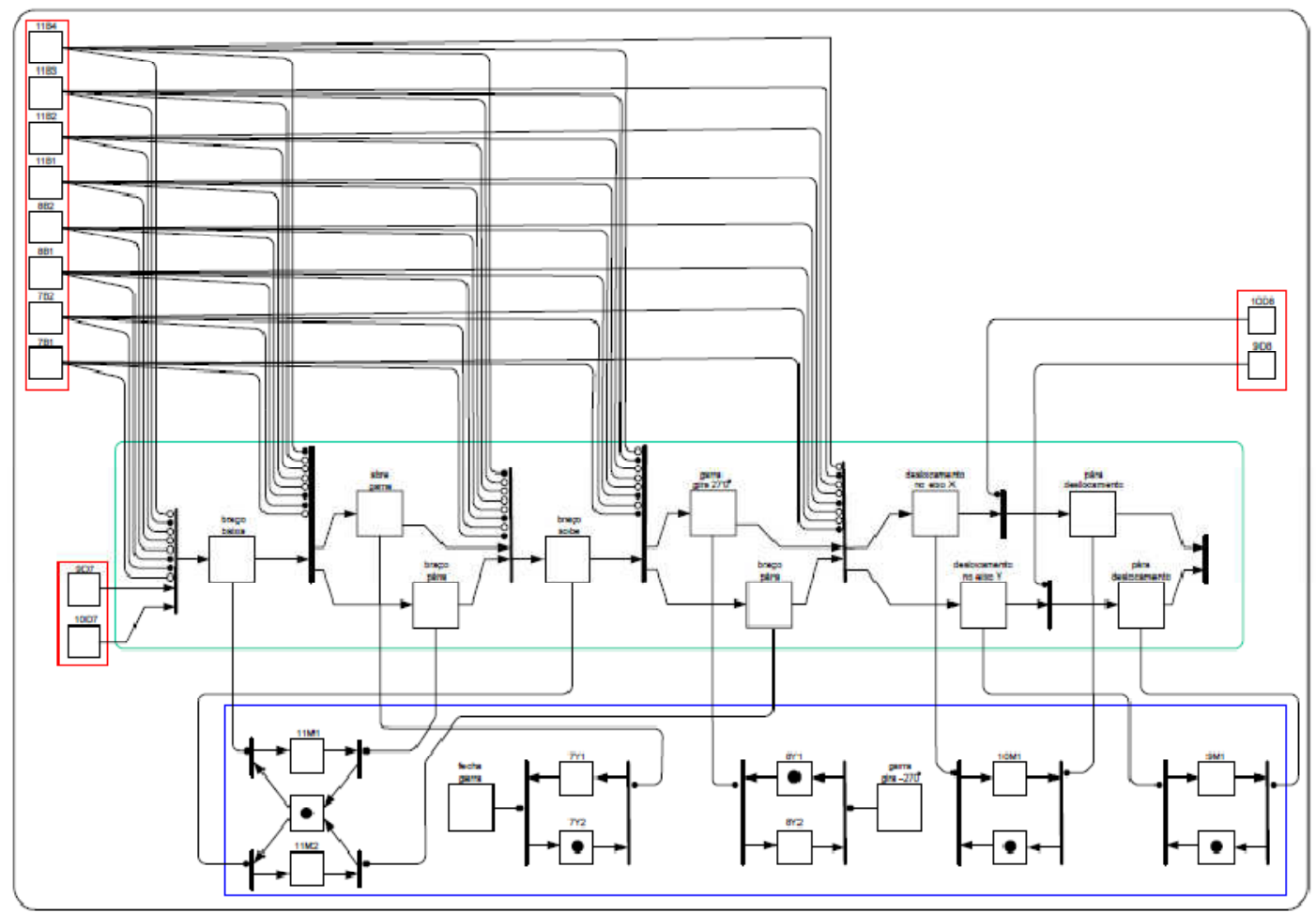

Figura 5.28. Rede de Controle Local da estação de Robô na atividade "montar mola" (Ro). 


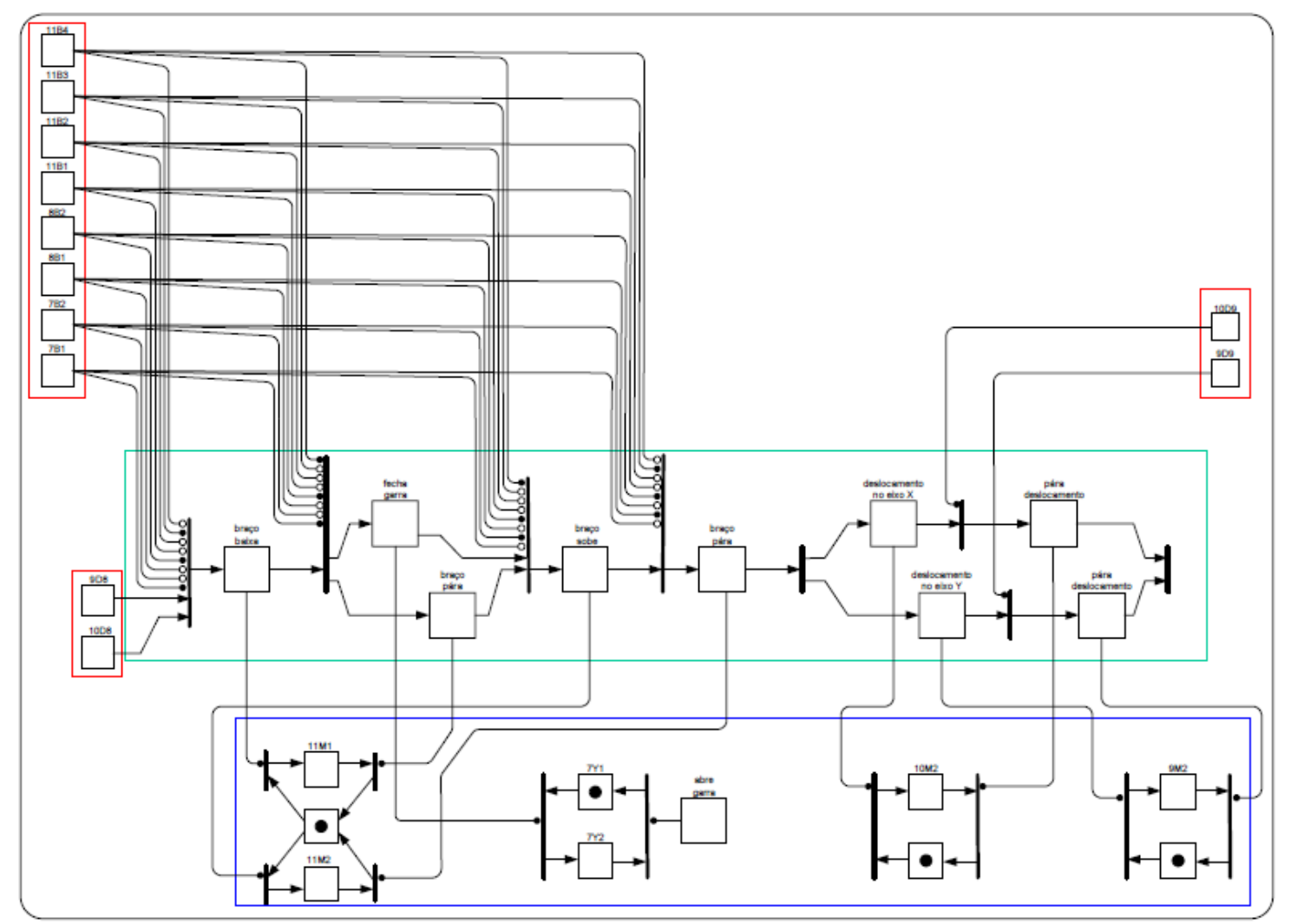

Figura 5.29. Rede de Controle Local da estação de Robô na atividade "pegar tampa" (Ro).

Na Fig. 5.30 são detalhas as operações de movimentação, montagem e fixação da tampa do produto. As válvulas solenóides $8 Y$ controlam o giro da garra do braço robótico tanto em sentido anti-horario para colocar na posição pré-fixação quanto em sentido horário para fixar a tampa após a movimentação. 


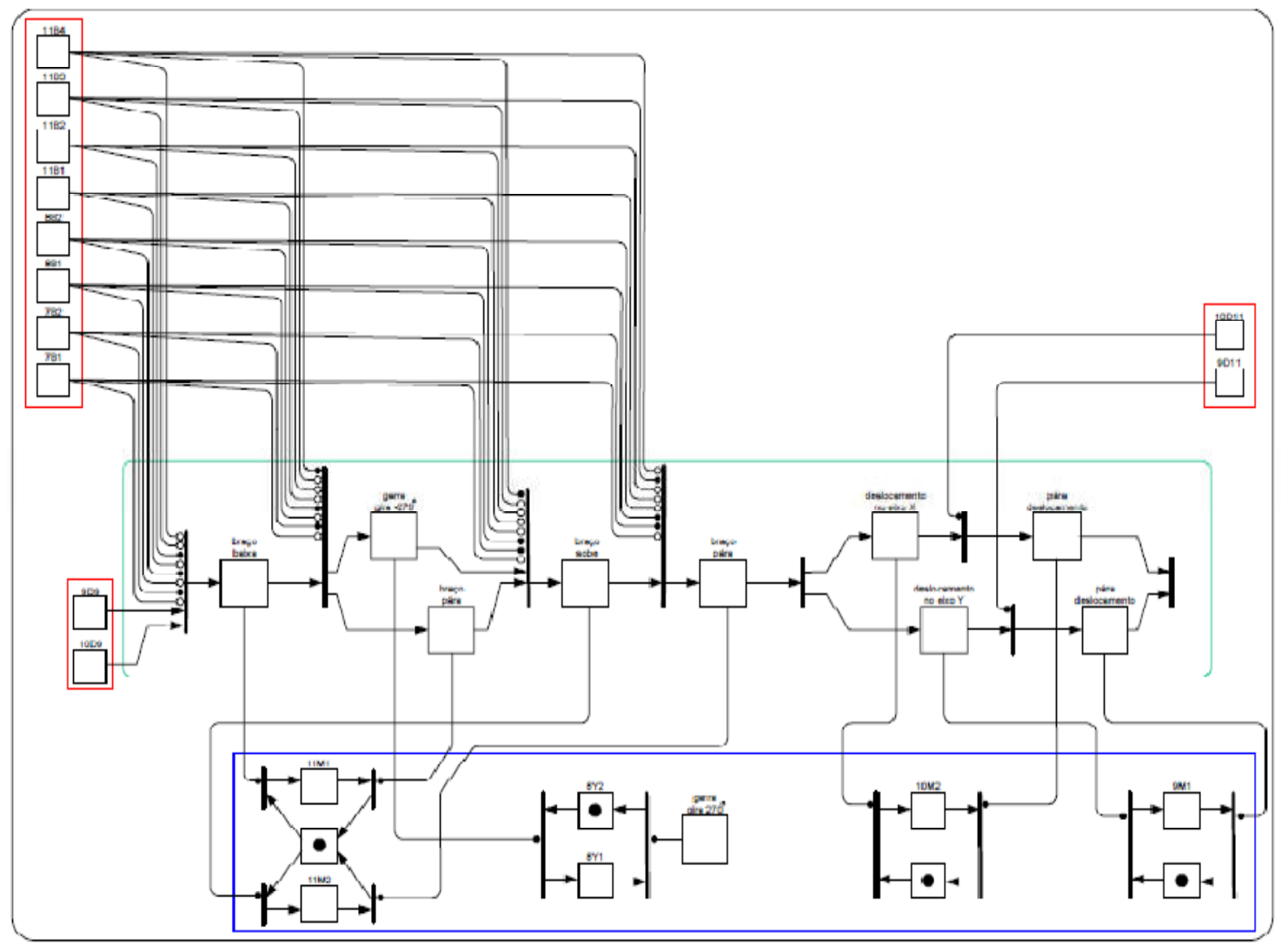

Figura 5.30. Rede de Controle Local da estação de Robô na atividade "fixar tampa" (Ro). 


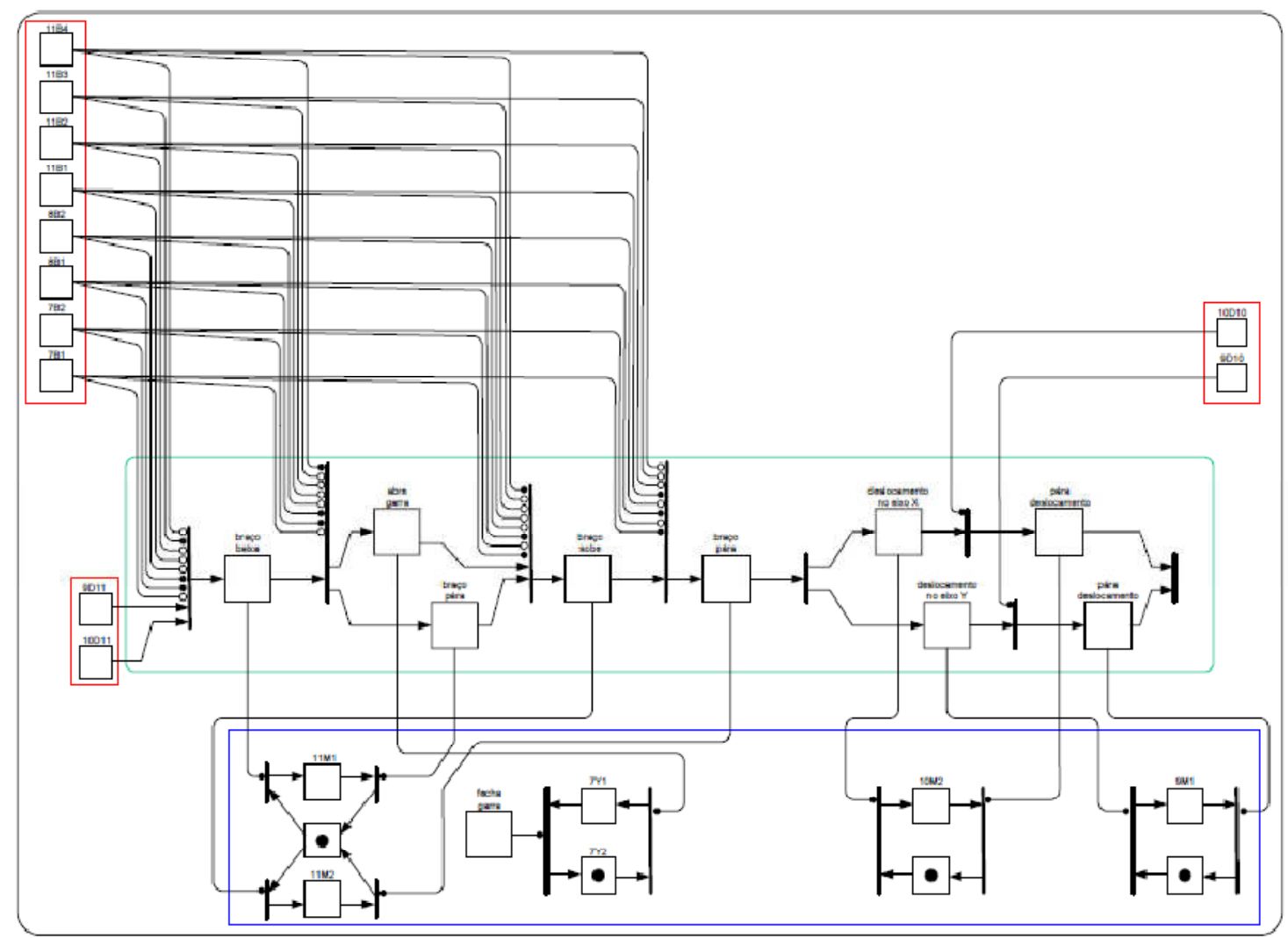

Figura 5.31. Rede de Controle Local da estação de Robô na atividade "movimentar peça montada" (Ro).

A Fig. 5.31 detalha as operações referentes à atividade da movimentação da peça montada para o pallet. Os atuadores utilizados são os mesmos que nas redes 5.23 a 5.27 . 


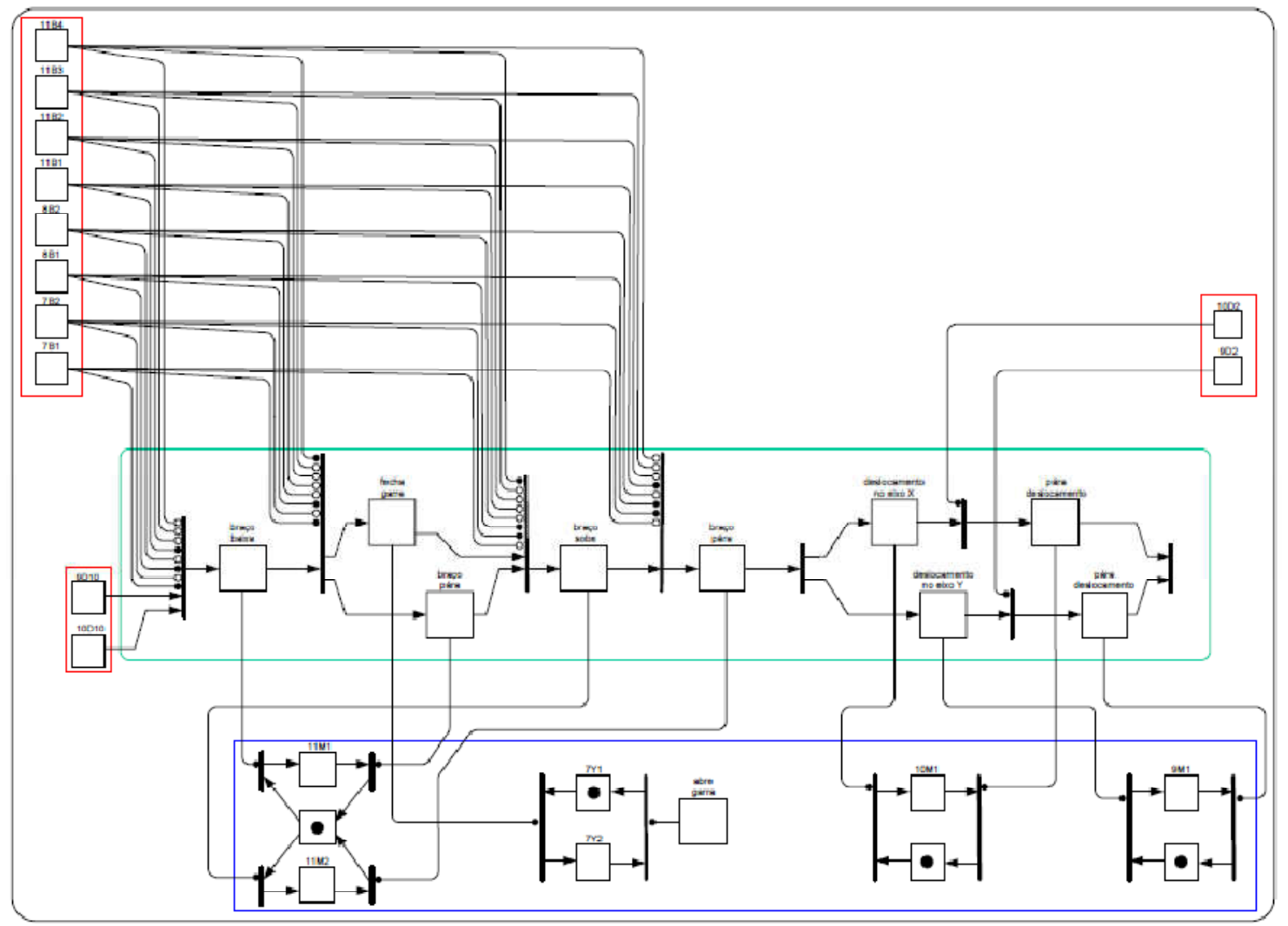

Figura 5.32. Rede de Controle Local da estação de Robô na atividade "pegar pallet" (Ro). 


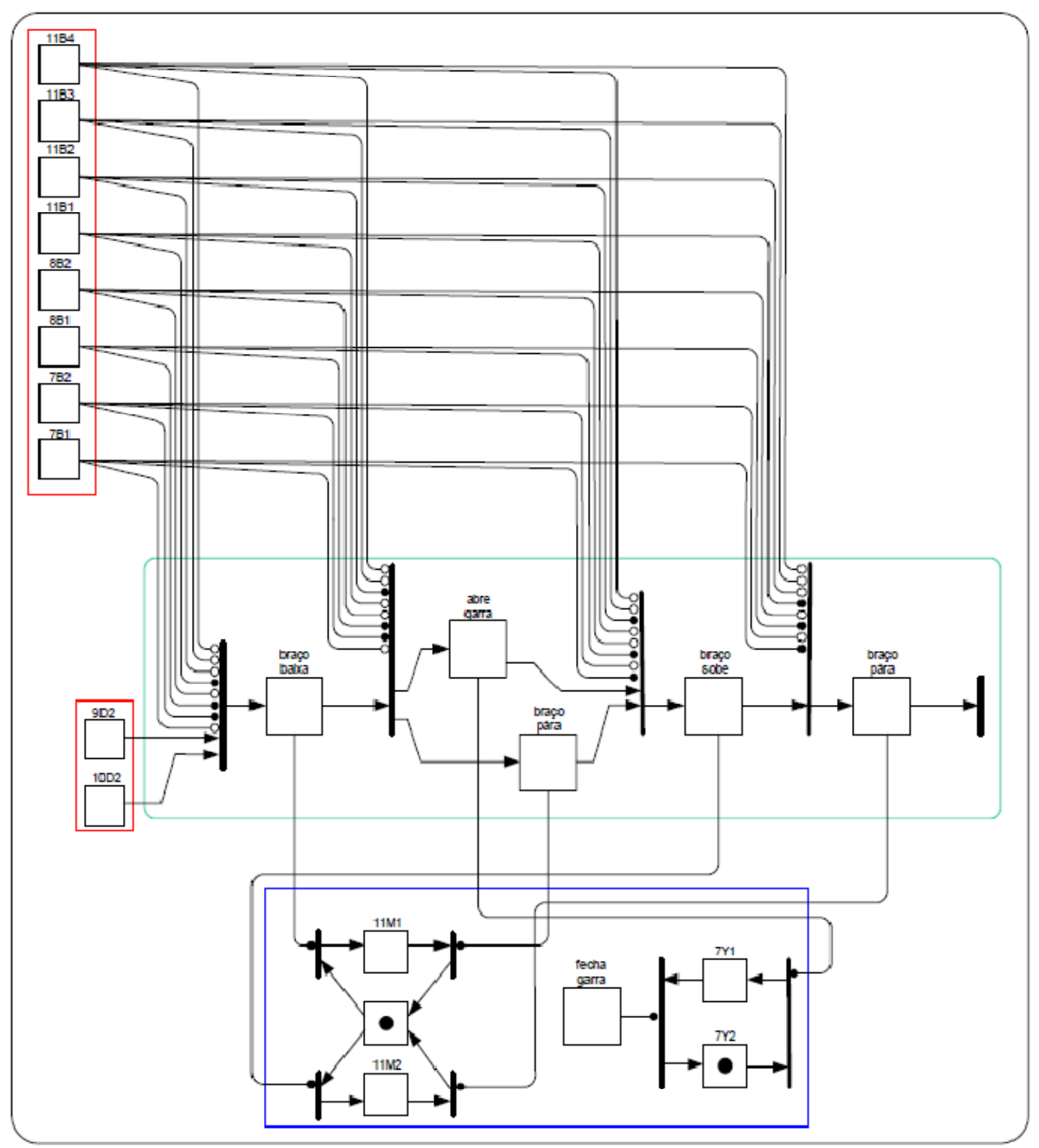

Figura 5.33. Rede de Controle Local da estação de Robô na atividade "deposita pallet" (Ro).

Na Fig. 5.34 é apresentada a rede de controle local para a estação de transporte. Nesta rede são enviadas sinais para os atuadores $16 \mathrm{Y}$ que libera a peça na posição 1 antes da área de alimentação, 17Y que eleva e desce o pallet na área de alimentação da peça corpo e $18 Y$ que libera e retém o pallet para a entrada na área de montagem. 


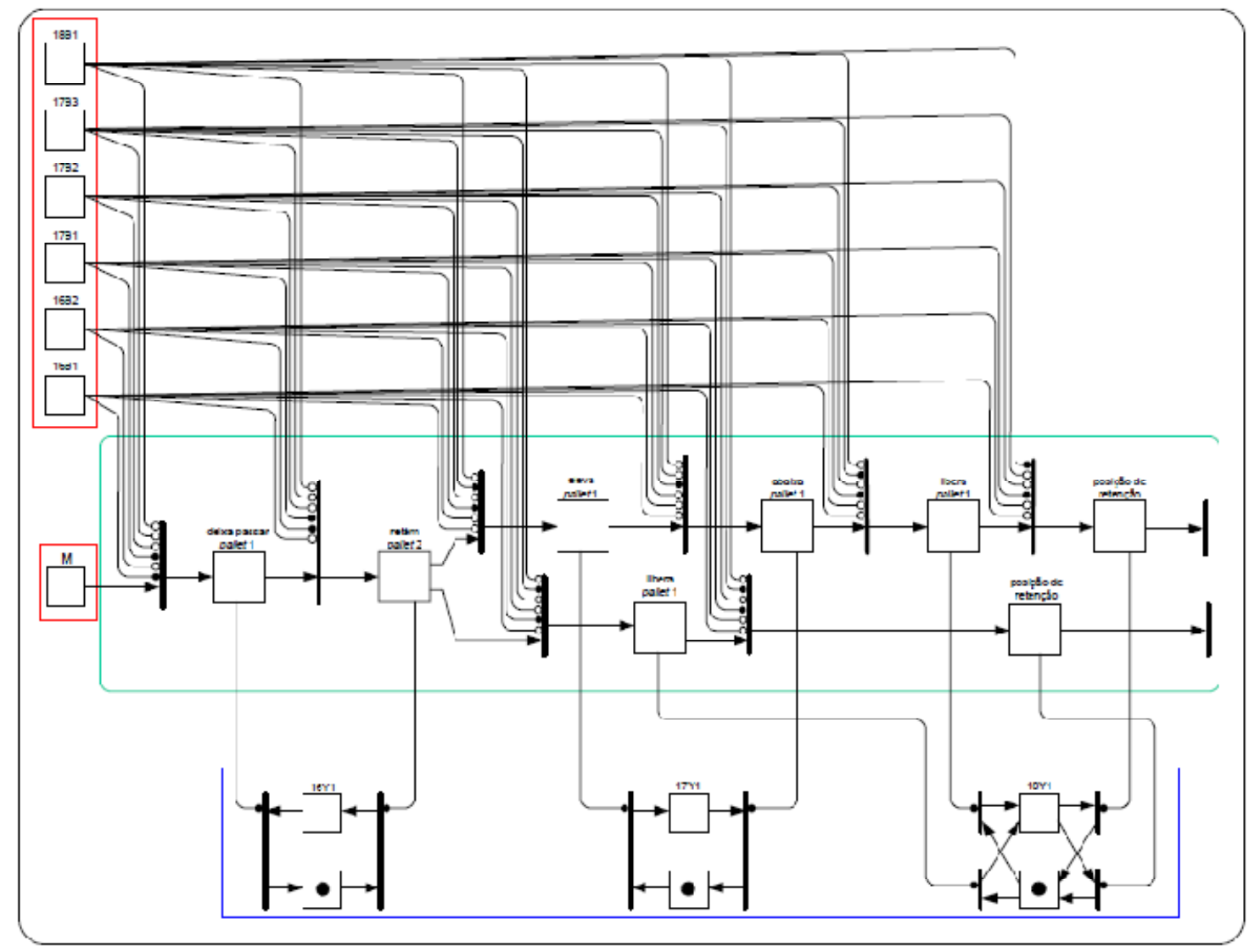

Figura 5.34. Rede de Controle Local da estação de Transporte (T).

\subsubsection{Classificação dos Componentes da rede de Controle Local}

Segundo o procedimento descrito no capítulo 4, o seguinte passo consiste em realizar uma classificação dos componentes da rede de controle local. Assim, é feito uma filtragem dos locais da rede de Petri MFG para cada subsistema modelado.

A seguir, encontram-se as tabelas resultantes deste procedimento: 
Tabela 5.16. Lista dos locais tipo B na rede de controle da estação de alimentação.

\begin{tabular}{|l|l|l|}
\hline Código & Tipo & Local \\
\hline $11^{\text {a }}$ & Cilindro pneumático & Alimenta peça \\
\hline $2^{\text {a }}$ & gerador de vácuo & Liga/desliga vácuo \\
\hline $3^{\text {a }}$ & Braço giratório pneumático & Carrega peça \\
\hline $1 \mathrm{~B} 1$ & Sensor magnético de proximidade & $1 \mathrm{~B} 1$ \\
\hline $1 \mathrm{~B} 2$ & Sensor magnético de proximidade & $1 \mathrm{~B} 2$ \\
\hline $1 \mathrm{~B} 3$ & sensor ótico & $1 \mathrm{~B} 3$ \\
\hline 2B1 & Vacuostato & $2 \mathrm{~B} 1$ \\
\hline $3 \mathrm{~S} 1$ & sensor fim de curso & $3 \mathrm{~S} 1$ \\
\hline $3 \mathrm{~S} 2$ & sensor fim de curso & $3 \mathrm{~S} 2$ \\
\hline
\end{tabular}

Tabela 5.17. Lista dos locais tipo B na rede de controle da estação de teste.

\begin{tabular}{|l|l|l|}
\hline Código & Tipo & Local \\
\hline $4^{\text {a }}$ & Cilindro pneumático & Elevador sobe/desce \\
\hline $5^{\text {a }}$ & Cilindro pneumático & expulsa peça \\
\hline $6^{\text {a }}$ & Cilindro pneumático & Medição de altura \\
\hline 4B1 & Sensor magnético de proximidade & $4 \mathrm{~B} 1$ \\
\hline 4B2 & Sensor magnético de proximidade & $4 \mathrm{~B} 2$ \\
\hline 4B3 & Sensor indutivo & $4 \mathrm{~B} 3$ \\
\hline 4B4 & sensor capacitivo & $4 \mathrm{~B} 4$ \\
\hline 4B5 & Sensor ótico & $4 \mathrm{~B} 5$ \\
\hline 5B1 & Sensor magnético de proximidade & $5 \mathrm{~B} 1$ \\
\hline 6B1 & Sensor magnético de proximidade & $6 \mathrm{~B} 1$ \\
\hline 6B2 & potenciômetro de deslocamento lineal & $6 \mathrm{~B} 2$ \\
\hline
\end{tabular}

Tabela 5.18. Lista dos locais tipo B na rede de controle de atuação do Robô.

\begin{tabular}{|l|l|l|}
\hline Código & Tipo & Local \\
\hline 7A & cilindro pneumático & Abre/fecha garra \\
\hline 8A & cilindro pneumático & gira a garra \\
\hline 9A & braço robótico em X & Deslocamento no eixo X \\
\hline 10A & braço robótico em Y & Deslocamento no eixo $Y$ \\
\hline 11A & braço robótico em Z densores magnéticos de & Deslocamento no eixo Z \\
\hline 7B & $\begin{array}{l}\text { Conjunto de se } \\
\text { proximidade (garra aberta/fechada) }\end{array}$ & $7 \mathrm{BX}$ \\
\hline 8B & $\begin{array}{l}\text { Conjunto de sensores magnéticos de } \\
\text { proximidade (girro da garra) }\end{array}$ & $8 \mathrm{BX}$ \\
\hline 9D & $\begin{array}{l}\text { Conjunto de encoder incrementais (posição eixo } \\
\text { X) }\end{array}$ & $9 \mathrm{DX}$ \\
\hline 10D & $\begin{array}{l}\text { Conjunto de encoder incrementais (posição eixo } \\
\text { Y) }\end{array}$ & $10 \mathrm{DX}$ \\
\hline 11B & $\begin{array}{l}\text { Conjunto de sensores magnéticos de } \\
\text { proximidade (posição eixo Z) }\end{array}$ & $11 \mathrm{BX}$ \\
\hline 11S & Sensores fim de curso (posição eixo Z) & $11 \mathrm{SX}$ \\
\hline
\end{tabular}


Tabela 5.19. Lista dos locais tipo B na rede de controle de estação de transporte.

\begin{tabular}{|c|c|c|}
\hline Código & Tipo & Local \\
\hline $\begin{array}{ll}16 \mathrm{~A} & - \\
18 \mathrm{~A} & - \\
19 \mathrm{~A} & - \\
22 \mathrm{~A}- & \\
24 \mathrm{~A} & \end{array}$ & cilindro pneumático & Retém pallet \\
\hline $\begin{array}{l}17 A- \\
20 A- \\
23 A \\
\end{array}$ & cilindro pneumático & eleva pallet \\
\hline $\begin{array}{l}\text { 16B1 - } \\
\text { 19B1 - } \\
22 \mathrm{~B} 1\end{array}$ & Sensor magnético de proximidade & $\begin{array}{l}\text { 16B1- } \\
\text { 19B1 - } \\
\text { 22B1 }\end{array}$ \\
\hline $\begin{array}{l}\text { 16B2 - } \\
\text { 19B2 - } \\
22 B 2\end{array}$ & Sensor magnético de proximidade & $\begin{array}{l}\text { 16B2 - } \\
\text { 19B2 - } \\
22 \mathrm{~B} 2\end{array}$ \\
\hline $\begin{array}{l}\text { 17B1 - } \\
\text { 20B1 - } \\
23 \mathrm{~B} 1-\end{array}$ & sensor indutivo & \begin{tabular}{|l} 
17B1 - \\
20B1 - \\
23B1 -
\end{tabular} \\
\hline $\begin{array}{l}\text { 17B2 - } \\
\text { 20B1 - } \\
\text { 23B2 }\end{array}$ & sensor capacitivo & \begin{tabular}{|l} 
17B2 - \\
20B1 - \\
$23 \mathrm{~B} 2$ \\
\end{tabular} \\
\hline $\begin{array}{l}\text { 17B3- } \\
\text { 20B3 - } \\
\text { 23B3 }\end{array}$ & sensor capacitivo & $\begin{array}{l}\text { 17B3- } \\
\text { 20B3 - } \\
23 B 3\end{array}$ \\
\hline $\begin{array}{l}\text { 18B1 - } \\
21 \mathrm{~B} 1- \\
24 \mathrm{~B} 1\end{array}$ & Sensor magnético de proximidade & $\begin{array}{l}\text { 18B1 - } \\
\text { 21B1 - } \\
24 \mathrm{~B} 1\end{array}$ \\
\hline
\end{tabular}

\subsubsection{Construção do Modelo de Diagnóstico}

Com base na metodologia proposta no capítulo 4, são ilustradas a seguir as redes de diagnóstico construídas para a identificação de falhas no sistema.

Na Fig. 5.35 é apresentada a rede de diagnóstico para a estação de alimentação. Note que assim que um defeito se manifesta no sistema (por exemplo, falta de peça), é disparada um conjunto de regras probabilísticas que retornam um conjunto de candidatos da causa da falha. Na tabela 5.20 são apresentados a relações probabilísticas entre os componentes da rede de diagnóstico. Algumas manifestações intermediária podem ser consideradas conforme os componentes da rede Isu.A, Isu.B, Isu.C e Isu.D. 


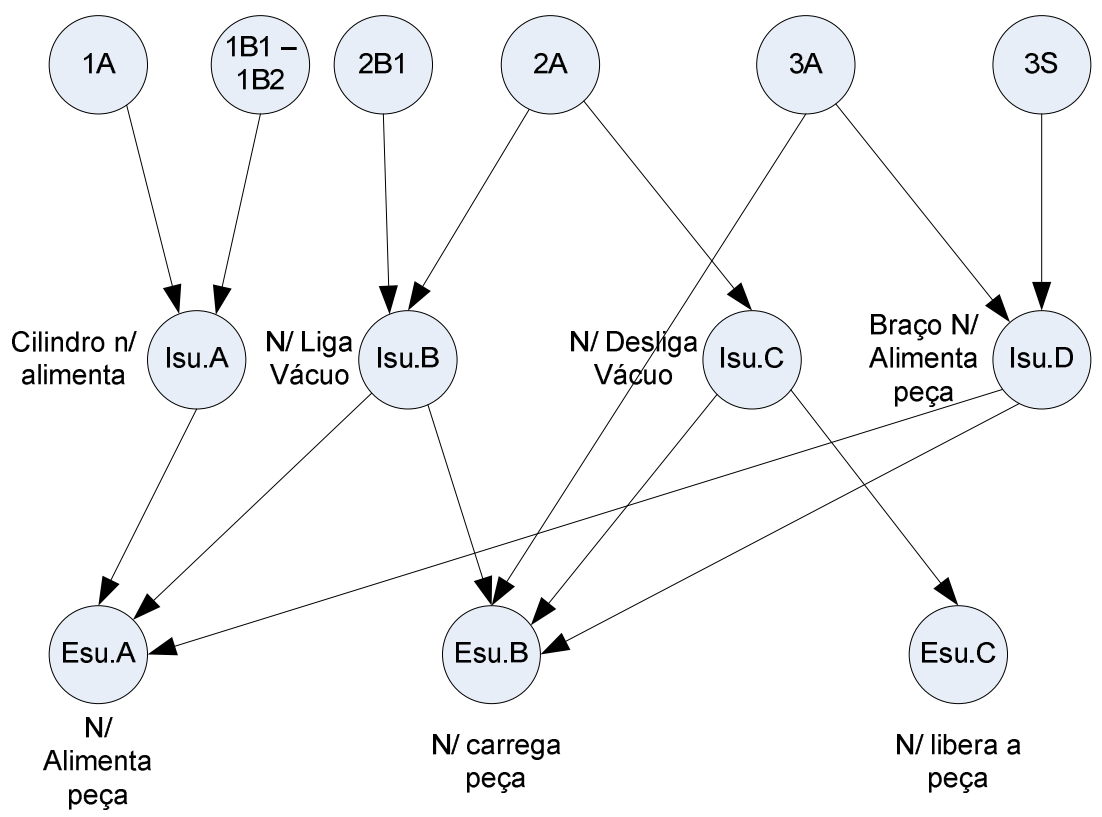

Figura 5.35. Rede de Diagnóstico da Estação de Alimentação (Su).

Tabela 5.20. Probabilidades de Rede de Diagnóstico Su.

\begin{tabular}{|c|c|}
\hline 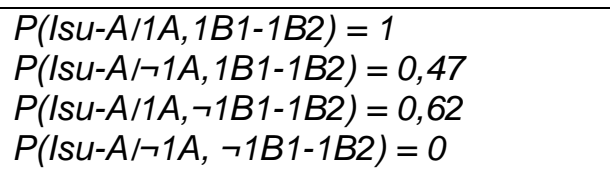 & 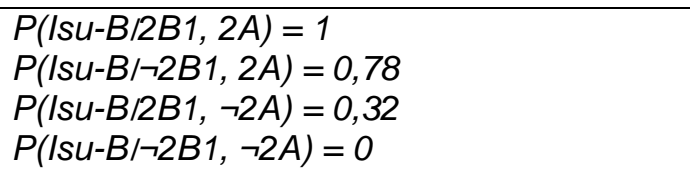 \\
\hline $\begin{array}{l}P(\text { Isu-C I2A }=1 \\
P(\text { Isu-C } / \neg 2 A)=0\end{array}$ & 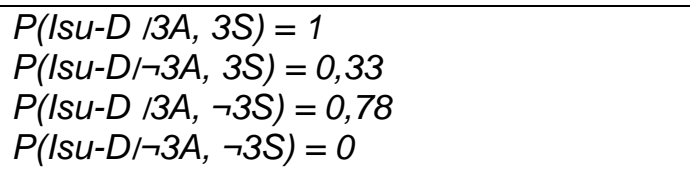 \\
\hline 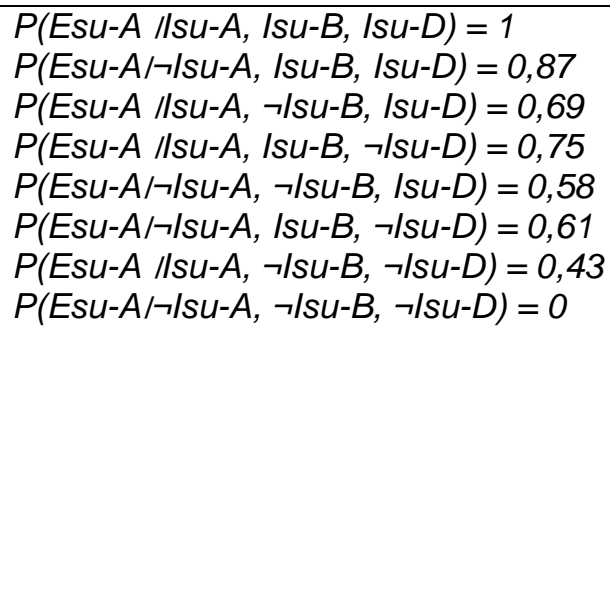 & 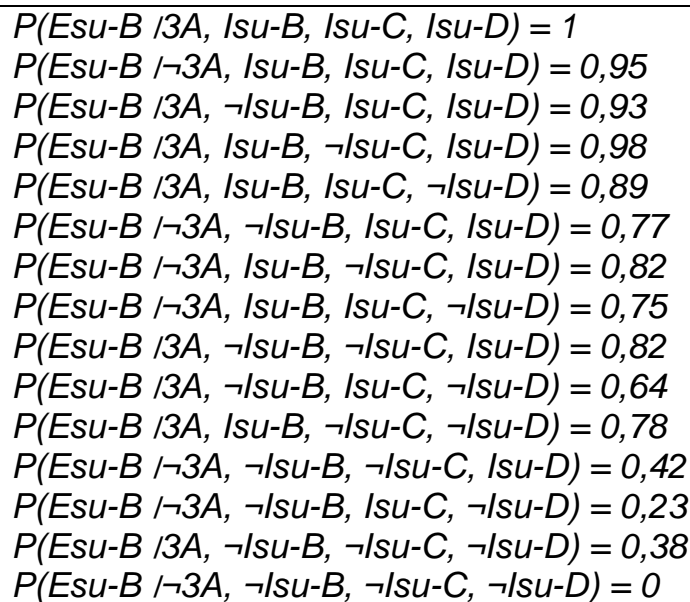 \\
\hline $\begin{array}{l}P(\text { Esu-C Ilsu-C })=1 \\
P(\text { Isu-C / Isu-C })=0\end{array}$ & \\
\hline
\end{tabular}


Na Fig. 5.36 é apresentada a rede de diagnóstico da estação de teste, e na tabela 5.21 é apresentada a tabela de probabilidades respectiva.

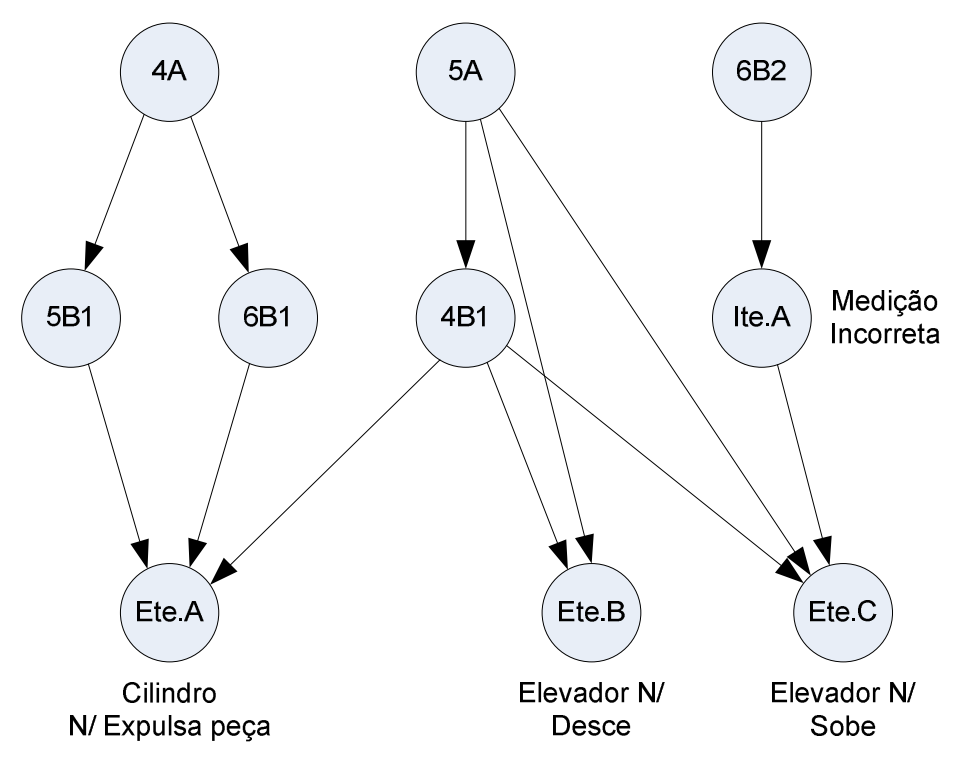

Figura 5.36. Rede de Diagnóstico da Estação de Teste (Te).

Tabela 5.21. Probabilidades de Rede de Diagnóstico Te.

\begin{tabular}{|l|l|}
\hline$P(4 B 1 / 5 A)=1$ & $P(5 B 1 / 4 A)=1$ \\
$P(4 B 1 / \neg 5 A)=0$ & $P(5 B 1 / \neg 4 A)=0$ \\
\hline$P(6 B 1 / 4)=1$, & $P($ Ite. $A / 6 B 2)=1$ \\
$P(6 B 1 / \neg 4 A)=0$ & $P($ Ite. $A / \neg 6 B 2)=0$ \\
\hline$P($ Ete. $A / 4 B 1,5 B 1,6 B 1)=1$ & $P($ Ete. $B / 4 B 1,5 A$, Ite. $A)=1$ \\
$P($ Ete. $A / \neg 4 B 1,5 B 1,6 B 1)=0,67$ & $P($ Ete. $B / \neg 4 B 1,5 A$, Ite. $A)=0,73$ \\
$P($ Ete. $A / 4 B 1, \neg 5 B 1,6 B 1)=0,52$ & $P($ Ete. $B / 4 B 1, \neg 5 A$, Ite. $A)=0,53$ \\
$P($ Ete. $A / 4 B 1,5 B 1, \neg 6 B 1)=0,65$ & $P($ Ete. $B / 4 B 1,5 A, \neg$ Ite. $A)=0,86$ \\
$P($ Ete. $A / \neg 4 B 1, \neg 5 B 1,6 B 1)=0,43$ & $P($ Ete. $B / \neg 4 B 1, \neg 5 A$, Ite. $A)=0,31$ \\
$P($ Ete. $A / \neg 4 B 1,5 B 1, \neg 6 B 1)=0,27$ & $P($ Ete. $B / \neg 4 B 1,5 A, \neg$ Ite. $A)=0,28$ \\
$P($ Ete. $A / 4 B 1, \neg 5 B 1, \neg 6 B 1)=0,36$ & $P($ Ete. $B / 4 B 1, \neg 5 A, \neg$ Ite.A $)=0,39$ \\
$P($ Ete. $A / \neg 4 B 1, \neg 5 B 1, \neg 6 B 1)=0,01$ & $P($ Ete. $B / \neg 4 B 1, \neg 5 A, \neg$ Ite. $A)=0,12$ \\
\hline$P($ Ete. $B / 4 B 1,5 A)=1$ & \\
$P($ Ete. $B / \neg 4 B 1,5 A)=0,5$ & \\
$P($ Ete. $B / 4 B 1, \neg 5 A)=0,7$ & \\
$P($ Ete. $B / \neg 4 B 1, \neg 5 A)=0$ & \\
\hline
\end{tabular}


A rede de diagnóstico da estação do Robô é apresentada na Fig. 5.37 e a tabela de relações probabilísticas é apresentada na Tabela 5.22. Para fins de análise, a rede pode ser simplificada conforme a manifestação de defeitos utilizando os conceitos de $d$-separação (Pearl, 1987).

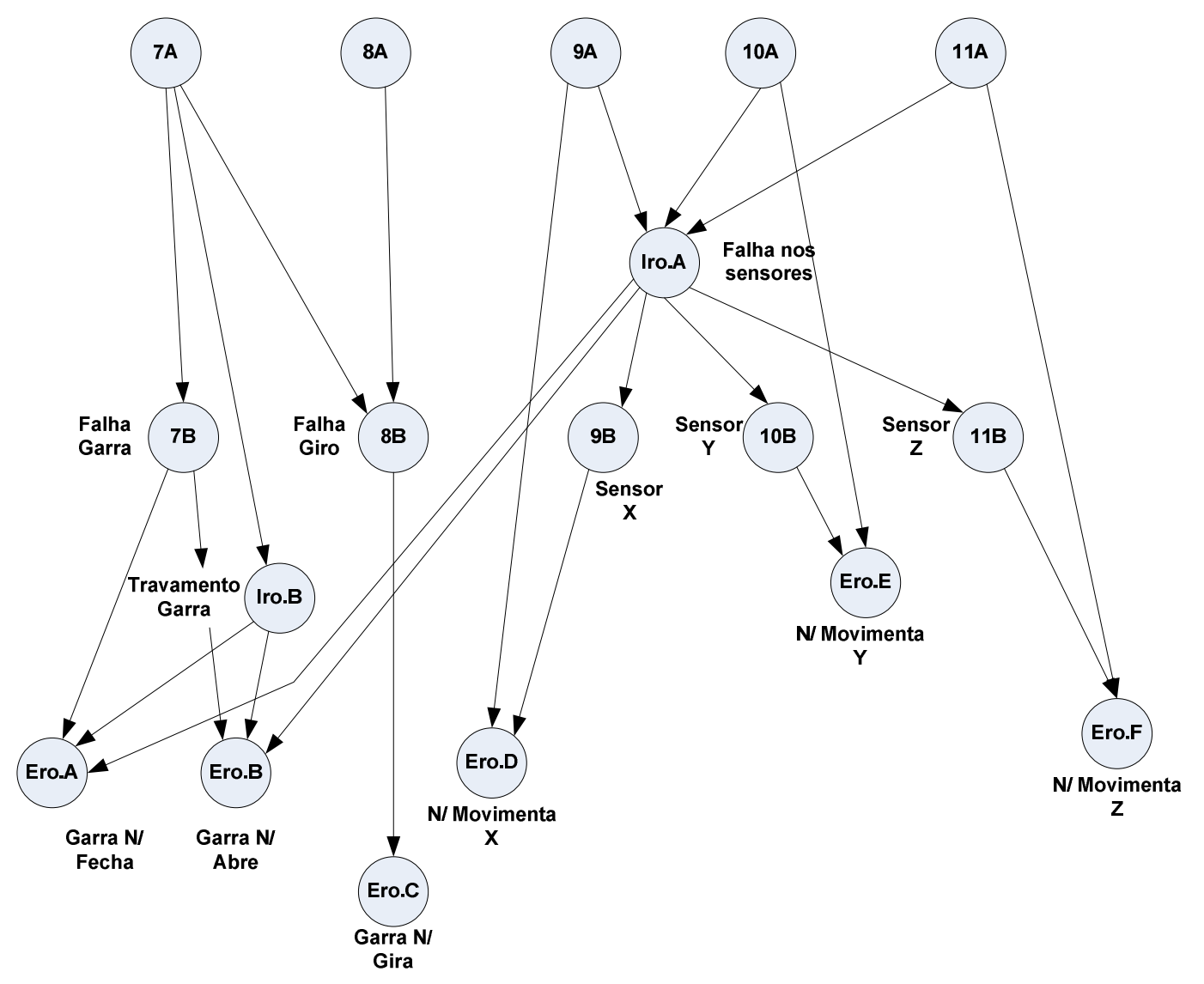

Figura 5.37. Rede de Diagnóstico da Estação de Robô (Ro).

Tabela 5.22. Probabilidades de Rede de Diagnóstico Ro.

\begin{tabular}{|l|l|}
\hline$P($ Iro. $A / 9 A, 10 A, 11 A)=1$ & $P(7 B / 7 A)=1$ \\
$P($ Iro. $A / \neg 9 A, 10 A, 11 A)=0,87$ & $P(7 B / \neg 7 A)=0$ \\
$P($ Iro. $A / 9 A, \neg 10 A, 11 A)=0,71$ & \\
$P($ Iro. $/ 9 A, 10 A, \neg 11 A)=0,69$ & \\
$P($ Iro. $A / \neg 9 A, \neg 10 A, 11 A)=0,45$ & \\
$P($ Iro. $A / \neg 9 A, 10 A, \neg 11 A)=0,56$ & \\
$P($ Iro. $A / 9 A, \neg 10 A, \neg 11 A)=0,37$ & \\
$P($ Iro. $A / \neg 9 A, \neg 10 A, \neg 11 A)=0,00$ & $P(9 B /$ Iro.A $)=1$ \\
$P(8 B / 7 A, 8 A)=1$ & $P(9 B / \neg$ Iro. $A)=0$ \\
$P(8 B / \neg 7 A, 8 A)=0,83$ & \\
$P(8 B / 7 A, \neg 8 A)=0,81$ & \\
$P(8 B / \neg 7 A, \neg 8 A)=0,12$ & \\
\hline
\end{tabular}




\begin{tabular}{|c|c|}
\hline $\begin{array}{l}P(10 B / / \text { ro. } A)=1 \\
P(10 B / \neg / \text { ro. } A)=0\end{array}$ & $\begin{array}{l}P(11 B / \operatorname{Iro} . A)=1 \\
P(11 B / \neg \mid \text { ro. } A)=0\end{array}$ \\
\hline $\begin{array}{l}P(\text { Iro. } B / 7 A)=1 \\
P(\text { Iro. } B / \neg 7 A)=0\end{array}$ & 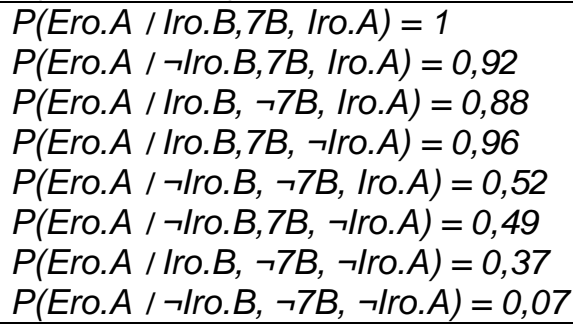 \\
\hline $\begin{array}{l}P(\text { Ero. } B / \text { Iro. } B, 7 B, \text { Iro. } A)=1 \\
P(\text { Ero. } B / \neg \text { Iro. } B, 7 B, \text { Iro. } A)=0,97 \\
P(\text { Ero. } B / \text { Iro. } B, \neg 7 B, \text { Iro. } A)=0,91 \\
P(\text { Ero. } B / \text { Iro. } B, 7 B, \neg \text { Iro. } A)=0,89 \\
P(\text { Ero. } B / \neg \text { Iro. } B, \neg 7 B, \text { Iro. } A)=0,47 \\
P(\text { Ero. } B / \neg \text { Iro. } B, 7 B, \neg \text { Iro. } A)=0,31 \\
P(\text { Ero. } B / \text { Iro. } B, \neg 7 B, \neg / \text { ro. } A)=0,67 \\
P(\text { Ero. } B / \neg \text { Iro. } B, \neg 7 B, \neg \text { Iro. } A)=0,01\end{array}$ & $\begin{array}{l}P(\text { Ero. } C / 8 B)=1 \\
P(\text { Ero. } C / \neg 8 B)=0\end{array}$ \\
\hline $\begin{array}{l}P(\text { Erro.D } / 9 A, 9 B)=1 \\
P(\text { Erro.D / } 99 A, 9 B)=0,89 \\
P(\text { Erro. } D / 9 A, \neg 9 B)=0,77 \\
P(\text { Erro.D / } 99 A, \neg 9 B)=0,13\end{array}$ & $\begin{array}{l}P(\text { Erro.E } / 10 A, 10 B)=1 \\
P(\text { Erro.E } / \neg 10 A, 10 B)=0,91 \\
P(\text { Erro. } E / 10 A, \neg 10 B)=0,66 \\
P(\text { Erro.E } / \neg 10 A, \neg 10 B)=0,17\end{array}$ \\
\hline $\begin{array}{l}P(\text { Erro.F } / 11 A, 11 B)=1 \\
P(\text { Erro. } F / \neg 11 A, 11 B)=0,97 \\
P(\text { Erro. } / / 11 A, \neg 11 B)=0,85 \\
P(\text { Erro.F } / \neg 11 A, \neg 11 B)=0,21\end{array}$ & \\
\hline
\end{tabular}

\subsubsection{Definição do Tratamento de Falhas}

Dentre os métodos propostos no capítulo 4 puderam ser utilizadas particularmente 0 método de entrada condicional e o método proposto de método de recuperação complementar. $O$ equipamento flexível permitiu testar diferentes alternativas de código baseado nestas propostas, permitindo observar como resultado um sistema tolerante a falhas em vários casos analisados. 


\section{CONCLUSÕES E RESULTADOS}

A seguir são apresentados os principais resultados obtidos com o procedimento apresentado no capitulo 4. São também apresentadas as conclusões que derivam na discussão sobre as principais vantagens e desvantagens da presente proposta enfocando-se nos aspectos da metodologia apresentada. Finalmente é apresentado o plano de trabalhos futuros que poderão ser seguidos em pesquisas posteriores.

\subsection{PRINCIPAIS RESULTADOS}

O procedimento proposto permite a construção de modelos de controle e supervisão que considerem o controle de sistemas de manufatura tanto em condições normais de funcionamento quanto em situações anormais ou em estado de falha. A proposta utiliza a rede de Petri como uma ferramenta para a modelagem do sistema de controle $\circ$ que permite que análises possam ser feitas para assegurar o funcionamento do sistema de acordo com as especificações do processo produtivo. É também utilizada a teoria de redes Bayesianas para realizar o diagnóstico de falhas quando se observa a partir da rede de controle a ocorrência de uma falha.

Neste sentido, numa primeira instância foi validada a efetividade da utilização de redes Bayesianas para o diagnóstico de falhas com um estudo de caso que trata sobre a caracterização do tipo de falhas num equipamento real, isto é, uma célula de combustível de hidrogeno. O diagnóstico é feito com base na monitoração de variáveis de acesso relativamente fácil como voltagem, corrente elétrica, temperatura e umidade. A construção do modelo foi realizada com base em dados estatísticos obtidos a partir do funcionamento simulado do sistema. Os testes realizados demonstraram a efetividade da ferramenta, obtendo-se em todos os casos as verdadeiras causas da falha. O tempo despendido no processo de diagnóstico também foi avaliado e verificou-se que é possível diagnosticar os 
estados de falha antes que estes se propagem através do sistema causando assim situações catastróficas.

Foi conduzido também um estudo de caso para a construção de modelos de sistemas supervisores de FMS tolerante a falhas. O procedimento proposto foi utilizado e confirmou-se que os modelos de controle e diagnóstico construídas com base em rede de Petri e redes Bayesianas respectivamente, podem ser desenvolvidas de modo racional e sistemático. O estudo foi conduzido com base num sistema flexível de montagem instalado no laboratório de automação e controle do Departamento de Mecatrônica da Escola Politécnica da USP.

Um terceiro estudo de caso foi conduzido para avaliar o procedimento detalhado no capitulo anterior. Trata-se de um sistema de alimentação de material de uma linha de decapagem numa instalação de tratamento de aço. Os resultados permitiram observar novamente que a proposta é afetiva para a construção de modelos que permitam o controle e o diagnóstico de falhas em sistemas de reais de manufatura. Tal sistema é parte das instalações de produção de aço da Companhia Siderúrgica Paulista (COSIPA) localizada em Cubatão no estado de São Paulo.

Considerando ainda o sistema de tratamento de aço da companhia COSIPA, foi desenvolvido o estudo de um sistema supervisor para o controle de uma planta de regeneração de acido clorídrico. Como tal sistema contém variáveis tanto de tipo discreta quanto de tipo contínua, uma adaptação do procedimento proposto teve que ser feita introduzindo o formalismo object-oriented differential preticate-transition net (OO-DPT) apresentada por VILLANI (2007). Assim, o modelo resultante utiliza as redes OO-DPT para representar estados contínuos como um conjunto de variáveis que evoluem segundo o tempo quando os respectivos lugares na rede de Petri estão marcados. Como a chamada de métodos é uma operação própria do paradigma da orientação a objetos, o diagnóstico de falhas é introduzido como um método externo representado em redes Bayesianas.

Com base em tais estudos de caso foram apresentados os seguintes artigos em congressos nacionais e internacionais. Estes são: 
"Fault Diagnosis in Fuel Cells based on Bayesian Networks", com co-autoria de Prof. Paulo E. Miyagi e Prof. Luis A. M. Riascos e apresentado no Congresso Brasileiro de Engenharia Mecânica COBEM 07, Brasília.

"Diagnosis and Treatment of Faults in Manufacturing Systems based on Bayesian Networks and Petri Net', com co-autoria de Prof. Paulo E. Miyagi, apresentado no Congresso Brasileiro de Engenharia Mecânica COBEM 07, Brasilia.

"Diagnosis and Treatment of Faults in Productive Systems based on Bayesian Networks and Petri Net", com co-autoria de Prof. Paulo E. Miyagi e Eng. José I. G. Mello, apresentado no IEEE Conference on Autonation Science and Engineering CASE07, Scottsdale, AZ, Estados Unidos.

Adicionalmente foram submetidos os seguintes trabalhos:

"Modeling of a Waste Pickle Liquor Recovery Process based on OO-DPT Net" com co-autoria de Prof. E. Paulo Miyagi e Eng. Christian Etnier da Technische Universitaet Muenchen Munich, Alemanha, submetido ao Congresso Nacional de Engenharia Mecânica CONEM 08.

"Supervisory systems for Hybrid Productive Systems based on Bayesian Networks and OO-DPT Nets", com co-autoria de Prof. Paulo E. Miyagi, e submetido ao IEEE Conference on Automation Science and Engineering CASE08, Washintong DC, WA, Estados Unidos.

"Modelagem da recuperação do ácido usado em processos de decapagem nas plantas siderúrgicas”, com co-autoria de Prof. Paulo E. Miyagi, Msc. Eng. Marcosiris A. O. Pessoa, Eng. Marilia G. V. Nassaf, submetido ao Congresso Brasileiro de Automatica, CBA2008.

\section{Trabalhos Complementares}

Além das atividades diretamente relacionadas ao mestrado, participou-se de outras tarefas de pesquisa e desenvolvimento dentro do laboratório de sistemas de automação e como resultado disso foram submetidos os seguintes trabalhos: 
"A Procedure to Model and Analysis of Service-Oriented and Distributed Productive Systems", com a autoria do Eng. Jose I. G. Mello e co-autoria do Prof. Paulo E. Miyagi, e submetido ao IEEE Conference on Automation Science and Engineering CASE08, Washintong DC, WA, Estados Unidos.

"Proposta de um procedimento para a modelagem e análise de sistemas produtivos orientados a serviços", com a autoria do Msc. Eng. José I. G. Mello e co-autoria do Prof. Paulo E. Miyagi, e Dr. Fabricio Junqueira , submetido ao Congresso Brasileiro de Automatica, CBA2008.

\subsection{TRABALHOS FUTUROS}

Dentre os principais trabalhos futuros encontra-se estender o procedimento para sistemas híbridos de produção, entendendo-se como híbridos àqueles que podem ser caracterizados mediante variáveis contínuas e discretas. Um primeiro passo já foi dado neste respeito e espera-se dar continuidade nessa linha de pesquisa. Os resultados do trabalho sugerem as aplicações possíveis do procedimento podem alcançar um nível mais estratégico, permitindo não somente facilitar decisões operacionais, mas também decisões táticas como problemas de scheduling, alocação de recursos, planejamento de produção, etc. 


\section{REFERÊNCIAS}

ARAKAKI, J., Análise de Sistema de Manufatura através da Metodologia MFG/PFS e Regras de Produção. São Paulo, 1993. Dissertação (Mestrado) - Escola Politécnica, Universidade de São Paulo.

AVIZIENIS et al., Basic concepts and taxonomy of dependable and secure computing. IEEE Transactions on Dependable and Secure Computing, v. 1, issue 1, pp. 11-33, 2004.

$\mathrm{BEACH}$ R. et al., A review of manufacturing flexibility. Transactions on European Journal of Operational Research, v. 122, Issue 1m pp. 41-57, 2000.

BOLWIJN, P.; KUMPE, T., Manufacturing in the 1990's - productivity, flexibility and innovation. Long Range Planning, v. 23, n. 4, pp. 44-57, 1990.

$\mathrm{BOOCH}$, G.; RUMBAUGH J; JACOBSON, I. The Unified Modeling Language user guide. Reading: Addison-Wesley, 482 p., 1999.

BRUCE D., What makes a good domain-specific language? APOSTLE, and its approach to parallel discrete event simulation. DSL '97 - First ACM SIGPLAN Workshop on Domain-Specific Languages, in Association with POPL '97, Paris, France, 1997.

CAO, X.-R., A comparison of the dynamics of continuous and discrete event systems. Proceedings of IEEE, v. 77, pp. 7-13, 1989.

CARDOSO J.; VALLETE R., Redes de Petri. Florianópolis: Editora da UFSC, 1997.

CASSANDRAS C. G., Discrete Event Systems: Modeling and Performance Analysis. Burr Ridge: Richard D. Irwin Inc., 1993. 
CASSANDRAS C. G., LaFORTUNE, S., Introduction to Discrete Event Systems, Springer, pp. 822, 1999.

CHANG S.-J.; DiCESARE F., GOLDBOGEN, G., Failure propagation trees for diagnosis in manufacturing systems. Transactions on Systems, Man and Cybernetics, v. 21, Issue 4, pp. 767-776, 1991.

CHINTAMANENI P. R.; JALOTE P.; SHIEH Y.-B., TRIPANTHI S.K., On fault tolerance in manufacturing systems, IEEE Network, v.2, Issue 3, pp. 32-39, 1988.

CHU F.; XIE X.-L., Deadlock analysis of Petri nets using siphons and mathematical programming, IEEE Transactions on Robotics and Automation, v. 13, Issue 6, pp. 793-804, 1996.

COFFMAN E. G.; ELPHICK M. J.; SHOSHANI A., System deadlocks, Comput. Surveys, v. 3, no. 2, pp. 67-78, 1971.

COMBACAU M.; COURVOUSIER M., A hierarchical and modular structure for FMS control and monitoring, Proceedings Al, Simulation, and Planning in High Autonomy Systems, pp. 80-88, 1990.

COZMAN, F. G., <http://www-2.cs.cmu.edu/ javabayes/ >, 2001.

CURY J.E.R., Teoria de Controle Supervisório de Sistemas a Eventos Discretos. In: V., Simpósio Brasileiro de Automação Inteligente, Canela-RS, PP. 68, 2001.

DASH, S.; VENKATASUBRAMANIAN, V., An integrated framework for abnormal situation management and process hazards analysis, AlChE Annual Meeting, Dallas, 1999. 
DASH S.; VENKATASUBRAMANIAN V., Challenges in the industrial applications of fault diagnostic systems, Computers \& Chemical Enginnering, v. 24, Issue 2-7, pp. 785-791, 2000.

DAVIS, W. J., MACRO, J; SETTERDAHL D., An integrated methodology for the modeling, scheduling and control of flexible automation. Journal on Robotics and Intelligent Control, 1997.

DEB, S.; PATTIPATI, K. R., RAGHAVAN, V.; SHAKERI, M.; SHRESTHA, R., Multi-signal flow graphs: a novel approach for system testability analysis an fault diagnosis, IEEE Aerospace and Electronic System Magazine, v. 10, Issue 5, pp. 14-25, 1994.

DESROCHERS, A. A.; AL-JAAR, R. Y., Applications of Petri Nets in Manufacturing Systems. Piscataway,IEEE Press, 1995.

ESTEBAN, P; COURVOISIER, M, Multilevel hierarchical control applied to a demonstration flexible assembly cell. International conference on industrial electronics, control and instrumentation, Proceedings, IECON, v. 2, pp. 878883, 1991.

FRANK, P., Principles of model-based fault detection, In: Proceedings of International Symposium on Al in Real-time Control, Delft, pp. 363-370, 1992.

GEIGER, D.; VERMA, T. S.; PEARL, J, Identifying independence in Bayesian networks. Networks, v. 20, issue 5, pp. 507-534, 1990.

HARIHARA, P. P.; KYUSUNG, KIM; PARLOS, A. G., Signal-based versus model-based fault diagnosis-a trade-off in complexity and performance. 4th IEEE International symposium on Diagnostics for Electric Machines, Power Electronics and Drivers, 2003 SDEMPED, pp. 277-282, 2003. 
HASEGAWA, K; TAKAHASHI, K; MIYAGI, P. E., Application of the Mark Flow Graph to represent discrete event production systems and system control, Transactions of the Society of Instrument and Control Engineers, v. 24, n. 1, pp. 67-75, 1988.

HASEGAWA, K, Modeling, control and deadlock avoidance of flexible manufacturing systems, In: Conferencias Plenárias of XI CBA, São Paulo, SBA, pp. 37-51, 1996.

HAYES-ROTH, F, Rule-based systems, Communications of the ACM, v. 28, Issue 9, pp. 921-932, 1985.

HENRION, M., Some Practical Issues in Constructing Belief Networks, Uncertainty in Artificial Intelligence: Proceedings of the Third Conference, 1989.

$\mathrm{HO}, \mathrm{YU}-\mathrm{CHI}$, Performance evaluation and perturbation analysis of discrete event dynamic systems, IEEE Transactions on Automatic control, v. 32, issue 7, pp. 563-572, 1987.

$\mathrm{HO}, \mathrm{YU}-\mathrm{CHI}$, Introduction to special issue on dynamics of discrete event systems, Proceedings of the IEEE, v. 77, issue 1, pp. 3-6, 1989.

HO, YU-CHI, 1992, Discrete Event Dynamics Systems Analyzing Complexity and Performance in the Modern World, IEEE Press, New York, 1992.

ISERMANN, R.; BALLÉ, P, Trends in the application of model-based fault detection and diagnosis of technical processes, Control Engineering Practice, v. 5, issue 5, pp. 707-719, 1997.

ISERMANN, R., Supervision, fault-detection and fault-diagnosis methods - an introduction. Control Engineering Practice, v. 5, issue 5, pp. 639-652, 1997. 
ISERMANN, R., Model-based fault-detection and diagnosis - status and applications. Annual Reviews in Control, v. 29, issue 1, pp. 71-85, 2005.

ITO, Y., A desirable production structure looking toward the $21^{\text {st }}$ century Anthropocentric Intelligence-Based Manufacturing. In: XI COBEM. Anais. Brazil, São Paulo, pp. 23-32, 1991.

JEN CHANG, S.; DiCESARE, F.; GOLDBOGEN, G., Failure propagation trees for diagnosis in manufacturing systems. IEEE Transaction on Systems, Man and Cybernetics, v. 21, n. 4, pp. 767-776, 1991.

JUNQUEIRA, F., Modelagem e Simulação Distribuída de Sistemas Produtivos. São Paulo, 2006. Dissertação (Doutorado) - Escola Politécnica, Universidade de São Paulo. 2006.

KAGOHARA, M. Y., Aplicação da Metodologia PFS/MFG a Sistemas de Produção Enxuta (Lean Manufacturing Systems). São Paulo, 1998. Dissertação (Mestrado) - Escola Politécnica, Universidade de São Paulo.

LAURITZEN, S. L.; SPIEGLHALTER, D. J., Local computation with probabilities on graphical structures and their application to expert systems. J. Roy. Stat. Soc., B, v. 50, pp. 157, 1988.

LIU, W., Aplicação da Metodologia MFG/PFS no Desenvolvimento de Sistema de Informação de Industrias de Manufatura. São Paulo, 1993. Dissertação (Mestrado) - Escola Politécnica, Universidade de São Paulo.

LUO, J.; SAVAKIS, A. E.; SINGHAL, A., A Bayesian network-based framework for semantic image understanding. Pattern Recognition, v. 38, issue 6, pp. 919-934, 2005. 
MEHRANBOD N.; MASOUD, S.; PIOVOSO M.; BABATUNDE, A. O.; Probabilistic model for sensor fault detection and identification. AIChE Journal, v. 49, n. 7, 2003.

MIYAGI, P. E.; Control System Design, Programming and Implementation for Discrete Event Production System Using Mark Flow. Tokyo, 1988. Tese (Doutorado) - Tokyo Institute of Technology.

MIYAGI, P. E.; Controle Programável - Fundamentos do Controle de sistemas a Eventos Discretos. São Paulo: Editora Edgard Blücher,1996.

MODARRES, M.; What Every Engineer Should Know About Reliability and Risk Analysis. CRC Press, pp. 350, 1992.

MORALES, R. A. G.; RIASCOS, L. A.; MIYAGI, P. E.; Fault diagnosis in fuel cells base don Bayesian networks. In: 19th International Congress of Mechanical Engineering, 2007, Brasília, DF. Proceeding of COBEM 2007. Rio de Janeiro : ABCM, pp. 1-8, 2007a.

MORALES, R. A. G.; RIASCOS, L. A.; MIYAGI, P. E., Diangosis and Treatment of faults in manufacturing systems based on Bayesian networks and Petri nets. In: 19th International Congress of Mechanical Engineering, 2007, Brasília, DF. Proceeding of COBEM 2007. Rio de Janeiro : ABCM, pp. 1-8, 2007b.

MORALES, R. A. G.; MELO, J. I. G.; MIYAGI, P. E., Diagnosis and treatment of faults in productive systems based on Bayesian networks and Petri net. IEEE International conference on Automation Science and Engineering, 2007, CASE 2007, pp. 357-362, 2007.

MURATA, T., State Equation, Controllability and Maximal Matchings of Petri Nets. IEEE Transactions on Automatic Control, v. 22, n. 3, pp. 412-416, 1977. 
MURATA, T., Petri nets: analysis and applications. Proceedings of the IEEE, v. 77 , n. 4, pp. 541-580, 1989.

MUSCAT, A.; FLEURY, A., Indicadores da qualidade e produtividade na indústria Brasileira, Revista Indicadores da Qualidade, n. 2, pp. 82-107, 1993.

NAKAMOTO, F. Y.; MIYAGI, P. E.; SANTOS FILHO, D. J., Uma proposta de algoritmo para a determinação dos ciclos fechados de espera em sistemas produtivos flexíveis. XIV Congresso Brasileiro de Automática, 2002.

OYELEYE, O. O.; KRAMER M. A., Qualitative simulation of chemical process systems: steady-state analysis. AlChE journal, v. 34, n. 9, pp. 1441-1454, 1988.

PEARL, J., Probabilistic Reasoning in Intelligent Systems. Morgan Kaufmann, 1988.

PEARL, J., Causality: Models, Reasoning, and Inference. Cambridge University Press, pp. 384, 2000.

PETERSON, J. L., Petri Net Theory and the Modeling of Systems. Englewood Cliffs, Prentice-Hall, 1981.

PORTINALE, L., Behavioral Petri nets: a model for diagnostic knowledge representation and reasoning. IEEE Transaction on Systems, Man, and Cybernetics, Part B, v. 27, n. 2, pp. 184-195, 1997.

POWER, Y.; BAHRI, P. A., A two-step supervisory fault diagnosis framework. Computers \& Chemical Engineering, v. 28, issue 11, pp. 2131-2140, 2000.

PRZYTULA, K. W.; THOMPSON D., Construction of Bayesian networks for diagnosis. Proceedings of 2000 IEEE Aerospace Conference, March 14-24, 2000. 
PRZYTULA, K. W.; THOMPSON D., Development of Bayesian diagnostic models using troubleshooting flow diagrams. Proceedings of SPIE $15^{\text {th }}$ Annual Symposium on Aerospace/Defense Sensing, Simulation, and Controls AeroSense, 2001, April 16-20, 2001.

PRZYTULA, K.; HAGEN, F.; YUNG, K., Bayesian networks for satellite payload testing. Proceedings of the Forty-Fourth SPIE, Denver, July, 1999.

PRZYTULA, K. W.; DASH, D.; THOMPSON, D., Evaluation of Bayesian networks used for diagnostics. Proceedings, 2003 Conference IEEE Aerospace conference, v. 7. Pp. 3177-3187, 2003.

RAMADGE, P. J.; WONHAM, W. M., The control of discrete event systems. Proceedings of the IEEE, v. 77, n. 1, 1989.

RANKY, P. G., Flexible Manufacturing Cells and Systems in CIM. CIMware Ltd, pp. 264, 1990.

REMBOLD, B.; TANCHOCO, J. M. A., A modular framework for the design of material flow systems. International Journal of Production Research, v. 32, issue 1, pp. 1-21, 1994.

RIASCOS, L. A. M., Metodologia para detecção e tratamento de falhas em sistemas de manufatura através de redes de Petri. São Paulo, 2002. 159 p. Tese de Doutorado - Escola Politécnica - Universidade de São Paulo.

SAHIN, F.; Yavuz, M. Ç.; ARNAVUT, Z.; ÖNDER U., Fault diagnosis for airplane engines using Bayesian networks and distributed particle swarm optimization. Parallel Computing, v. 33, Issue 2, pp. 124-143, 2007.

SAMPATH, M.; SENGUPTA, R.; LaFORTUNE, S.; SINNAMOHIDEEN K., TENEKETZIS, D., Diagnosability of discrete-event systems. IEEE Transactions on Automatic Control, v. 40, n. 9, pp. 1555-1575, 1995. 
SANTOS FILHO, D. J., Aspectos do Projeto de Sistemas Produtivos, Tese de Livre Docência, Escola Politécnica - Universidade de São Paulo, 2000.

SANTOS FILHO, D. J., Proposta do Mark Flow Graph Estendido para a Modelagem d Controle de Sistemas Integrados de Manufatura, São Paulo, 1993, Dissertação (Mestrado) Escola Politécnica - Universidade de São Paulo.

SILVA, J. R.; MIYAGI, P. E., A formal approach to PFS/MFG: A Petri net representation of discrete manufacturing systems. Studies in Informatics and Control, v. 5, n. 2, 1996.

SOBOL, I.M., A Primer for MonteCarlo Methods. Florida: CRC Press, Inc., 1994.

VENKATASUBRAMANIAN, V.; RENGASWAMY, R.; YIN, K.; KAVURI, S. N., A review of process fault detection and diagnosis part I: quantitative modelbased methods. Computers and Chemical engineering, v. 27, pp. 293-311, 2002a.

VENKATASUBRAMANIAN, V.; RENGASWAMY, R.; YIN, K.; KAVURI, S. N., $A$ review of process fault detection and diagnosis part II: qualitative models and search strategies. Computers and Chemical engineering, v. 27, pp. 313-326, 2002b.

VILLANI, E, Abordagem Híbrida para Modelagem de Sistemas de $\mathrm{Ar}$ condicionado em Edifícios Inteligentes. São Paulo, 2000. 154 p., Dissertação (Mestrado) - Escola Politécnica - Universidade de São Paulo, 2000.

VILLANI, E., Modelagem e analise de sistemas supervisórios híbridos, 2004. 339 p., Tese (Doutorado) - Escola Politécnica - Universidade de São Paulo, 2004. 
VILLANI, E., MIYAGI, P. E., VALLETE, R., Modelling and Analysis of Hybrid Supervisory Systems. Sprinder Verlag, 2007.

ZHOU, M. C.; DiCESARE, F., A Petri net method for automated manufacturing systems with shared resources. 1999 IEEE International Conference on Robotics and Automation, v. 1, pp. 526-531,1990.

ZHOU, M. C.; DiCESARE, F., Adaptive design of Petri net controllers for error recovery in automated manufacturing systems. IEEE Transactions on Systems, Man, and Cybernetics, v. 19, issue 5, pp. 963-973, 1989.

ZHOU, M. C.; DiCESARE, F., Petri Net Synthesis for Discrete Event Controlo f Manufacturing Systems. Springer, pp. 256, 1993.

ZHOU, M. C.; VENKATESH, K., Modeling, Simulation, and Control of Flexible Manufacturing Systems: A Petri Net Approach. World Scientific, pp. 409, 1999.

ZHOU, M. C.; DiCESARE, F.; DESROCHERS, A. A., A hybrid methodology for synthesis of Petri net models for manufacturing systems. IEEE Transactions on Robotics and Automation, v. 8, pp. 350-361, 1992. 